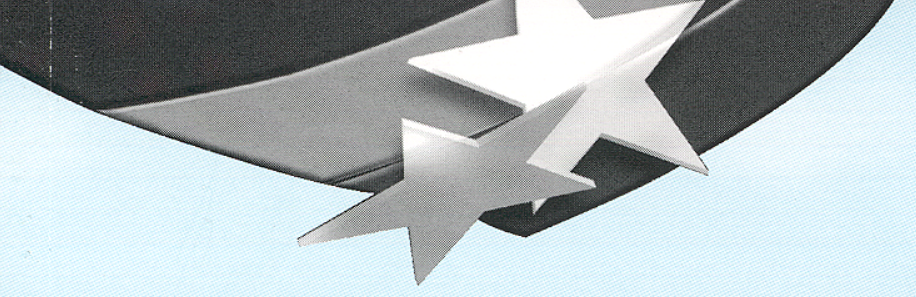

\title{
An Evaluation of Molten-5alt Power Tovers Including Results of the Solar Two Project
}

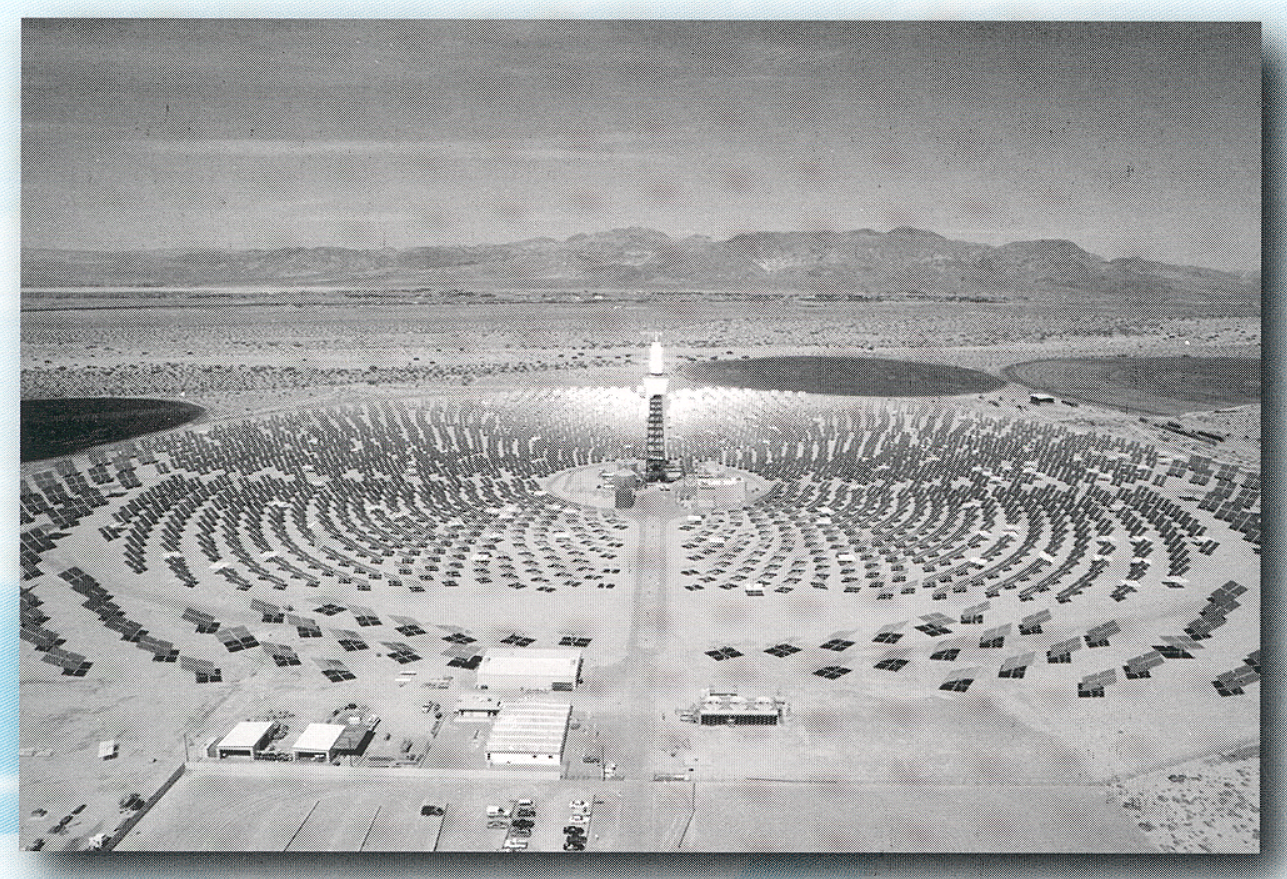

\section{Hugh E. Reilly and Gregory J. Kolb Solar Thermal Technology Department}


Issued by Sandia National Laboratories, operated for the United States Department of Energy by Sandia Corporation.

NOTICE: This report was prepared as an account of work sponsored by an agency of the United States Government. Neither the United States Government, nor any agency thereof, nor any of their employees, nor any of their contractors, subcontractors, or their employees, make any warranty, express or implied, or assume any legal liability or responsibility for the accuracy, completeness, or usefulness of any information, apparatus, product, or process disclosed, or represent that its use would not infringe privately owned rights. Reference herein to any specific commercial product, process, or service by trade name, trademark, manufacturer, or otherwise, does not necessarily constitute or imply its endorsement, recommendation, or favoring by the United States Government, any agency thereof, or any of their contractors or subcontractors. The views and opinions expressed herein do not necessarily state or reflect those of the United States Government, any agency thereof, or any of their contractors.

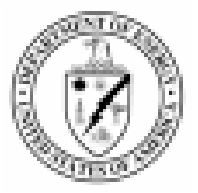


SAND2001-3674

Unlimited Release

Printed November 2001

\title{
An Evaluation of Molten-Salt Power Towers Including Results of the Solar Two Project
}

\author{
Hugh E. Reilly and Gregory J. Kolb \\ Solar Thermal Technology Department \\ Sandia National Laboratories \\ P.O. Box 5800 \\ Albuquerque, NM 87185-0703
}

\begin{abstract}
This report utilizes the results of the Solar Two project, as well as continuing technology development, to update the technical and economic status of molten-salt power towers. The report starts with an overview of power tower technology, including the progression from Solar One to the Solar Two project. This discussion is followed by a review of the Solar Two project-what was planned, what actually occurred, what was learned, and what was accomplished. The third section presents preliminary information regarding the likely configuration of the next moltensalt power tower plant. This section draws on Solar Two experience as well as results of continuing power tower development efforts conducted jointly by industry and Sandia National Laboratories. The fourth section details the expected performance and cost goals for the first commercial molten-salt power tower plant and includes a comparison of the commercial performance goals to the actual performance at Solar One and Solar Two. The final section summarizes the successes of Solar Two and the current technology development activities. The data collected from the Solar Two project suggest that the electricity cost goals established for power towers are reasonable and can be achieved with some simple design improvements.
\end{abstract}


Evaluation of Molten Salt Power Tower Technology 


\section{Contents}

1. Overview of Solar Power Tower Technology ............................................................................ 1-1

$1.1 \quad$ Molten-Salt Power Tower Technology (Solar Two) ................................................ 1-1

$1.2 \quad$ History of Power Tower Development ................................................................ 1-4

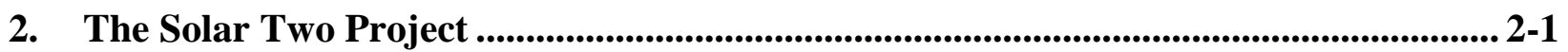

2.1 Background and Original Project Plan ................................................................... 2-1

2.2 Project Execution and Schedule.......................................................................... 2-6

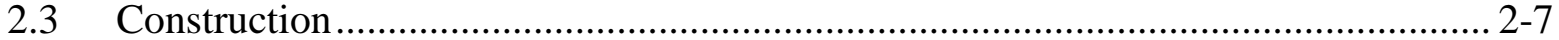

2.3.1 Thermal Storage System ................................................................. 2-8

2.3.2 Receiver System............................................................................ 2-9

2.3.3 Steam Generation System and Salt Piping, Valves, and Heat Trace ........ 2-15

2.3.4 Electric Power Generation System Refurbishment................................... 2-17

2.3.5 Collector System .......................................................................... 2-17

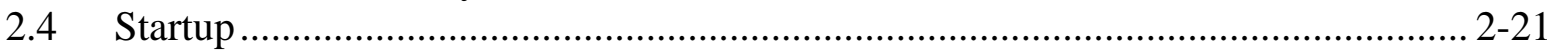

2.4.1 Salt Loading and Melting (August-October 1995) .................................. 2-21

2.4.2 Unexpected Need to Thermally Treat the Nitrate Salt (AugustDecember 1995) ............................................................................... 2-22

2.4.3 Improper Installation of Heat Trace on Salt Piping (June-October 1996)2-23

2.4.4 Evaporator Tube Failure and Evaporator Modification (November 1996 - October 1997) ……………………............................................. 2-24

2.4.5 Intergranular Corrosion (August 1997) ……………………………..... 2-26

2.4.6 Impact of Startup Delays on the Remainder of the Project ...................... 2-27

2.5 Operational Phase of Solar Two ……………............................................... 2-28

2.5.1 Plant Operation to Meet Test Goals (March-June 1998) .......................... 2-29

2.5.2 Continuous Production of Electricity (June-July 1998) ............................ 2-29

2.5.3 Power Production Under Semi-Optimized Conditions (SeptemberNovember 1998) ....................................................................... 2-29

2.5.4 Receiver Downcomer Piping Failure, Subsequent Repairs, and Plant Operation (November 98-April 1999).................................................... 2-30

2.5.5 Additional Operating Results.............................................................. 2-30

2.6 Overview of Collector System Problems.............................................................. 2-31

2.6.1 Problems with Aging and Outdated Equipment ...................................... 2-33

2.6.2 Mirror Condition ................................................................................. 2-33

2.6.3 Heliostat Aiming ................................................................................ 2-33

2.6.4 Beam Characterization System ……………………………………..... 2-34

2.7 Final Briefings to Industry and Shutdown of Solar Two ....................................... 2-34

3. Design of the Next Molten-Salt Power Tower Plant................................................................... 3-1

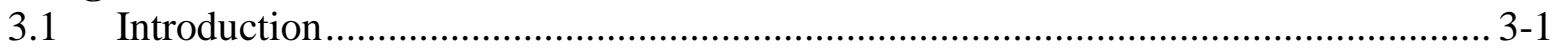

3.2 Technology Validation at Solar Two ................................................................. 3-1

3.2.1 Receiver System............................................................................... 3-1

3.2.2 Thermal Storage System ...................................................................... 3-1

3.2.3 Electricity Dispatch.......................................................................... 3-1

3.2.4 Steam Generation System ……………………............................... 3-2

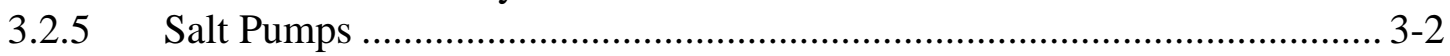


3.2.6 Instrumentation ...................................................................... 3-2

3.3 Design Considerations and Enhancements for the Next Molten-Salt Power Tower

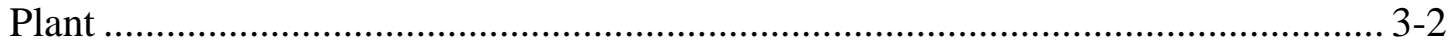

3.3.1 Long-Shafted Pumps for Salt Service ………………………................... 3-2

3.3.2 Salt Valves ............................................................................ 3-3

3.3.3 Heat Trace ............................................................................... 3-3

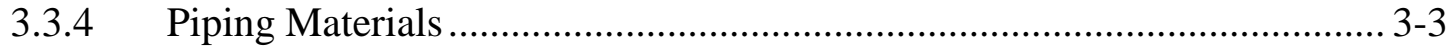

3.4 Preliminary Design of the Next Molten-Salt Power Tower Plant ............................. 3-3

3.4.1 Commercialization Approach and Plant Size ............................................. 3-4

3.4.2 Expected New Design Features .............................................................. 3-4

3.4.3 Current Development Efforts.................................................................... 3-4

4. Power Tower Commercial Technology Goals versus Actual Experience ....................... 4-1

4.1 Actual Plant Performance versus Commercial Goals .............................................. 4-2

4.1.1 Peak Performance ................................................................................. 4-2

4.1.2 Annual Performance ........................................................................ 4-5

4.1.3 Daily Performance ……………………………..................................... 4-9

4.2 Actual Capital Costs versus Commercial Goals ...................................................... 4-21

4.3 Actual O\&M Cost versus Commercial Goals..................................................... 4-24

4.4 Actual Electricity Dispatch versus Commercial Goals........................................... 4-26

5. Summary and Conclusions ................................................................................................................ 5-1

6. References ............................................................................................................................................................ 6-1 


\section{Figures}

1-1. Molten-Salt Power Tower System Schematic. ............................................................. 1-2

1-2 In a Solar Power Tower, Plant Design Can be Altered to Achieve Different Capacity Factors................................................................................................... 1-2

1-3. A Power Tower With 15 Hours of Storage Operates Around the Clock and is Capable of a 70\% Annual Capacity Factor...................................................................... 1-3

1-4. Dispatchability of Molten-Salt Power Towers. ............................................................. 1-4

1-5. Historical and Future Projections of Solar Electricity Costs From Concentrating Solar Power Plants ............................................................................................... 1-5

1-6. The Solar One Power Tower Plant. ............................................................................ 1-6

2-1. The Solar Two Plant in Operation in 1998................................................................ 2-1

2-2. Solar Two System Schematic. ........................................................................ 2-4

2-3. The Solar One Thermal Storage System Being Demolished in 1993 ............................. 2-9

2-4. The Solar Two Cold Salt Storage Tank Under Construction. ....................................... 2-10

2-5. Details of Receiver Piping (Panel Vents not Shown)................................................ 2-11

2-6. Typical Serpentine Flowpath between Adjacent Receiver Panels................................ 2-12

2-7. Receiver Crossover Flow Pattern.......................................................................... 2-13

2-8. The Solar One Receiver Being Dismantled.............................................................. 2-14

2-9. A Solar Two Receiver Panel Being Hoisted to the Top of the Tower............................ 2-16

2-10. The Solar Two Steam Generation Area Under Construction ....................................... 2-17

2-11. The Solar Two Kettle-Boiler Style Evaporator Prior to Installation. ............................ 2-18

2-12. Installed Heat Trace Circuits, Prior to Insulation. ...................................................... 2-19

2-13. Refurbished Solar One Turbine Rotor Being Lowered into Bottom Half of Turbine Casing................................................................................................... 2-19

2-14. One of 108 Lugo Heliostats Installed for the Solar Two Project.................................. 2-20

2-15. 1000-kg Bags of Nitrate Salt After Shipment to the Solar Two Site............................. 2-22

2-16. Equipment Required to Load, Melt, and Thermally Treat the Nitrate Salt. .................. 2-23

2-17. Structure Assembled for Prilling Tower ................................................................. 2-35

4-1. Solar Two Maximum Daily Heliostat Availability, December 1996 to April 1999........ 4-4

4-2 Solar Two Heliostat Availability in Early March 1999 ................................................. 4-5

4-3. Daily Solar Energy Collected by the Heliostat/Receiver Systems at Solar Two versus SOLERGY Goal ......................................................................................... 4-10

4-4. Conversion of Thermal Energy to Electric Energy at Solar Two versus

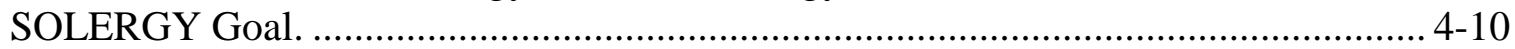

4-5. Parasitic Consumption at Solar Two versus SOLERGY Goal. .................................... 4-11

4-6. The Daily Energy Collected versus a Corrected SOLERGY Goal That was Corrected for Aiming Problems, Actual Daily Field Availability, and Actual Daily Cleanliness........................................................................................................ 4-12

4-7. Causes for Outages at Solar Two During September (left) and October (right)

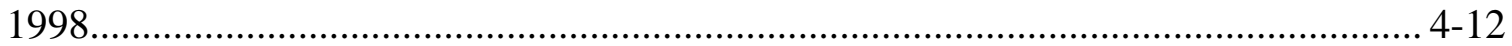

4-8. Comparison of Daily Collection Efficiency Goals...................................................... 4-13

4-9. Average Turbine Output was Maintained Closer to the 10 MW Rating from Late September to Mid-November. ................................................................................... 4-15

4-10. It Took Time to Achieve the Startup Energy Goal for the Molten-Salt Steam Generator. 
4-11. Daily Thermal-To-Electric Conversion Efficiency Improved Over Time. .................... 4-16

4-12. Comparison of Daily Thermal-to-Electric Conversion Efficiency Goals...................... 4-16

4-13. The Daily Parasitic Energy Consumption Goal was Routinely Met After Initiating Parasitic Reduction Tests on September 25, 1998..................................................... 4-17

4-14. Comparison of Daily Parasitic Efficiency Goals....................................................... 4-18

4-15. Comparison of Daily Solar-to-Electric Conversion Efficiency Goals, on a GROSS

Basis, with Actual Experience at Solar One and Solar Two from September 25 to November 13, (1985 at Solar One, 1998 at Solar Two)

4-16. Comparison of Daily Solar-to-Electric Conversion Efficiency Goals, on a NET Basis, with Actual Experience at Solar One and Solar Two from September 25 to November 13, (1985 at Solar One, 1998 at Solar Two............................................... 4-20

4-17. Heliostat Costs versus Cumulative Heliostats Built. .................................................... 4-22

4-18. Molten-Salt Steam Generator Cost versus Turbine Generator Size. ............................. 4-22

4-19. Molten-Salt Storage Cost versus Storage Size..................................................... 4-23

4-20. Receiver System Cost Versus Heliostat Field Size...................................................... 4-23

4-21. Actual Solar Energy Collection and Electricity Delivery at Solar Two versus SOLERGY Prediction........................................................................................... 4-29

\section{Tables}

1-1. Comparison of Solar-Energy Storage Systems …….................................................. 1-3

1-2. Experimental Power Towers .............................................................................. 1-6

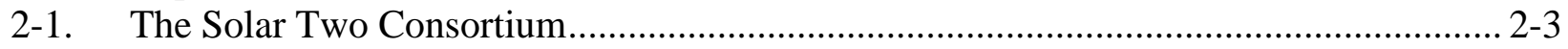

2-2. Solar Two Major Equipment Summary .................................................................... 2-6

2-3. Solar Two Project Phases and Milestones ................................................................. 2-7

2-4. A Brief History of the Solar Two Collector System.................................................. 2-32

4-1. Power Tower Key Design Features .................................................................. 4-1

4-2. Comparison of Peak Efficiencies............................................................................... 4-2

4-3. Comparison of Annual Efficiencies............................................................................ 4-6

4-4 Annual Energy Performance of Solar One and Solar Two During T\&E ....................... 4-9

4-5. Solar-Specific Subsystem Costs of Solar Tres versus TC Report Goals ....................... 4-24

4-6. Comparison of O\&M Staffing ......................................................................... 4-27

4-7. Comparison of Total O\&M Cost for Commercial Plant............................................. 4-27

4-8. Examples of Electricity Dispatch from Solar Two ……......................................... 4-28 


\section{Preface}

The successful conclusion of the Solar Two project provides an appropriate time to update and evaluate the status of molten-salt power tower technology. This report addresses the status of the technology, both in terms of Solar Two experience and in current thinking on the probable path to commercialization.

As the Solar Two project ended and molten-salt power tower development continued, this report was written to summarize technical and economic information and projections regarding the technology. The report starts with an overview of power tower technology development through Solar One. This overview is followed by a summary of the Solar Two project. The report next provides a look at what the next plant might look like, based on the Solar Two experience and the results of continuing design and development of molten-salt components, systems, and overall preliminary plant design. To complete the technology assessment, the report concludes with current projections of the cost and performance goals for the first commercial plant. These goals are compared to actual experiences at both Solar One and Solar Two.

Concurrent with operation of Solar One and after it concluded operations in 1988, industry and Sandia National Laboratories conducted a number of studies of power tower technology. A power tower that utilized molten salt for thermal energy collection and storage was deemed a likely successor to the water/steam system utilized at Solar One. Industry and Sandia therefore conducted small-scale experiments on molten-salt components and systems. By the early 1990s, interest was high in demonstrating molten-salt power tower technology at a large scale. Sandia assembled a briefing package on the merits of the technology and the need for a field demonstration. Sandia presented this briefing to virtually all major electric utilities in the Western United States. In 1992, the United States Department of Energy (DOE) accepted a proposal from eight utilities, plus the Electric Power Research Institute and the California Energy Commission, to cost-share the design, construction, and operation of a $10 \mathrm{MWe}$ molten-salt power tower plant. When the entities formed a consortium, Solar Two was born. 


\section{Acronyms/Abbreviations}

BCS Beam Characterization System

BOP Balance of Plant

DAPS Dynamic Aimpoint Processing System

DNI Direct Normal Insolation

DOE U.S. Department of Energy

DPCS Distributed Process Control System

E\&CM Engineer and Construction Manager

EPGS Electric Power Generation System

EPRI Electric Power Research Institute

e-PROM Erasable, Programmable, Read-Only Memory

ESI Energy Services Incorporated

IGC Intergranular Corrosion

LEC Levelized-Electricity Costs

MCS Master Control System

MSEE Molten-Salt Electric Experiment

O\&M Operations and Maintenance

PV Photovoltaic

R\&D Research and Development

RTD Resistance Temperature Device

SAPS Static Aimpoint Processing Software

S\&B Shading and Blocking

SCE Southern California Edison Company

SEGS Solar Electric Generating System

SGS Steam Generation System

SNL Sandia National Laboratories

SSPS Small Solar Power Systems Project

SWI Swinerton Walberg, Inc.

TC Technology Characterization

TIC The Industrial Company 


\section{Overview of Solar Power Tower Technology}

Solar power towers generate electric power from sunlight by focusing concentrated solar radiation on a tower-mounted heat exchanger (receiver). The system uses a few thousand suntracking mirrors called heliostats to reflect the incident sunlight onto the receiver. These plants are best suited for utility-scale applications in the 10 to $100 \mathrm{MW}_{\mathrm{e}}$ range. The technology has been the subject of research and development (R\&D) in the United States since the mid-1970s and the Solar Two project represents the culmination of that effort. This chapter provides an overview of the history of power towers, along with a discussion of the capabilities and benefits of power tower technology.

\subsection{Molten-Salt Power Tower Technology (Solar Two)}

At Solar Two, molten-nitrate salt was the working fluid in the solar receiver. This distinguishes it from other power tower technologies (e.g., those using water/steam or air as the working fluid). Liquid salt at $550^{\circ} \mathrm{F}\left(288^{\circ} \mathrm{C}\right)$ is pumped from a 'cold' storage tank through the receiver, where it is heated to $1050^{\circ} \mathrm{F}\left(565^{\circ} \mathrm{C}\right)$, and then on to a 'hot' tank for storage. When power is needed from the plant, hot salt is pumped to a steam generating system that produces superheated steam for the turbine/generator. From the steam generator, the salt is returned to the cold tank where it is stored and eventually reheated in the receiver. Figure 1-1 is a schematic diagram of the primary flow paths. Determining the optimum storage size to meet power-dispatch requirements is an important part of the system design process. Some plant designs provide up to 16 hours of full-power operation from storage.

The heliostat field that surrounds the tower is laid out to optimize the annual performance of the plant. The field and the receiver are also sized depending on the needs of the utility. In a typical installation, solar energy collection occurs at a rate that exceeds the maximum heat rate required to provide steam to the turbine. Consequently, the thermal storage system can be charged at the same time that the plant is producing power at full capacity. The ratio of the thermal power provided by the collector system (the heliostat field and receiver) to the peak thermal power required by the turbine generator is called the solar multiple. With a solar multiple of $\sim 3$, a molten-salt plant located in a high-insolation region can be designed for an annual capacity factor of $\sim 70 \%$. Consequently, power towers could potentially operate at full power for $70 \%$ of the year without the need for a back-up fuel source.

Thermal storage gives the power-plant designer freedom to develop power plants with a wide range of capacity factors to meet the needs of the utility grid. By varying the size of the solar field, solar receiver, and size of the thermal storage, plants can be designed with annual capacity factors ranging between 20 and 70\% (see Figures 1-2 and 1-3). 


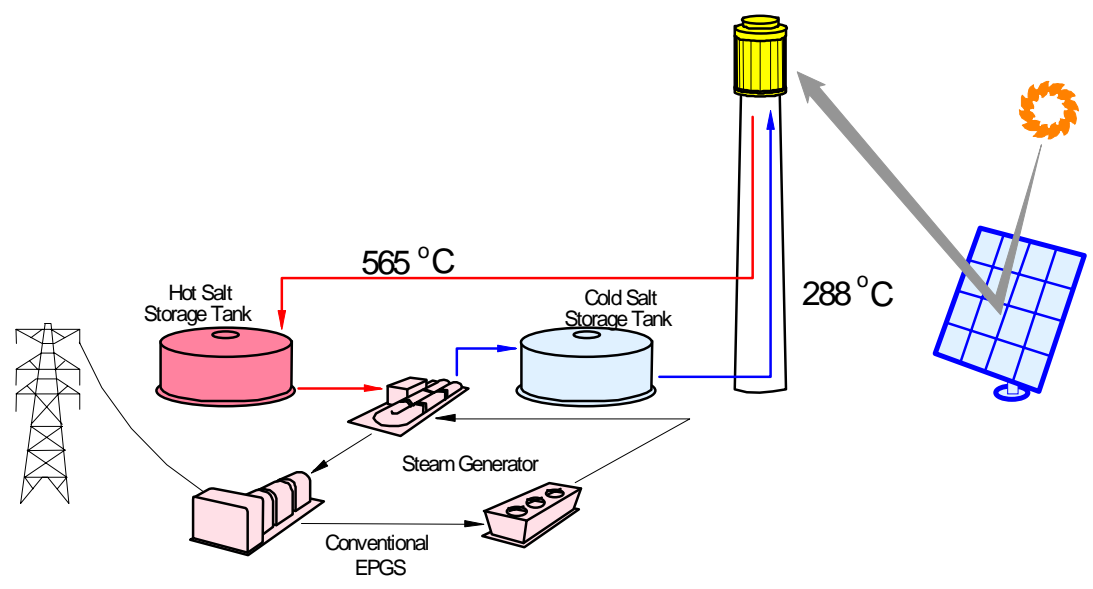

Figure 1-1. Molten-Salt Power Tower System Schematic.

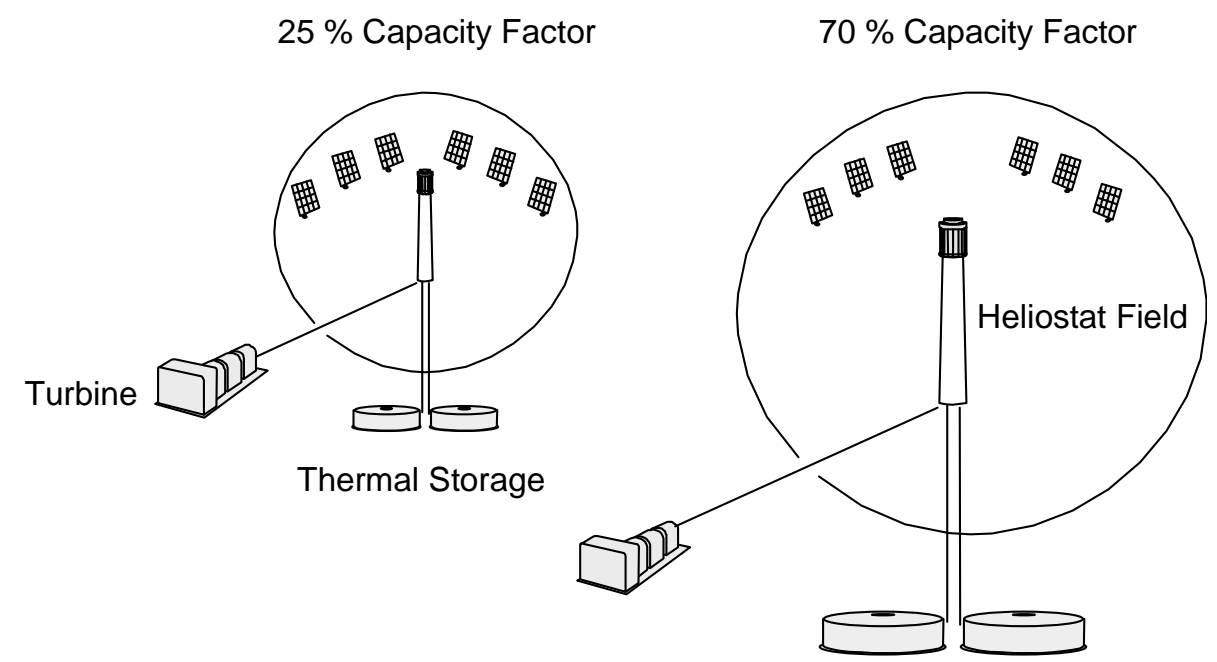

Figure 1-2 In a Solar Power Tower, Plant Design Can be Altered to Achieve Different Capacity Factors. To increase capacity factor for a given turbine size, the designer would 1) increase the number of heliostats, 2) enlarge the thermal storage tanks, 3) raise the tower, and 4) increase the receiver size. Plants with a $25 \%$ capacity factor would only have buffer storage (<1hr) and a solar multiple of approximately 1. Plants with $70 \%$ capacity factor would have $\sim 15$ hours of storage and a solar multiple of 3. 


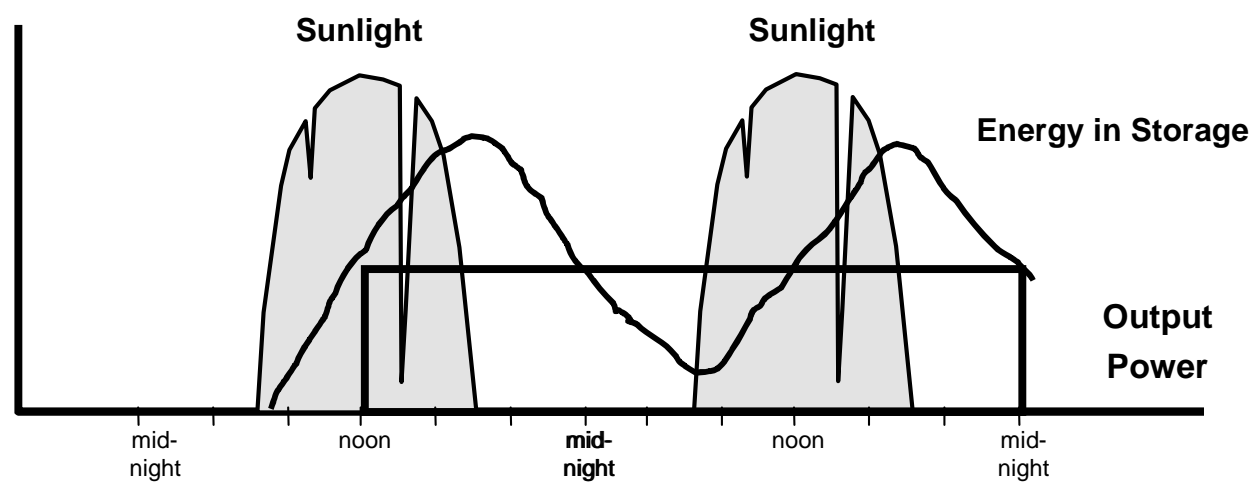

Figure 1-3. A Power Tower With 15 Hours of Storage Operates Around the Clock and is Capable of a 70\% Annual Capacity Factor.

Economic studies have shown that levelized energy costs are reduced by increasing the solar multiple to $\sim 3$ ( $\sim 70 \%$ capacity factor with 15 hours of storage) (DOE and EPRI, 1997). This plant runs throughout the night; storage is nearly emptied at sunrise before being recharged again. A large storage system is practical in a molten salt plant because adding up to 15 hours of storage actually lowers the levelized electricity cost (LEC) of the solar plant by as much as $30 \%$. LEC drops because use of the highly efficient (99\%) and low cost (20 times less than batteries; see Table 1-1) energy storage system improves the economic utilization of the plant capital equipment and Operations and Maintenance $(\mathrm{O} \& \mathrm{M})$ crew. This gives power towers a unique advantage over other solar technologies, like photovoltaic (PV); storage is typically not added to a grid-connected PV system because LEC is increased when it is included.

Table 1-1. Comparison of Solar-Energy Storage Systems

\begin{tabular}{|l|c|c|c|c|}
\hline $\begin{array}{c}\text { Solar Energy } \\
\text { Storage System }\end{array}$ & $\begin{array}{c}\text { Installed Cost of } \\
\text { Energy Storage for a } \\
\mathbf{2 0 0} \mathbf{~ M W ~ P l a n t ~ ( \$ / k W h r} \text { ) }\end{array}$ & $\begin{array}{c}\text { Lifetime of } \\
\text { Storage } \\
\text { System (years) }\end{array}$ & $\begin{array}{c}\text { Annual Round- } \\
\text { trip Storage } \\
\text { Efficiency (\%) }\end{array}$ & $\begin{array}{c}\text { Maximum } \\
\text { Operating } \\
\text { Temperature }\left({ }^{\circ} \mathbf{C}\right)\end{array}$ \\
\hline $\begin{array}{l}\text { Molten-salt power } \\
\text { tower }\end{array}$ & 30 & 30 & 99 & 567 \\
\hline $\begin{array}{l}\text { Battery Storage Grid } \\
\text { Connected }\end{array}$ & 500 to 800 & 5 to 10 & 76 & $\begin{array}{c}\text { Not } \\
\text { Applicable }\end{array}$ \\
\hline
\end{tabular}

Inclusion of storage also allows the electricity to be dispatched to the grid to meet peak power demands. Figure 1-4 depicts a system with six-hour storage and a solar multiple of 1.8 that has been sized to meet the peak demand on the grid that occurs between $1 \mathrm{pm}$ and $11 \mathrm{pm}$, a common pattern in many areas of the world.

Dispatchability using storage was successfully demonstrated during the Solar Two project. Operation into the evening hours was routinely done, and on one occasion, the plant ran $24 \mathrm{hrs} /$ day for nearly one week. Dispatchability with power towers can also be done via hybridization if a source of fossil fuel is readily available (this was not done at Solar Two). Use of thermal storage is preferred because a larger fraction of the plant output is derived from solar energy, but if a fuel source is nearby, it could be used to ensure a higher degree of dispatchability. 


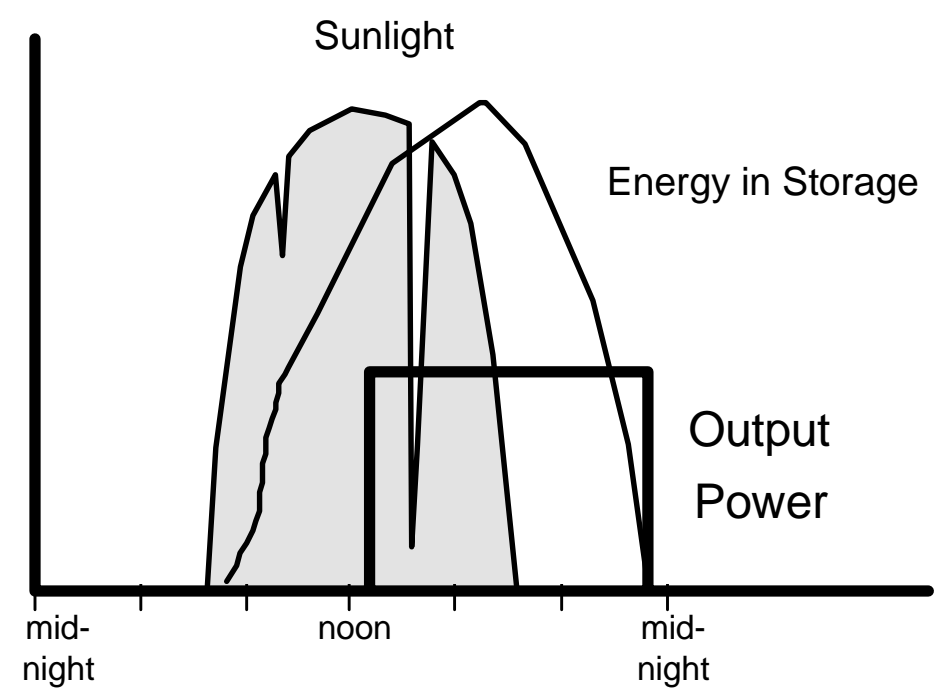

Figure 1-4. Dispatchability of Molten-Salt Power Towers.

Power towers must be fairly large (>30 MW) to be economically preferred over other solar technologies. In the United States, the southwest is ideal for these plants because of its low-cost land, ease of interconnect to the western utility grid, and high levels of direct-normal insolation. Similar locations in northern and southern Africa, southern Europe, Mexico, the Middle East, Australia, and India are also well-suited for power towers and it is feasible for much of the world's population to receive clean and affordable electricity from this technology.

Studies in the United States (DOE and EPRI, 1997) indicate that large molten-salt power towers should be able to produce the lowest cost solar electricity of any solar technology expected to be available within the next 30 years. The historical electricity costs from concentrating solar power plants and future projections are depicted in Figure 1-5.

Parabolic trough technology has been implemented at the Solar Electric Generating System (SEGS) plants in California. Cost of electricity from current SEGS trough plant technology is $\sim 12$ cents $/ \mathrm{kWh}$. To reduce costs further, technology breakthroughs must be demonstrated to allow solar technology to progress down the "advanced learning curve." Demonstration of the unique low-cost energy storage at Solar Two is a technology breakthrough that should continue to drop solar electricity costs into the competitive range.

\subsection{History of Power Tower Development}

Although power towers are commercially less mature than parabolic trough systems, a number of component and system experiments have been fielded around the world in the last 20 years, demonstrating the engineering feasibility and economic potential of the technology. Since the early 1980s, power towers have been fielded in Russia, Italy, Spain, Japan, France, and the United States (Meinecke and Bohn, 1995). In Table 1-2, these experiments are listed along with 


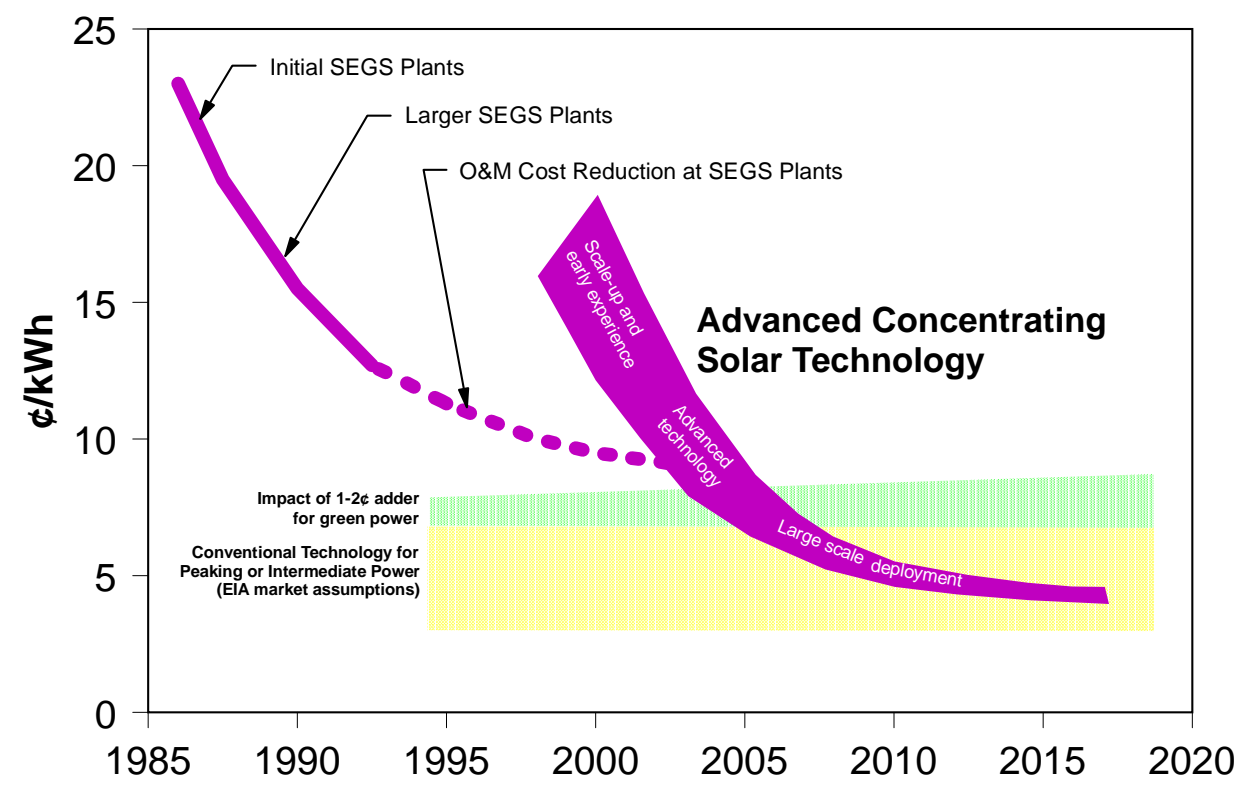

Figure 1-5. Historical and Future Projections of Solar Electricity Costs From Concentrating Solar Power Plants. Power costs from initial "advanced technology" plants will be higher than today's plants because they will be much smaller and less mature than today's technology. However, as the advanced technology is scaled up and matures, electricity costs should be significantly lower than today's plants.

some of their more important characteristics. The facilities were built both to prove that solar power towers can produce electricity and to improve on the individual system components. All the power tower projects were experimental in nature and were not intended as commercial ventures, i.e., unlike the SEGS trough plants, power was not sold from the projects. It can be seen that Solar Two (USA) and TSA (Europe) were the latest power tower projects. After a flurry of projects in the early 1980s, a seven-year hiatus occurred to perform detailed engineering studies (Pacific Gas \& Electric Company, 1988; Becker et al., 1993) in order to decide the next steps in power tower development. Two leading technology candidates emerged: molten salt, because of the low-cost storage and the promising results of the small scale MSEE and Themis experiments, and atmospheric-pressure-air, because of the inherent reliability associated with a simple design. Sodium technology was discarded because it is a dangerous fluid to work with ${ }^{1}$ and water/steam was not pursued further because of the inherit limitations of the technology, as described in the next section. The Solar Two and TSA projects were built to resolve technical risk issues identified by these studies. With the successful completion of the Solar Two and TSA (Haeger et al., 1994) projects in 1999, commercial consortia are progressing towards the construction of first commercial plants in Spain (Osuna et al., 2000; Gould et al., 2000).

1 The SSPS sodium test facility was destroyed by a sodium fire in 1986. 
Table 1-2. Experimental Power Towers

\begin{tabular}{|c|c|c|c|c|c|}
\hline Project & $\begin{array}{l}\text { Sponsoring } \\
\text { Country }\end{array}$ & $\begin{array}{l}\text { Power } \\
\text { Output } \\
\text { (MWe) }\end{array}$ & Heat Transfer Fluid & $\begin{array}{l}\text { Storage } \\
\text { Medium }\end{array}$ & $\begin{array}{c}\text { Operation } \\
\text { Began }\end{array}$ \\
\hline SSPS & Spain & 0.5 & Liquid Sodium & Sodium & 1981 \\
\hline EURELIOS & Italy & 1.0 & Steam & $\begin{array}{c}\text { Nitrate } \\
\text { Salt/Water }\end{array}$ & 1981 \\
\hline SUNSHINE & Japan & 1.0 & Steam & $\begin{array}{c}\text { Nitrate } \\
\text { Salt/Water }\end{array}$ & 1981 \\
\hline Solar One & United States & 10.0 & Steam & Oil/Rock & 1982 \\
\hline CESA-1 & Spain & 1.0 & Steam & Nitrate Salt & 1983 \\
\hline MSEE/Cat B & United States & 1.0 & $\begin{array}{l}\text { Molten Nitrate } \\
\text { Salt }\end{array}$ & Nitrate Salt & 1984 \\
\hline THEMIS & France & 2.5 & Hi-Tec Salt & Hi-Tec Salt & 1984 \\
\hline SPP-5 & Russia & 5.0 & Steam & $\begin{array}{l}\text { Water/ } \\
\text { Steam }\end{array}$ & 1986 \\
\hline TSA & Europe & 1.0 & Air & Ceramic & 1993 \\
\hline Solar Two & USA & 10.0 & Molten Nitrate Salt & Nitrate Salt & 1996 \\
\hline
\end{tabular}

\section{$\underline{\text { Solar One }}$}

Solar One, which operated from 1982 to 1988 near Barstow, California, proved that power tower technology is effective, reliable, and practical for utility-scale power generation (Figure 1-6).

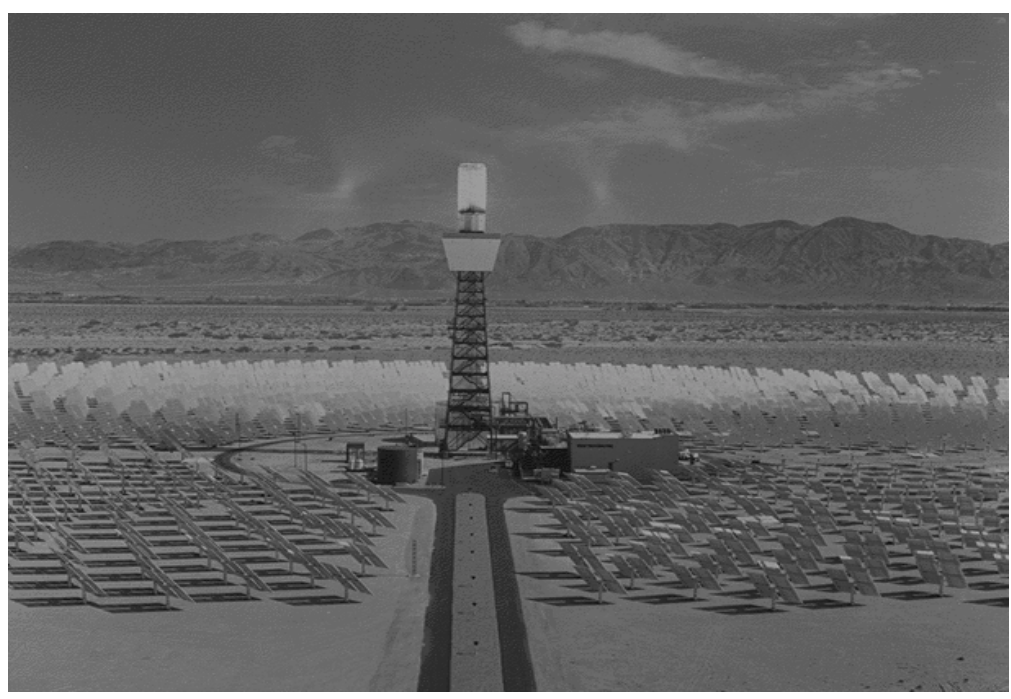

Figure 1-6. The Solar One Power Tower Plant. 
In this plant, water was converted to steam in the receiver and used directly to power a conventional Rankine-cycle steam turbine. The heliostat field consisted of 1818 heliostats of $39.3 \mathrm{~m}^{2}$ reflective area each. The project met most of its technical objectives by demonstrating the feasibility of generating power at $10 \mathrm{MW}_{\mathrm{e}}$ for eight hours a day at summer solstice and four hours a day near winter solstice. The project also proved that the technology can be very reliable. For example, the heliostat field routinely achieved $>98 \%$ availability on an annual-average basis, and during its final year of operation, the availability of the overall plant during hours of sunshine was $95 \%$.

Because the turbine generator was directly connected to the solar receiver, passing clouds would often trip the plant in just a few minutes and interrupt electricity supply to the grid. It is not desirable to subject the utility grid to this intermittency, especially if solar plants should eventually become a significant portion of the grid's supply. The plant had a storage system that could be used to buffer the effects of clouds, but it was seldom used, as described below.

The Solar One thermal storage system stored solar heat in a tank filled with rocks and sand using oil as the heat-transfer fluid. Several banks of heat exchangers allowed the heat to pass between the oil/rock storage tank and the steam cycles used in the receiver and turbine. The system extended the plant's power-generation capability into the night and provided heat for generating low-grade steam to keep parts of the plant warm during off-hours and for morning startup. Unfortunately, the design of the storage system was complex, thermodynamically inefficient, and used a flammable working fluid that eventually led to its destruction (Radosevich, 1988).

While Solar One successfully demonstrated power tower technology, it also revealed the disadvantages of a water/steam system, such as the intermittent operation of the turbine due to cloud transients and lack of effective thermal storage.

Solutions to these problems were demonstrated at Solar Two through the use of molten salt. A consortium of utilities led by Southern California Edison joined with the United States Department of Energy (DOE) to retrofit the Solar One plant with a molten-salt heat-transfer system. The next section provides details regarding Solar Two. 
Evaluation of Molten Salt Power Tower Technology 


\section{The Solar Two Project}

\subsection{Background and Original Project Plan}

Solar Two was a DOE and industry cost-shared project to design, build, test, and operate a $10 \mathrm{MWe}$ solar power tower plant utilizing molten salt as the heat transfer and storage medium. Solar Two, shown in Figure 2-1, was built on the Solar One site near Barstow, California, and utilized many Solar One systems. Construction on Solar Two began in September of 1994. The plant was dedicated on June 5, 1996; the final day of plant operation was April 8, 1999.

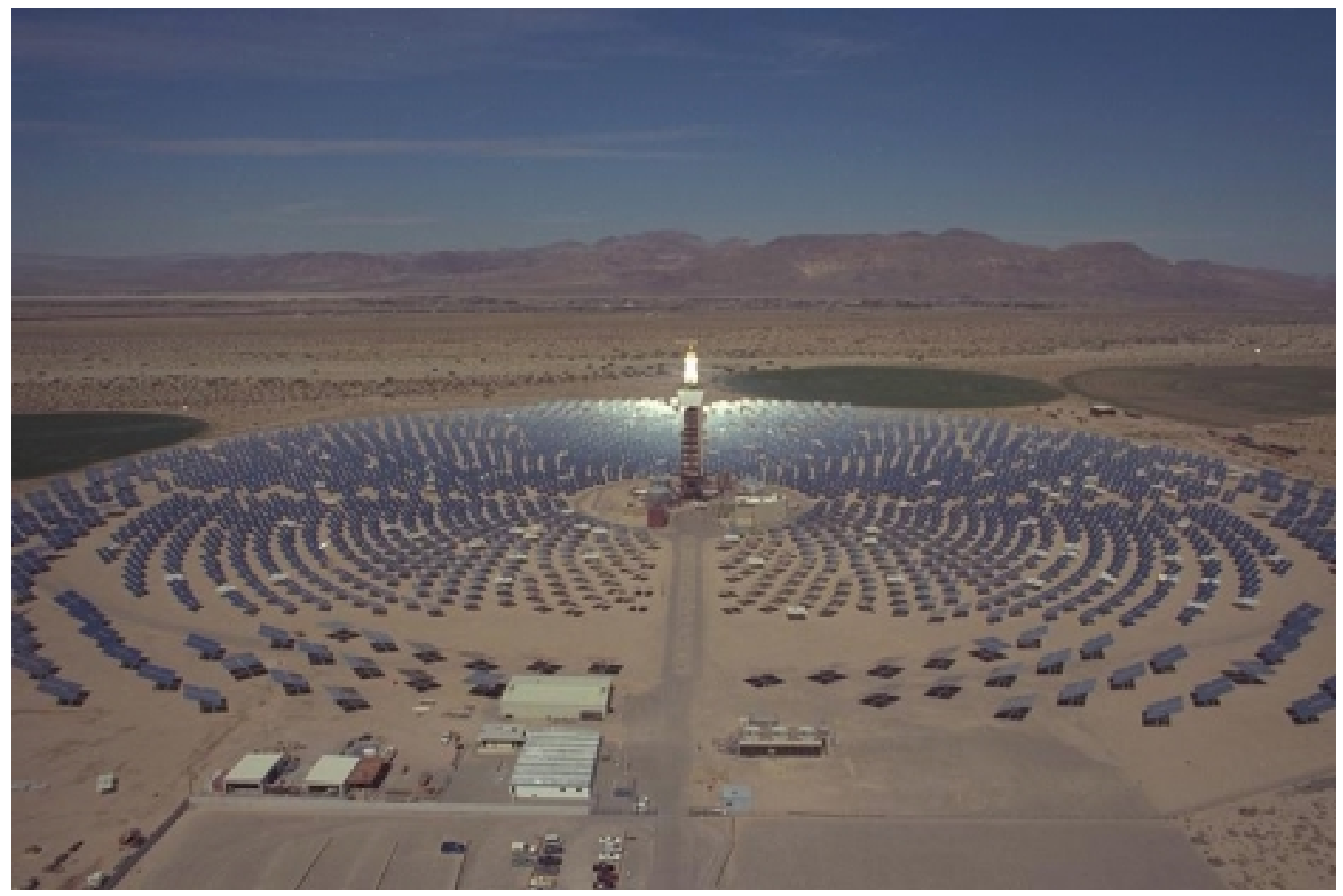

Figure 2-1. The Solar Two Plant in Operation in 1998.

As mentioned in Section 1, there were a number of limitations imposed on Solar One because of the use of water/steam as the heat transfer fluid and oil, sand, and gravel as energy storage media. One limitation was in receiver design and performance. Producing steam in the receiver meant that it operated at high pressure, requiring thick-walled tubes. The heavy-walled tubes limited the solar heat transfer to the steam, limited the solar flux that could be applied, and increased tube stresses.

A second limitation was imposed by the process of transferring energy between steam and the oil/sand/gravel thermal storage system. During charging of the thermal storage system, energy was transferred from the steam to the large inventory of oil, which, in turn, transferred energy to 
the sand and gravel in the tank. The process was reversed when the thermal storage system was being discharged. These heat transfer operations required a complex train of heat exchangers, each with its energy and thermodynamic availability losses. The heat transfer oil itself imposed additional limitations since its maximum operating temperature was limited to $580^{\circ} \mathrm{F}\left(304^{\circ} \mathrm{C}\right)$. The Solar One plant also suffered a fire in the thermal storage tank that left it badly damaged. Even before the fire, the thermal storage system was used primarily for auxiliary steam. Steam from the receiver typically bypassed storage and was sent directly to the turbine.

Lack of a practical means to store thermal energy imposed the final limitations. Without storage, collecting and using thermal energy were directly coupled. Therefore, Solar One operation was difficult during periods of intermittent clouds because the clouds would often cause steam production to degrade to the point that the turbine/generator would trip offline. Turbine operation ended when the skies became cloudy. Turbine operation after sundown was not practical without an effective energy storage system.

Solar Two's molten-salt heat transfer/energy storage system was proposed as a means to address the shortcomings of a water/steam system. Molten salt provided an effective energy storage system and required no heat exchange processes between energy collection and storage. Effective energy storage also allowed the generation of electricity to be uncoupled from the collection of solar energy. This uncoupling solved the major problems inherent in a water/steam system. It allowed stable turbine operation during periods of intermittent clouds, and allowed full dispatchability of energy-after sundown, or even 24 hours/day, as demonstrated by Solar Two.

Solar Two was built as a retrofit of the Solar One plant. This approach reduced the required capital investment, and helped meet the objective of demonstrating molten-salt technology on a large scale. For Solar Two, many Solar One systems were refurbished and reused, including the receiver tower, turbine/generator, some of the process controls, and the heliostat field. Section 2.2 describes this approach in more detail.

The Solar Two project sought to reduce the perceived risks of building the first commercial plant. To this end, the project objectives were as follows:

1. Validate the technical characteristics (reliability, annual net electric performance, minimal environmental impact, and capability for dispatch) of the nitrate salt receiver, storage system, and steam generator technologies.

2. Improve the accuracy of economic projections for commercial projects by increasing the database of capital, operating, and maintenance costs.

3. Simulate the design, construction, and operation of the first $100 \mathrm{MWe}$ (or larger) power plants.

4. Collect, evaluate, and distribute to United States utilities and the solar industry the knowledge gained to foster wider utility interest in the first commercial projects.

5. Stimulate the formation of a commercialization consortium that would facilitate the financing and construction of the initial commercial projects. 
Solar Two was funded and directed by a consortium. Table 2-1 lists the consortium members. Depending on the amount of contribution and the desired rights in the project, each member signed up as a Participant, Contributor, or as a company providing industrial cost share. The DOE provided half of the project funding, with the remaining members providing the other half. Southern California Edison Company acted as the lead utility and managed the overall project, including the project budget. Edison's leadership role and the industrial makeup of the consortium were in keeping with the intent that the project be an industry-led demonstration of power tower technology as a necessary last step to commercialization. The consortium formed a steering committee to direct the project. In addition, a technical advisory committee, chaired by Sandia National Laboratories (SNL), was formed to provide technical guidance and input to the Solar Two Steering Committee. As needed, the Solar Two Technical Advisory Committee formed ad hoc subcommittees to address specific issues, such as reviewing bid proposals, developing a test and evaluation plan, and addressing technical issues that arose during plant startup and operation.

Table 2-1. The Solar Two Consortium

\begin{tabular}{|l|l|}
\hline \multicolumn{1}{|c|}{ Participants } & \multicolumn{1}{c|}{ Contributors } \\
\hline Arizona Public Service Company & Chilean Nitrate (A New York Company) \\
\hline Bechtel Corporation & Nevada Power Company \\
\hline California Energy Commission & South Coast Air Quality Management District \\
\hline Electric Power Research Institute & \multicolumn{1}{|c|}{ Industrial Cost Share } \\
\hline Idaho Power Company & ABB Lummus \\
\hline Los Angeles Department of Water and Power & Goulds Pumps \\
\hline PacificCorp & General Process Controls \\
\hline Sacramento Municipal Utility District & Pitt-Des Moines \\
\hline Salt River Project & Raychem \\
\hline Southern California Edison Company & Boeing (Rockwell International Corp.) \\
\hline DOE & The Industrial Company \\
\hline
\end{tabular}

As described in Section 1, a molten-salt power tower utilizes a large inventory of molten nitrate salt to collect and store solar thermal energy. The salt selected for Solar Two was a mixture of $60 \mathrm{wt} \%$ sodium nitrate and $40 \mathrm{wt} \%$ potassium nitrate. This mixture is near the eutectic proportions and had an initial melting point of $404^{\circ} \mathrm{F}\left(207^{\circ} \mathrm{C}\right)$.

Figure 2-2 provides a schematic of the Solar Two molten-salt power tower plant. The receiver loop operated as follows. Cold salt was held at $550^{\circ} \mathrm{F}\left(288^{\circ} \mathrm{C}\right)$ in the cold salt storage tank. The salt then flowed by gravity to the receiver pump sump, where two cold salt pumps pumped it up the tower to the receiver inlet vessel. The pressurized inlet vessel supplied the cold salt to the receiver. The receiver heated the salt to $1050^{\circ} \mathrm{F}\left(565^{\circ} \mathrm{C}\right)$, after which the salt flowed through the 


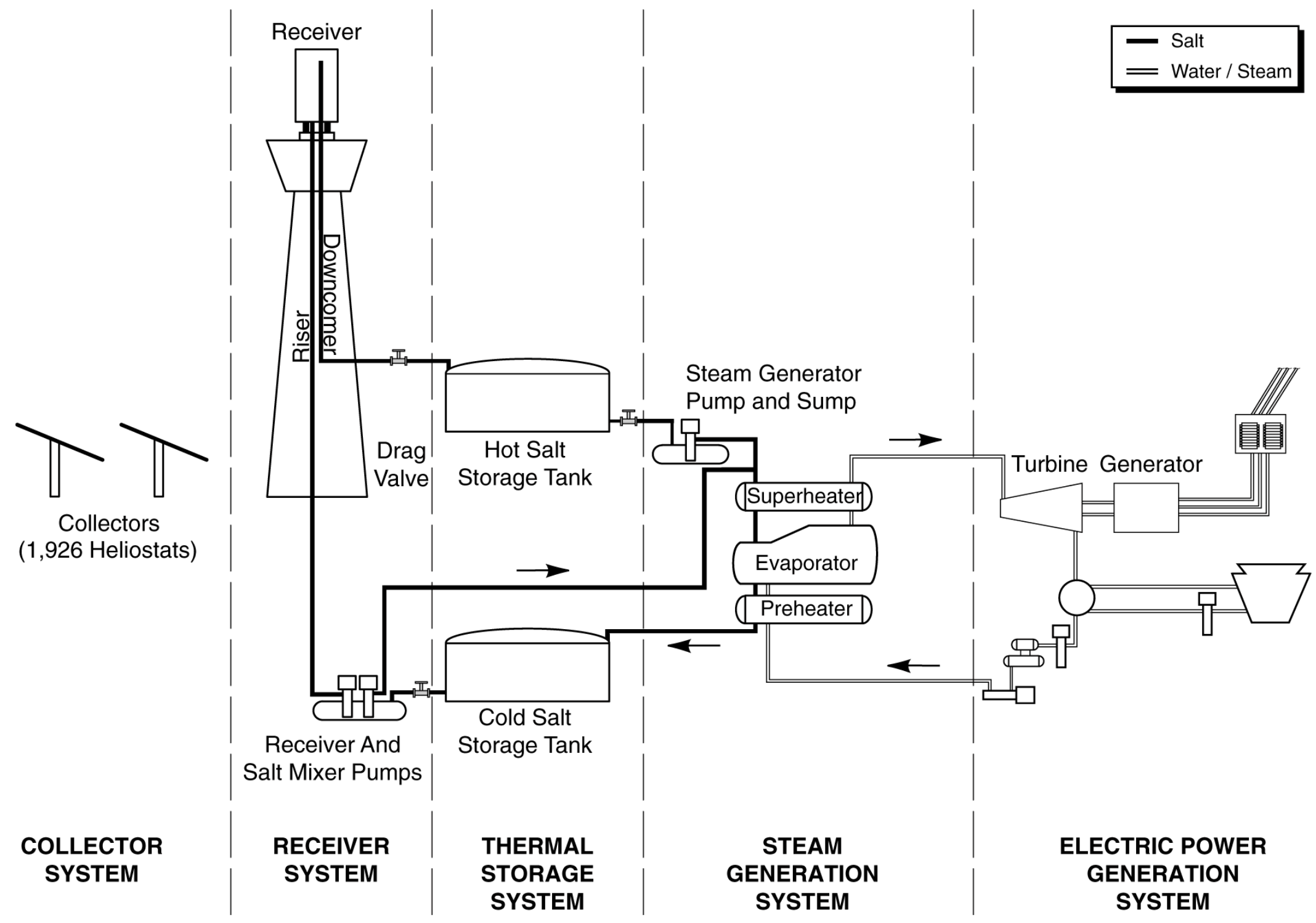

Figure 2-2. Solar Two System Schematic. 
outlet vessel, downcomer, drag valve, and into the hot tank. Unintended bypass valve leakage and thermal losses caused the salt temperature to drop to approximately $1025^{\circ} \mathrm{F}\left(552^{\circ} \mathrm{C}\right)\left(25^{\circ} \mathrm{F}\right.$ $\left(13^{\circ} \mathrm{C}\right)$ below the design temperature) by the time it reached the hot salt storage tank. The steam generator loop operated as follows. Hot salt was held at approximately $1025^{\circ} \mathrm{F}\left(552^{\circ} \mathrm{C}\right)$ in the hot salt storage tank. The salt then flowed by gravity to the steam generator pump sump, where one of the two hot salt pumps (one active, one installed spare) pumped it to the steam generator. The salt flowed through the superheater, evaporator, and preheater, then flowed to the cold salt storage tank.

Solar Two was comprised of the following six major systems:

1. Receiver System

2. Steam Generation System (SGS)

3. Thermal Storage System

4. Collector System

5. Electric Power Generation System (EPGS) and Balance of Plant (BOP)

6. Master Control System

Table 2-2 lists these six systems, the initial system costs, and the major components and suppliers for each system.

The Solar Two project was organized into the following six phases:

1. Systems Engineering

2. Major Procurements

3. Detailed Engineering

4. Construction

5. Startup, Checkout, and Acceptance Testing

\section{Operation}

Progression from one project phase to the next required approval by the Solar Two Steering Committee. The phases were not accomplished in a strictly serial fashion. A number of times, the steering committee approved start of the next phase before completion of the preceding one.

The following section describes the actual project experience as the project progressed through each of the planned phases. 
Table 2-2. Solar Two Major Equipment Summary

\begin{tabular}{|c|c|c|}
\hline Item & Major Suppliers & $\begin{array}{c}\text { Cost }^{\star} \\
\text { (Thousands) }\end{array}$ \\
\hline $\begin{array}{l}\text { Receiver System } \\
\text { Solar Two receiver, spare panel and spare } \\
\text { tubes, inlet and outlet vessels } \\
\text { Solar One receiver demolition }\end{array}$ & $\begin{array}{l}\text { Rocketdyne (Boeing) } \\
\text { Swinerton Walberg, Inc. } \\
\text { (SWI) } \\
\text { Sachs Electric }\end{array}$ & $\$ 8,534$ \\
\hline $\begin{array}{l}\text { SGS } \\
\text { Preheater, Evaporator, Superheater } \\
\text { Pumps, pump sumps }\end{array}$ & $\begin{array}{l}\text { ABB Lummus } \\
\text { Titan Steel } \\
\text { The Industrial Company (TIC) }\end{array}$ & $\$ 3,102$ \\
\hline $\begin{array}{l}\text { Thermal Storage System } \\
\text { Hot and cold salt storage tanks, founda- } \\
\text { tions, heaters, and spargers }\end{array}$ & $\begin{array}{l}\text { Pitt-Des Moines, Inc. } \\
\text { F2M Company }\end{array}$ & $\$ 3,460$ \\
\hline $\begin{array}{l}\text { Collector System } \\
108 \text { Lugo heliostats } \\
\text { Replacement facets for Solar One he- } \\
\text { liostats } \\
\text { Canting of inner } 17 \text { rows of heliostats }\end{array}$ & $\begin{array}{l}\text { Advanced Thermal Systems } \\
\text { Modern Alloys, Inc. } \\
\text { TIC }\end{array}$ & $\$ 3,115$ \\
\hline $\begin{array}{l}\text { Electric Power Generation System and } \\
\text { Balance of Plant } \\
\text { Turbine refurbishment } \\
\text { BOP refurbishment } \\
\text { Heat Trace } \\
\text { Diesel generator }\end{array}$ & $\begin{array}{l}\text { TIC } \\
\text { General Electric } \\
\text { Elliott Company } \\
\text { Raychem Corp. } \\
\text { M\&M Valve }\end{array}$ & $\$ 2,121$ \\
\hline $\begin{array}{l}\text { Master Control System } \\
\text { New master control computers and soft- } \\
\text { ware } \\
\text { Modify, refurbish Solar One Distributed } \\
\text { Process Control System (DPCS) } \\
\text { Heliostat control software (DAPS, SAPS) }\end{array}$ & $\begin{array}{l}\text { Queue Systems, Inc. } \\
\text { Associated Process Control } \\
\text { Fisher-Rosemount Systems } \\
\text { University of Houston }\end{array}$ & $\$ 2,021$ \\
\hline Total Initial Equipment Costs & & $\$ 22,353$ \\
\hline
\end{tabular}

* Costs are as of 10/24/96 Steering Committee meeting

\subsection{Project Execution and Schedule}

There are a number of approaches that can be taken to design, construct, and start up a large field project. The Solar Two project selected an engineering firm to serve as an Engineer and Construction Manager (E\&CM). Bechtel Corporation was chosen for this role. As the E\&CM, Bechtel designed the plant, entered into subcontracts and purchase orders for equipment and 
services, managed the construction of the plant, performed the plant startup, and turned the plant over to the Operations and Maintenance (O\&M) contractor.

As mentioned above, Solar Two project execution was planned in six phases. Table 2-3 shows the project phases and the planned and actual timelines for each. As shown in the table, the project met the planned schedule through the start of construction (Phase 4) and was within one month of the schedule at the end of the nearly one-year construction phase. However, significant delays occurred during Phase 5 (Startup, Checkout, and Acceptance Testing).

Table 2-3. Solar Two Project Phases and Milestones

\begin{tabular}{|ll|l|l|}
\hline \multicolumn{1}{|c|}{ Phase } & \multicolumn{1}{c|}{ Planned Start } & \multicolumn{1}{c|}{ Actual Start } \\
\hline 1: & Systems Engineering & June 1993 & January 1993 \\
\hline 2: & Major Procurements & October 1993 & October 1993 \\
\hline 3: & Detailed Engineering & March 1994 & March 1994 \\
\hline 4: & Construction & October 1994 & September 1994 \\
\hline 5: & $\begin{array}{l}\text { Startup, Checkout and Acceptance Testing } \\
\text { First electricity to grid }\end{array}$ & July 1995 & August 1995 \\
& $\begin{array}{l}\text { Dedication } \\
\text { Acceptance Testing }\end{array}$ & October 1995 & April 1996 \\
6:-- & Operation & November 1995 1996 \\
& Test and Evaluation & January 1996 & November 1997 \\
& Operate for Power Production & January 1996 & February 1998 \\
& Shutdown & January 1997 & production \\
\hline & December 1998 & March 1998 \\
\hline
\end{tabular}

Although retrofitting Solar One reduced the capital investment, this approach was not without drawbacks, imposing O\&M cost and performance penalties on Solar Two. Considerable effort and expense were expended throughout the Solar Two project to refurbish and maintain old, abandoned equipment and to interface with 1970s-vintage hardware and software. The following sections discuss the project phases, what happened during each phase, and the impact of schedule slippage on the overall project.

\subsection{Construction}

As the E\&CM, Bechtel was responsible for design, overall construction, and startup of Solar Two. Plant construction was accomplished through subcontracts between Bechtel and the various service and equipment suppliers. The Solar Two Steering Committee approved major subcontracts, such as TIC as the general mechanical and electrical contractor and the Rocketdyne Division of Rockwell Corporation (now the Rocketdyne Division of The Boeing Company) as the receiver supplier.

Solar Two utilized the following major Solar One plant equipment and systems: 
- Receiver tower

- EPGS (turbine, generator, condenser, and feedwater heaters)

- Heliostat field

- Distributed Process Control System

The major systems installed or refurbished during Solar Two construction were as follows:

- Installation of a new thermal storage system, including one hot and one cold salt storage tank

- Installation of a new receiver system, including a 24-panel salt-in-tube cylindrical receiver

- Installation of a new SGS, including a superheater, evaporator, and preheater

- Installation of salt piping, valves, and heat trace

- Installation of an emergency diesel generator for backup power to the receiver salt pumps

- Refurbishment of the Solar One electric power generation system

- Installation of 108 south-field heliostats, each with $95.1 \mathrm{~m}^{2}$, to supplement the original 1818 Solar One heliostats

- Installation of replacement mirror modules for missing or damaged Solar One heliostat mirror modules and relocation of 32 Solar One heliostats from the north to the south field

The following sections describe the construction of these systems and equipment items, as well as the problems encountered during the construction phase. Timely solutions to these and other construction-related problems allowed the startup phase to begin in July 1995, keeping the project within a month of its original schedule.

\subsubsection{Thermal Storage System}

In preparation for Solar Two, the Solar One thermal storage system was removed, and the area restored, during the last half of 1993 and the first half of 1994. Figure 2-3 shows the thermal storage tank being demolished. The heat transfer oil from the system was sold as boiler fuel, the tank and foundation were demolished, the oil-steam heat exchangers were salvaged, and the oilsaturated sand and gravel were used in asphalt, which in turn was used to pave the parking lot at Barstow Community College. For Solar Two, Pitt-Des Moines was chosen to construct a new, two-tank molten-salt thermal storage system. Each tank was sized to store the entire salt inventory. Both tanks utilized open pipes in the foundation to create a chimney effect to passively cool the tank foundations. Figure 2-4 shows the Solar Two cold salt storage tank under construction. 


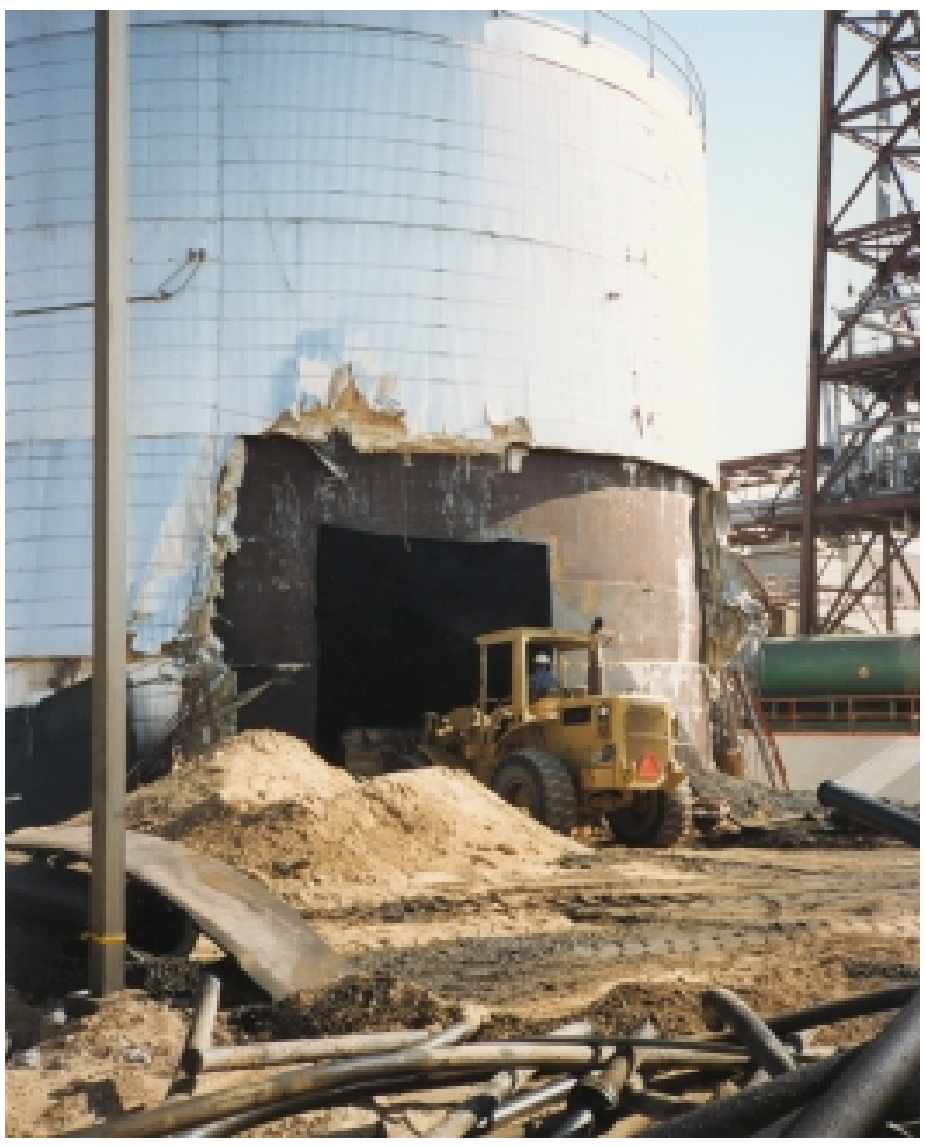

Figure 2-3. The Solar One Thermal Storage System Being Demolished in 1993.

\subsubsection{Receiver System}

The receiver system accepts cold salt from the cold salt storage tank and returns heated salt to the hot salt storage tank. During normal operation, salt enters the receiver inlet vessel from the riser piping, flows through one of the two 12-panel flow circuits, flows into the receiver outlet vessel, then exits the system via the downcomer piping. Figure 2-5 illustrates the normal receiver flow path, as well as the bypass and drain piping (the receiver vent piping is not shown). Figure 2-6 illustrates the serpentine flow arrangement between adjacent receiver panels. The salt flow may be described as follows. Salt enters the receiver through the two northernmost panels (panels E1 and $\mathrm{W} 1$ ), flows in a serpentine fashion through the adjacent six panels, crosses over from one side of the receiver to the other along the east-west centerline, then completes the path through the remaining six panels, exiting the receiver through panels E12 and W12. This singlecrossover, serpentine flowpath is illustrated in Figure 2-7.

The receiver system was the responsibility of the Rocketdyne division of the Boeing Company. Major receiver system construction included:

- Refurbishment and reinstallation of the Solar One receiver crane 


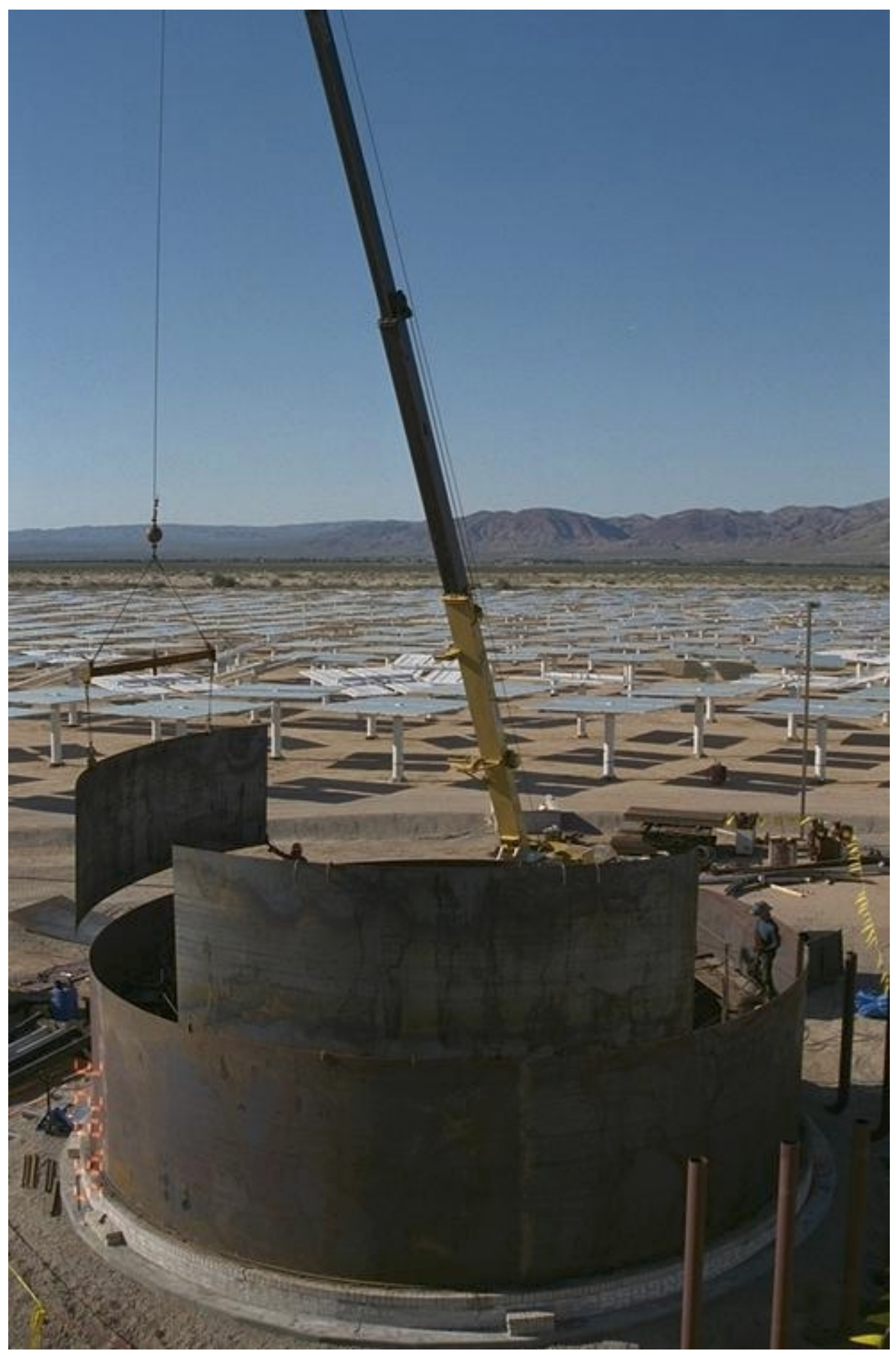

Figure 2-4. The Solar Two Cold Salt Storage Tank Under Construction. 


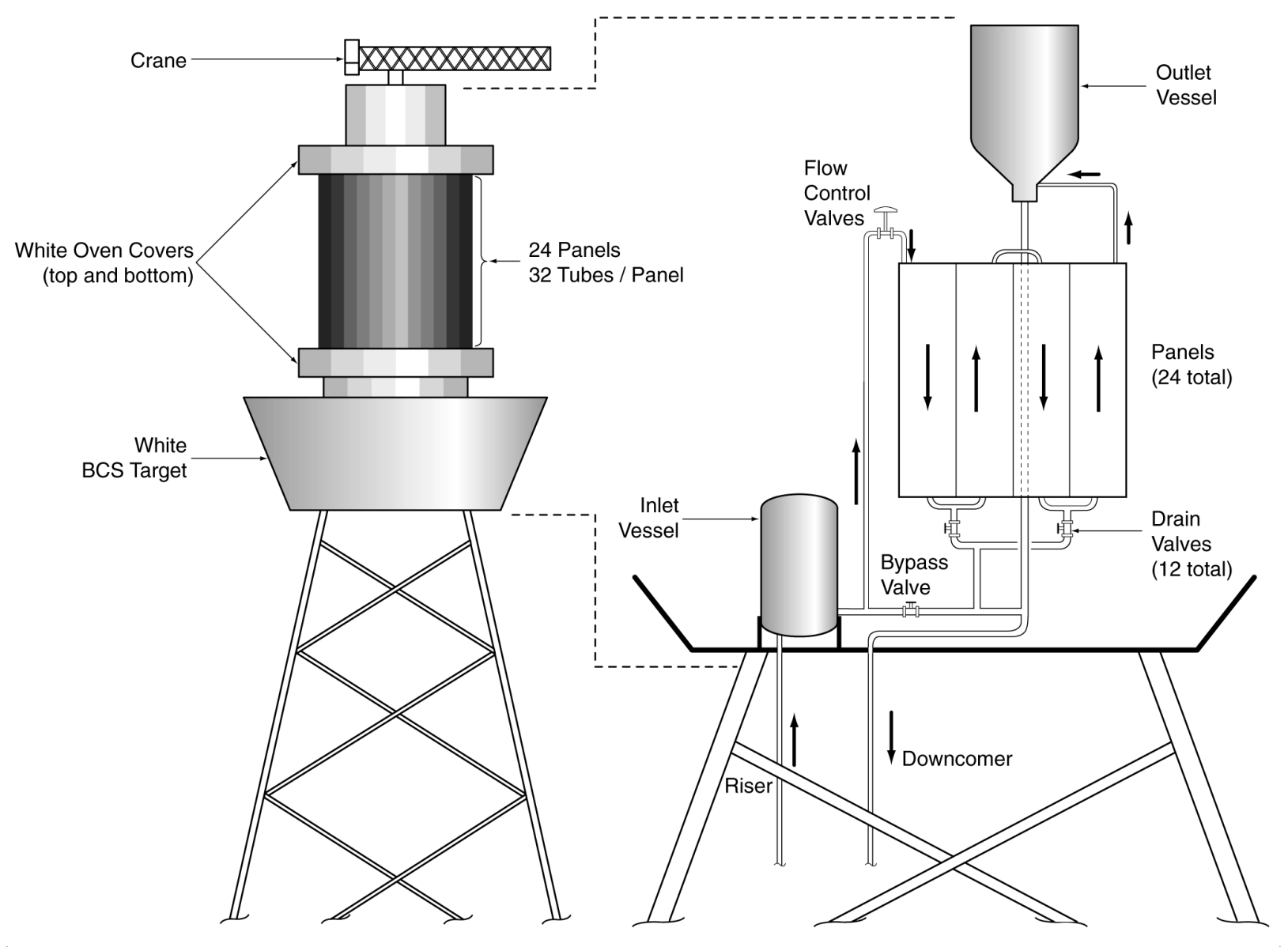

Figure 2-5. Details of Receiver Piping (Panel Vents not Shown).

- Demolition of the Solar One receiver (see Figure 2-8)

- Modification of the receiver tower and receiver support structures to accommodate the Solar Two receiver

- Installation of the Solar Two receiver inlet and outlet vessels

- Installation of the 24 Solar Two receiver panels and associated piping

- Tie-in of the receiver inlet piping to the riser piping

- Tie-in of the receiver outlet piping to the new downcomer piping

The original Solar One downcomer, a 6-in., Schedule 160, CrMo pipe, was used as the Solar Two riser. The Solar Two downcomer was new stainless steel piping constructed by TIC. 


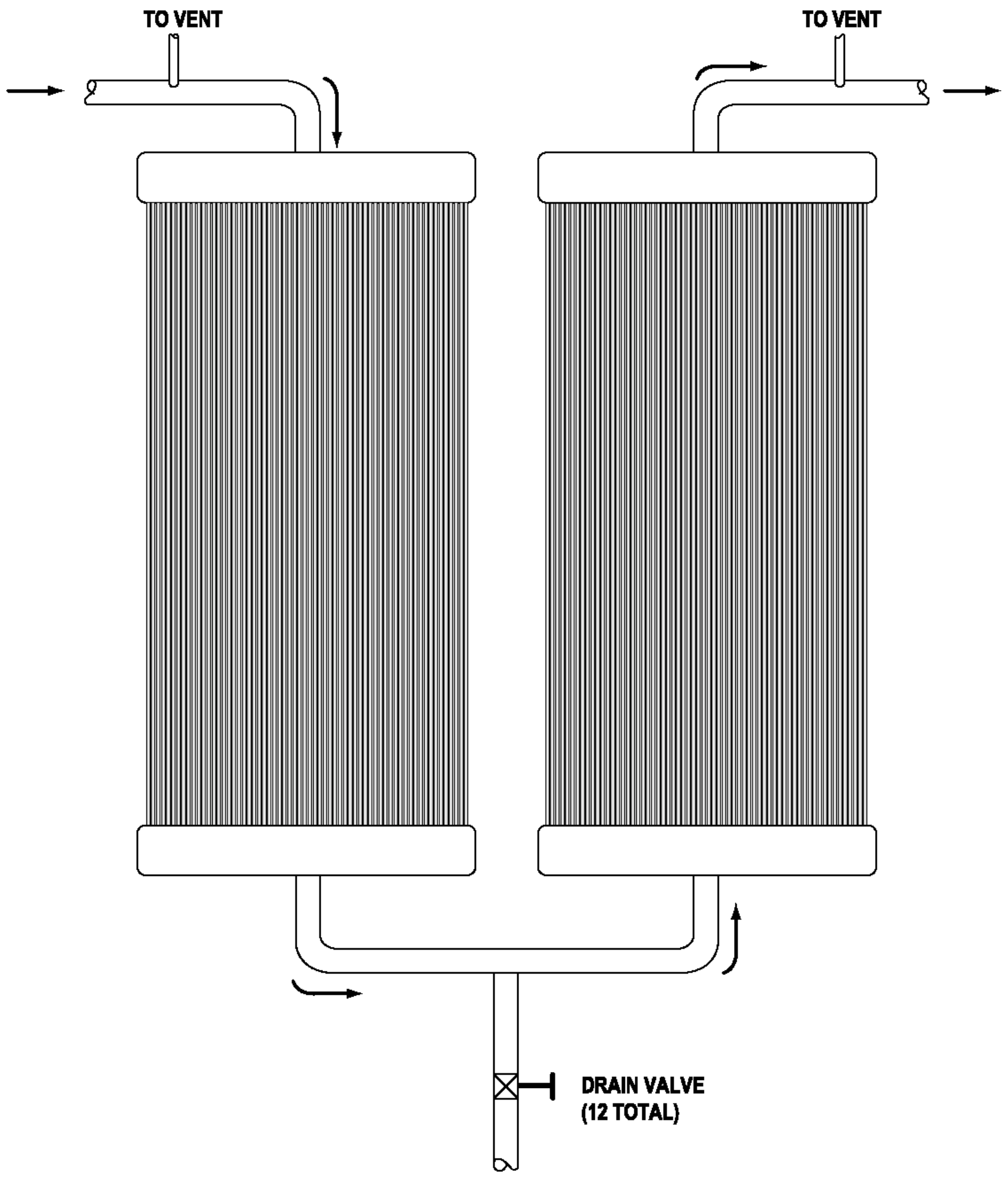

Figure 2-6. Typical Serpentine Flowpath between Adjacent Receiver Panels. 


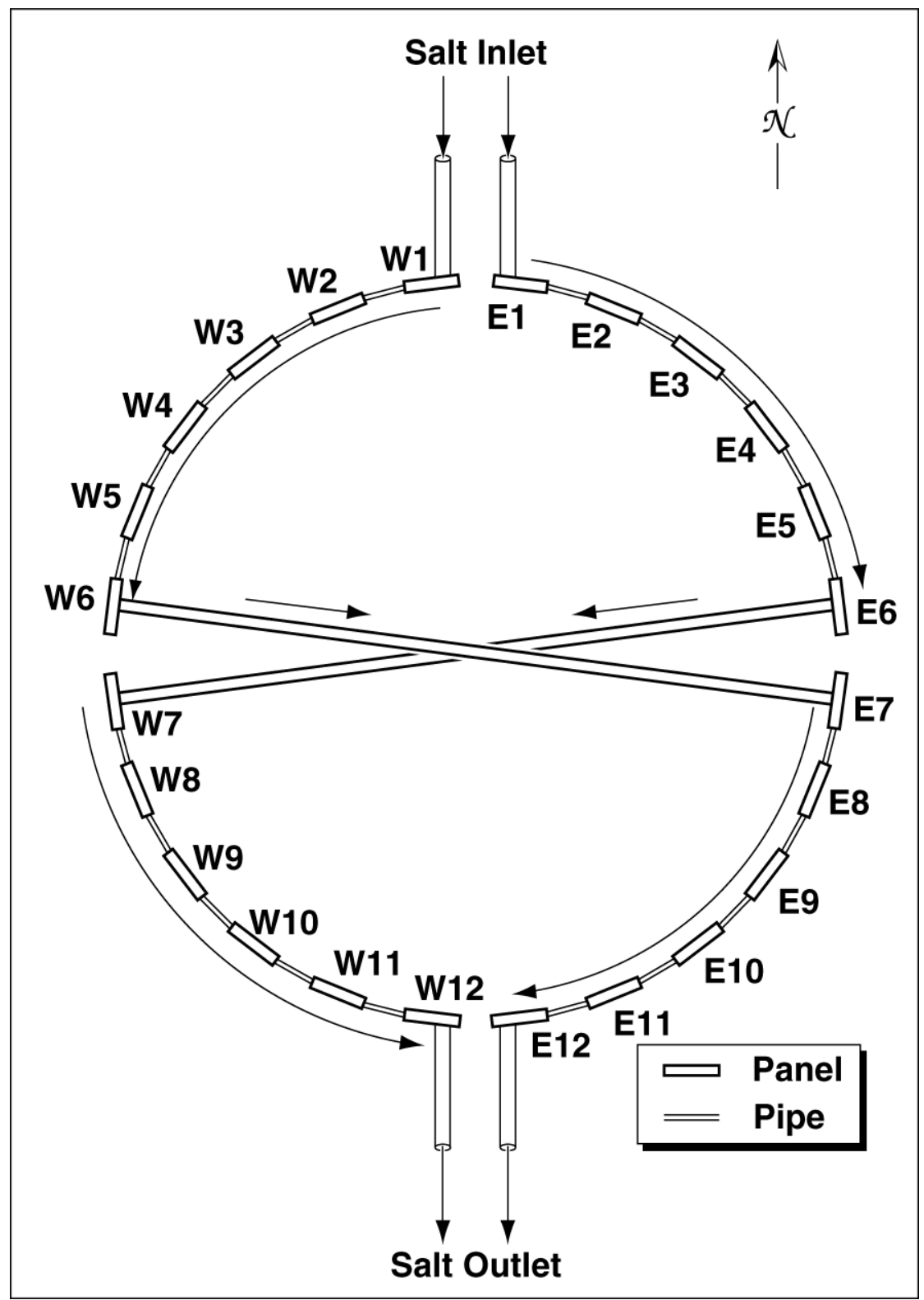

Figure 2-7. Receiver Crossover Flow Pattern.

Several problems occurred during manufacture and construction of the Solar Two receiver. First, Boeing encountered difficulties in the tube-to-tube-clip weld. This manufacturing problem was quickly isolated and resolved and the receiver tubes were manufactured on schedule.

A second problem occurred when a crack was discovered in the ring gear on the refurbished and reinstalled receiver crane. The crane had to be removed, repaired, and reinstalled before equipment and materials could be lifted to the top of the tower. 


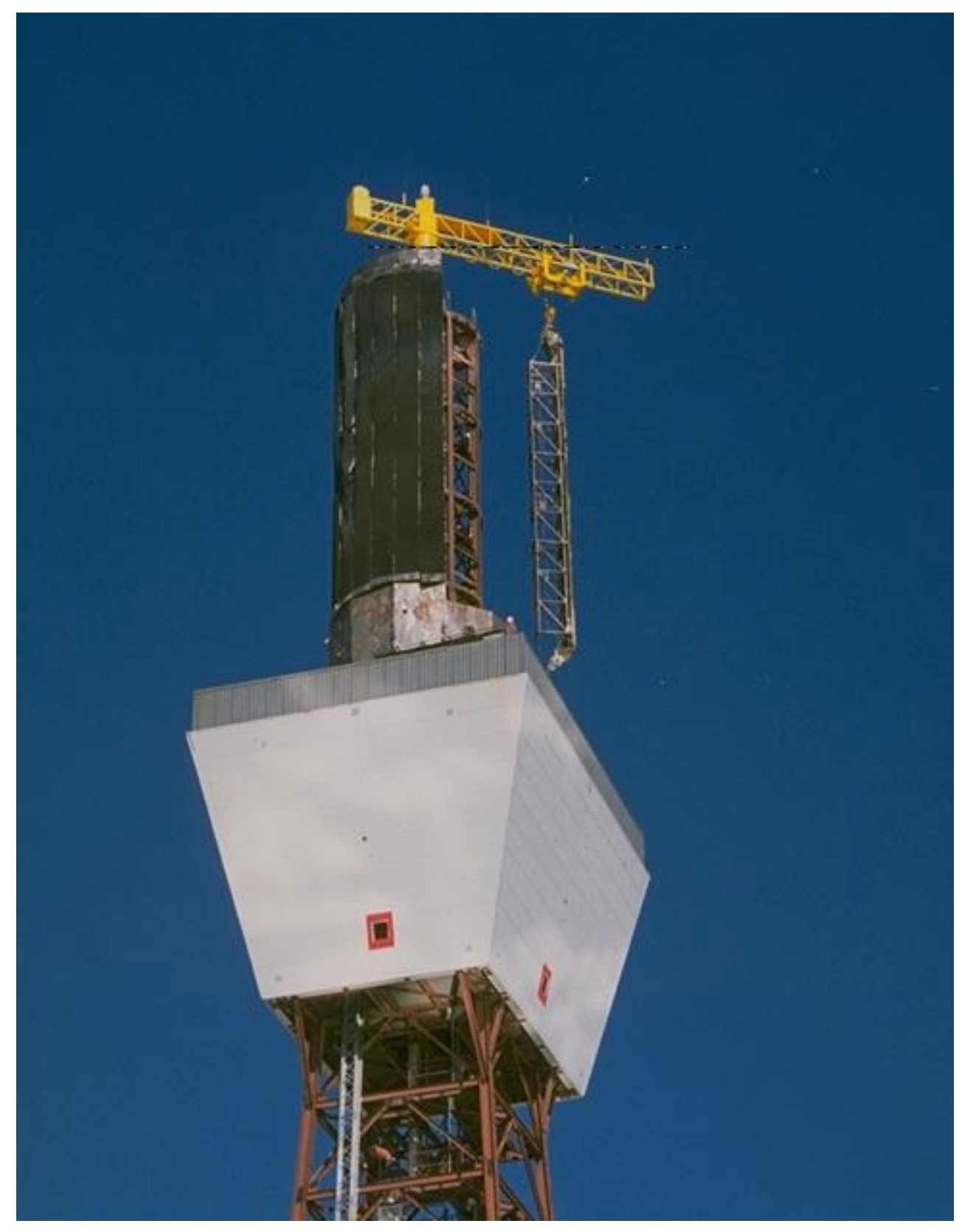

Figure 2-8. The Solar One Receiver Being Dismantled.

The next problem involved an unexpected interference between the tower receiver support structure and the receiver panels. The panel strongbacks (the rigid box beams behind the panel tubes and insulating layers) had to be modified to eliminate the interference. The interference was discovered on the first few panels, so the strongback modification was made prior to shipping the remaining panels to the site.

Finally, receiver panel installation proved difficult. Boeing had originally planned to install the 24 panels in eight, three-panel modules. However, the module weights would approach or exceed the lifting capability of the refurbished crane. The panels were therefore individually lifted 
and installed. Using the receiver crane, each panel had to be hoisted up the side of the receiver tower and then moved radially inwards into position (see Figure 2-9). Once in position, the panels were bolted to the tower support structure and welded into the connecting piping. Lifting the panels was attempted in March 1995. It was quickly apparent that, for safe lifting, the winds had to be nearly calm. The Solar Two site is quite windy in the springtime, causing difficulties and delays in lifting the panels. In addition, the winds made it difficult to maintain the purge gas cover needed to complete welds on the panels. Receiver panel installation was completed in June of 1995.

SWI constructed the receiver system under subcontract to Boeing. The receiver pumps were installed by TIC, the project's general mechanical and electrical contractor. The receiver pumps consisted of two six-stage turbine pumps, each capable of $50 \%$ of the design receiver flow. A used, $750 \mathrm{KWe}$ diesel generator was installed northeast of the receiver tower to supply emergency power to the receiver pumps in the event of loss of power to the site. Operation of the diesel generator was automatic. Upon loss of power to the receiver pumps, pressure in the receiver inlet vessel continued to supply salt to the receiver while the diesel generator started. Once the generator started, the receiver pumps would start and replenish the salt inventory in the inlet vessel, thereby protecting the receiver from overheating. The diesel generator did not supply power to the heliostat field. If power was lost in the heliostat field, damage to the receiver tower could still occur as the sun continued to move and the heliostat beams "walked off" the receiver and onto the tower.

\subsubsection{Steam Generation System and Salt Piping, Valves, and Heat Trace}

Figure 2-10 shows the steam generator area under construction. The initial design of the SGS consisted of a straight-shell, u-tube preheater (salt on the shell side), a kettle-boiler evaporator (salt in the u-tubes), and a straight-shell, u-tube superheater (salt on the shell side). The evaporator vessel is shown in Figure 2-11. As described later, the system generation system design was modified during startup by the addition of a startup feedwater heater.

The salt piping, valves, heat trace, hot and cold salt pump sumps, and all pumps were installed by TIC. The steam generator pumps consisted of two cantilevered centrifugal pumps, each capable of $100 \%$ of the steam generator flow. The salt mixer pump, used to attemperate the hot salt during SGS startup, was a multistage turbine pump installed on the receiver pump sump. A hydrostatic test and flow test (using water as the flow medium) were conducted as part of the construction and startup of the SGS.

Electric heat trace was installed on all salt piping. Figure 2-12 shows how heat trace was initially installed on piping systems. Unfortunately, the heat trace was not installed uniformly, leading to the problems discussed in Section 2.4.3. In the initial heat trace installation, valves were heat-traced as part of the piping system in which they were installed. This approach was later changed so that 4-in. and larger diameter valves had their own heat trace cables and control zone. 


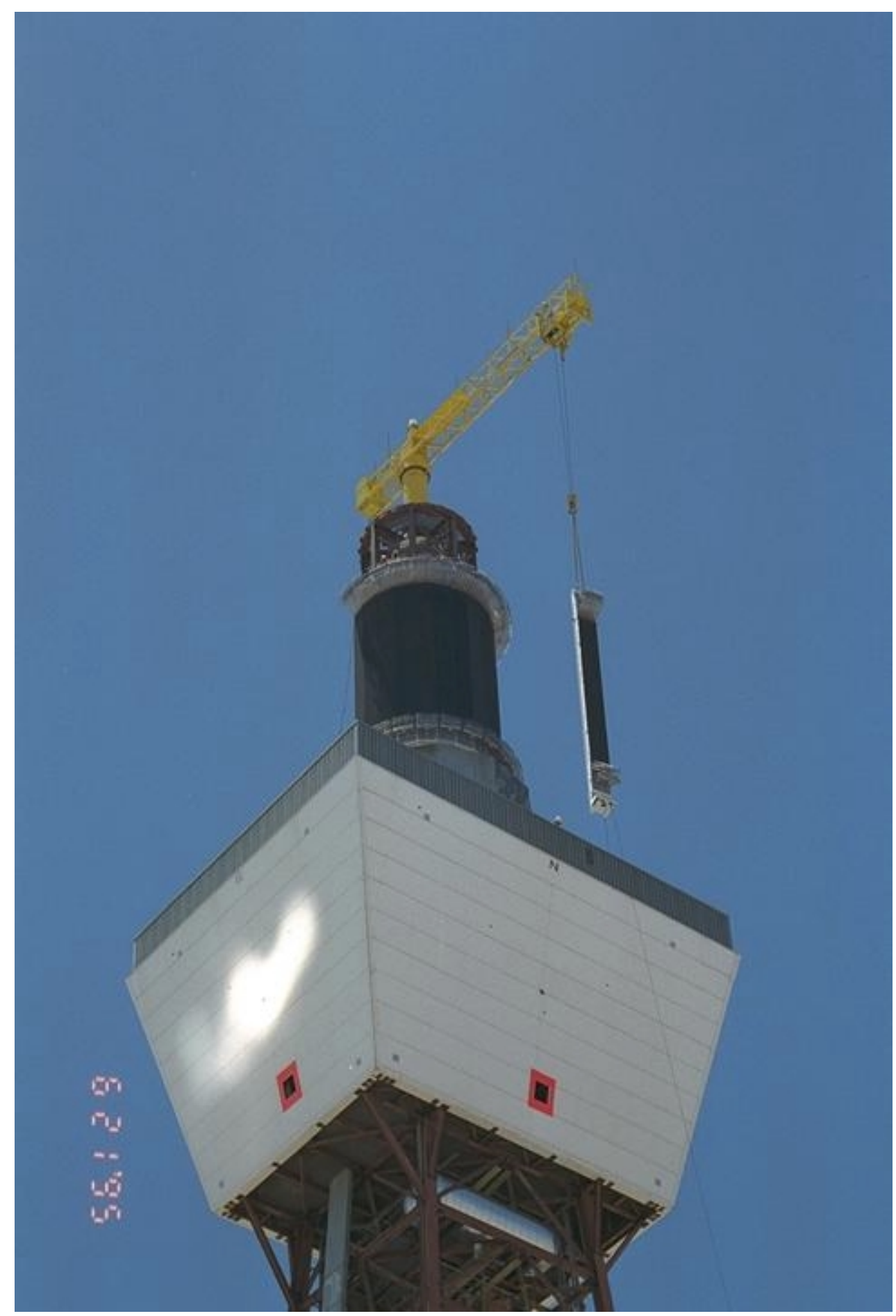

Figure 2-9. A Solar Two Receiver Panel Being Hoisted to the Top of the Tower. 


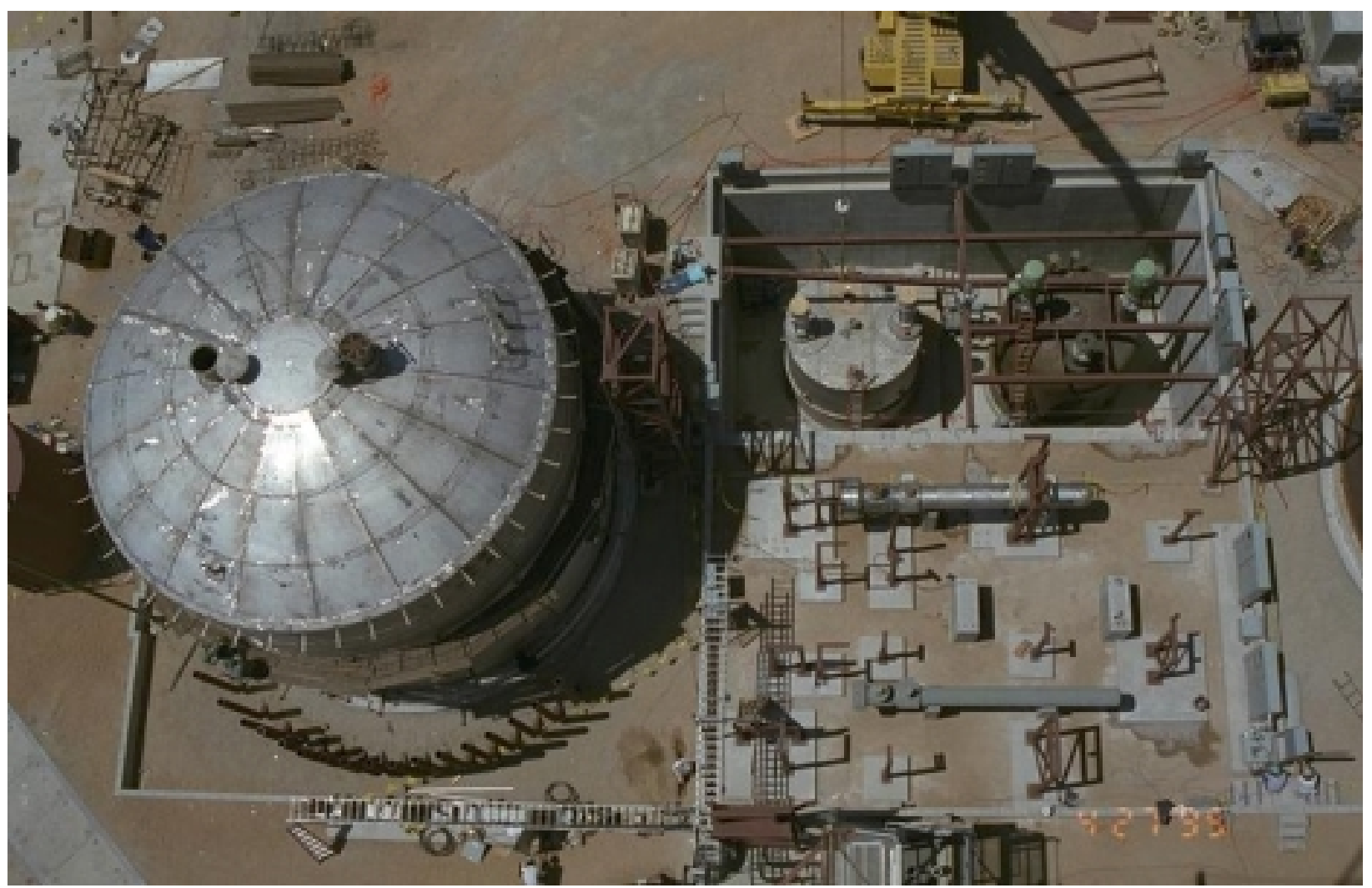

Figure 2-10. The Solar Two Steam Generation Area Under Construction. The Hot Salt Storage Tank is to the left.

\subsubsection{Electric Power Generation System Refurbishment}

The Solar Two construction phase included refurbishment of the Solar One EPGS. Bechtel contracted with The General Electric Company to refurbish the Solar One turbine and generator. (A previous evaluation had determined that the turbine-generator system was in good shape, requiring only refurbishment to be operational.) The turbine rotor was removed (see Figure 2-13) for reconditioning and then reinstalled in its casing. TIC was responsible for evaluating and refurbishing other EPGS equipment, including valves and heat exchangers, and installing two new air compressors to provide plant instrument air.

\subsubsection{Collector System}

Solar Two was able to utilize the Solar One heliostat field by refurbishing and slightly expanding it. The following construction was undertaken on the heliostat field:

- Relocation of 32 Solar One heliostats along the eastern and western edges of the field

- Installation of 108 large-area heliostats along the southern perimeter of the field 


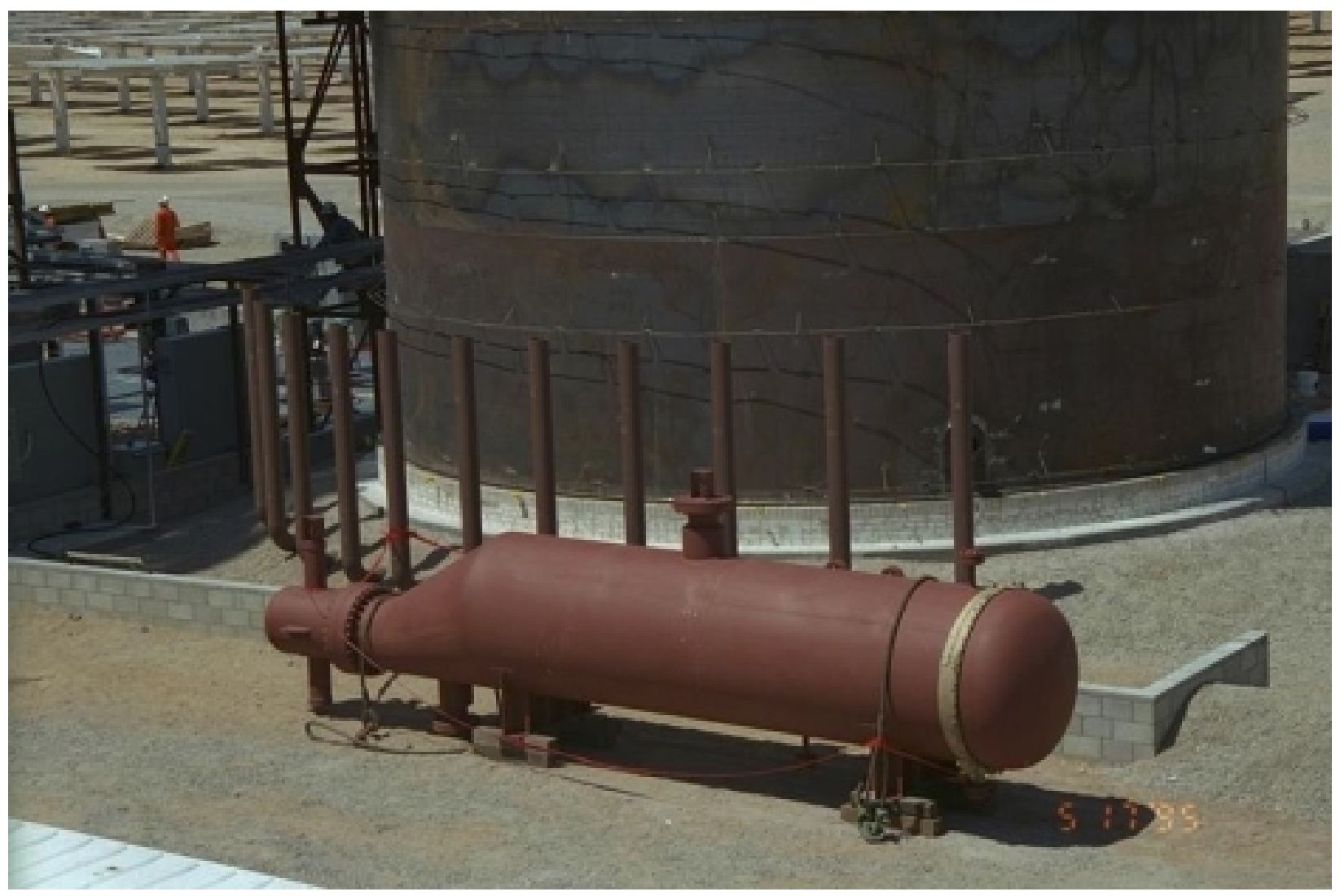

Figure 2-11. The Solar Two Kettle-Boiler Style Evaporator Prior to Installation.

- Installation of replacement mirror modules for missing or damaged Solar One heliostat mirror modules. Corrosion and mechanical failures resulting from such sources as wind and the nearby 1992 Landers earthquake caused damage to the 12-year-old original mirror modules.

- Canting of the inner 17 rows of the field; the new and relocated heliostats; and the replacement mirror modules.

The Solar Two molten salt receiver required more power input (solar flux) on the south side than did the Solar One water/steam receiver. The 108 heliostats were added, and the 32 Solar One heliostats relocated, in order to increase the power on the south side of the receiver. The 108 heliostats were fabricated from used components from two defunct solar photovoltaic projects. The mirror modules came from the Carrissa Plains Photovoltaic project. The pedestals and tracking components came from the Lugo photovoltaic site near Hesperia, California. As a result, the 108 heliostats came to be known as "Lugo" heliostats. A Lugo heliostat is shown in Figure 2-14. The mirror modules were constructed of flat glass in a sandwich design: $1 \mathrm{~mm}$ of silvered glass, backed by $3 \mathrm{~mm}$ of glass for support. Each module measured $4 \times 16 \mathrm{ft}(1.22 \times 4.87 \mathrm{~m})$; each Lugo heliostat utilized 16 mirror modules, providing $95.1 \mathrm{~m}^{2}$ of reflective area. The 108 heliostats therefore added $10,270 \mathrm{~m}^{2}$ of reflective area. Additional Carrissa Plains mirror modules were cut to a length of $12 \mathrm{ft}(3.66 \mathrm{~m})$ and used as replacements for missing or damaged Solar One mirror modules. 


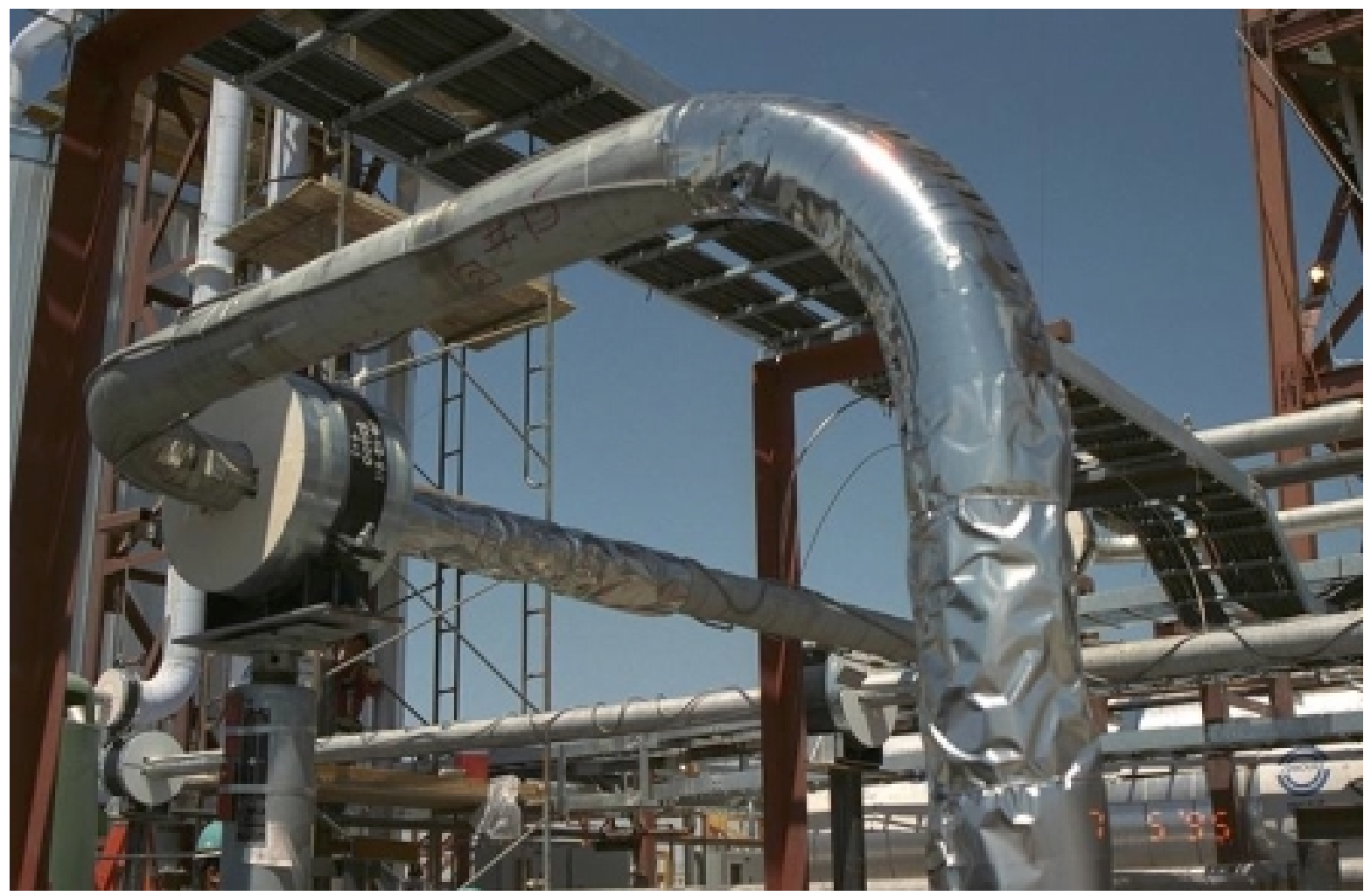

Figure 2-12. Installed Heat Trace Circuits, Prior to Insulation.

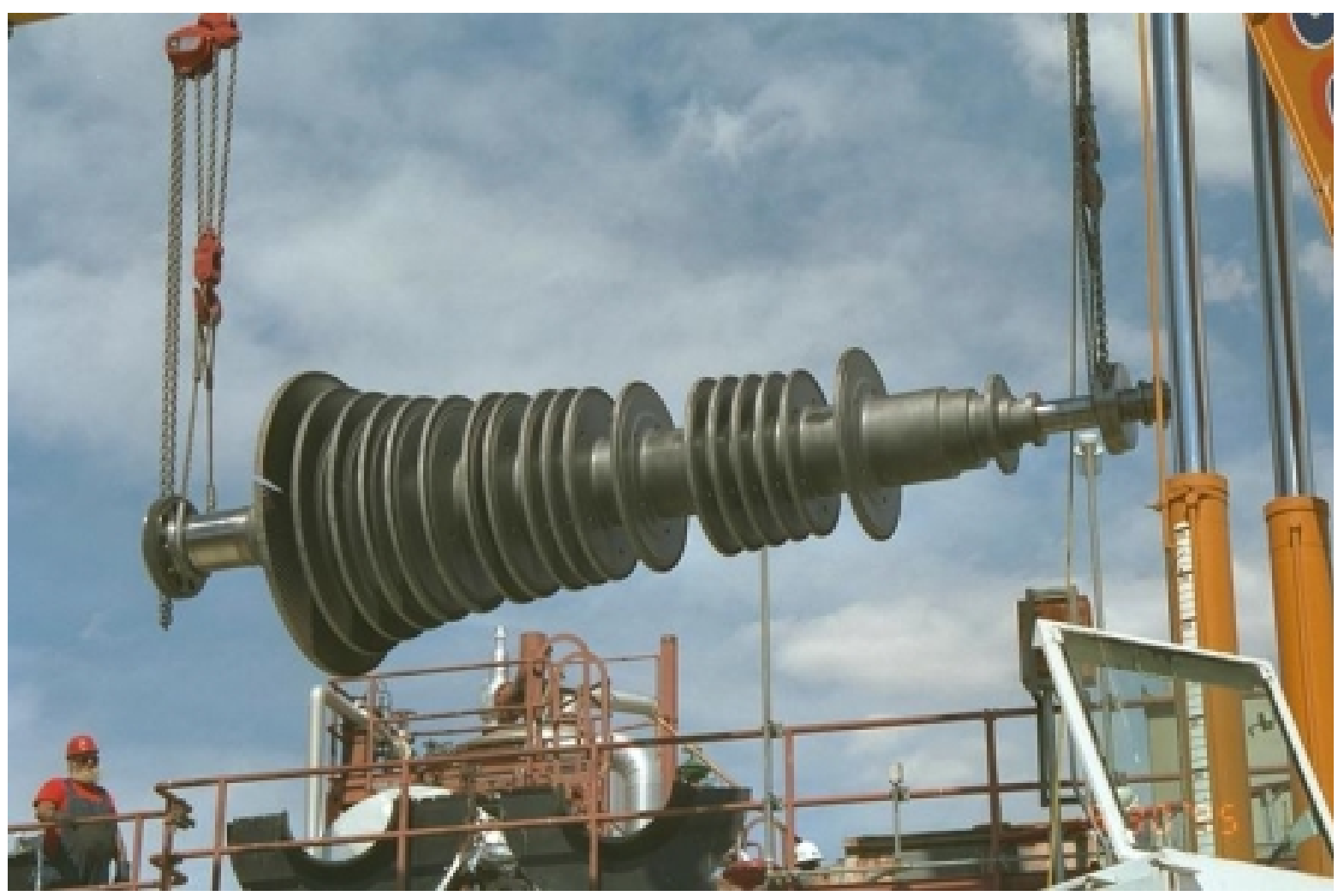

Figure 2-13. Refurbished Solar One Turbine Rotor Being Lowered into Bottom Half of Turbine Casing. 


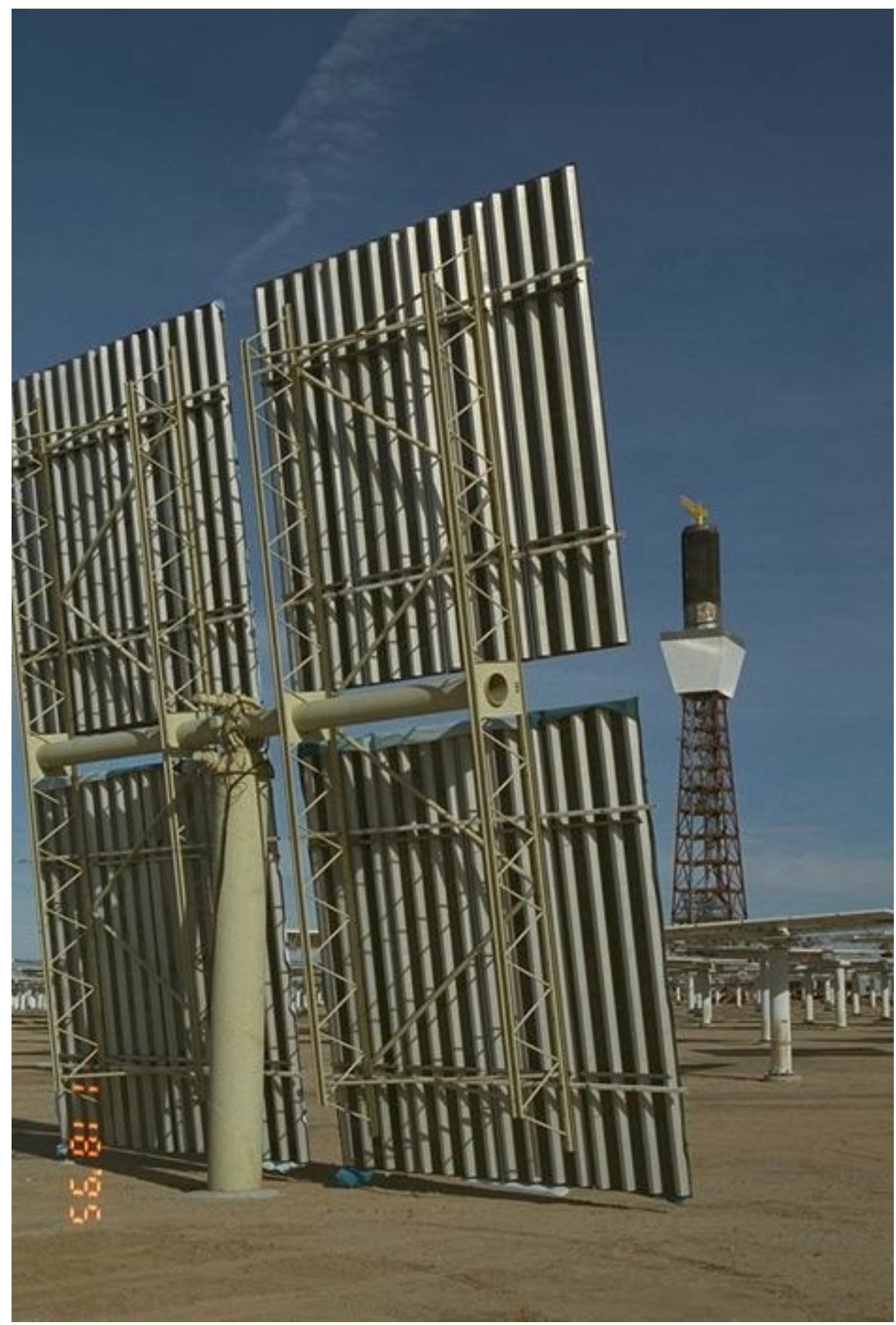

Figure 2-14. One of 108 Lugo Heliostats Installed for the Solar Two Project. 
Ideally, the Solar One replacement mirror modules and the Lugo heliostats would have used curved glass, rather than flat glass. Similar to the Solar One mirror modules, curved mirror modules would have produced a smaller beam, which, in turn, would have better matched the receiver dimensions. However, since heliostat technology was demonstrated by the Solar One project, budget was not allocated in the Solar Two project to further demonstrate heliostat technology. Since optimized mirror modules were not available and the flat glass was inexpensive and readily available, flat mirror modules were used.

When the Solar One field was constructed in the early 1980s, the heliostats had been canted (aligned) to optimize the power to the Solar One receiver. The Solar Two receiver was smaller than the Solar One receiver. To take this size difference into account, the Solar Two project recanted (realigned) the mirror modules on the inner 17 rows of Solar One heliostats. An analysis performed by SNL indicated that the benefit of recanting the inner 17 rows was nearly the same as recanting the entire field. However, as mentioned in Section 4, the recanting was not done properly during Solar Two and did not improve (and may have reduced) field performance, as compared to the original field as originally canted during the Solar One project.

\subsection{Startup}

The startup phase of Solar Two commenced in August 1995. At that point, some construction activities were continuing and Bechtel's startup manager had been on site for a few months to ease the transition from construction to startup. The startup phase was difficult and protracted, with many problems being identified and addressed. The following sections present, in chronological order, some of the most significant problems and sources of delays during the startup phase.

\subsubsection{Salt Loading and Melting (August-October 1995)}

The nitrate salt was delivered to Solar Two from a mine in Chile. Prior to arrival at Solar Two, the salt was mixed to the $60 \mathrm{wt} \% \mathrm{NaNO}_{3}, 40 \mathrm{wt} \% \mathrm{KNO}_{3}$ proportions and prilled (melted and formed into small spheres). The salt arrived in $1000 \mathrm{~kg}$ bags, or "super sacks," with 24 bags per flatbed truck. The bags were offloaded and stacked two-high, just south of the heliostat field (see Figure 2-15). A total of 1360 bags were delivered to Solar Two for a total of 1.36 million $\mathrm{kg}$ of salt.

Nitrate salt is highly hygroscopic. The salt had absorbed moisture, either during transport or storage at the site. Therefore, although the salt had been prilled, moisture had caused much of the salt to agglomerate into large salt chunks. These chunks required considerable manual labor to break up and load into the salt handling system. A hammer mill had to be added to the original solid-salt-handling equipment. Loading salt into the salt melter became a dusty and laborintensive operation. Both the crushed and prilled salt were loaded onto a conveyor belt, which delivered the salt into a hopper. The salt in the hopper was then fed into a propane-fired salt melting chest. SteamTech Company provided most of the equipment, with SNL providing a used sump pump to pump the melted salt into the hot tank. In preparation for salt loading, the empty hot tank was heated with the exhaust from a propane heater to avoid thermally shocking the tank walls and floor. 


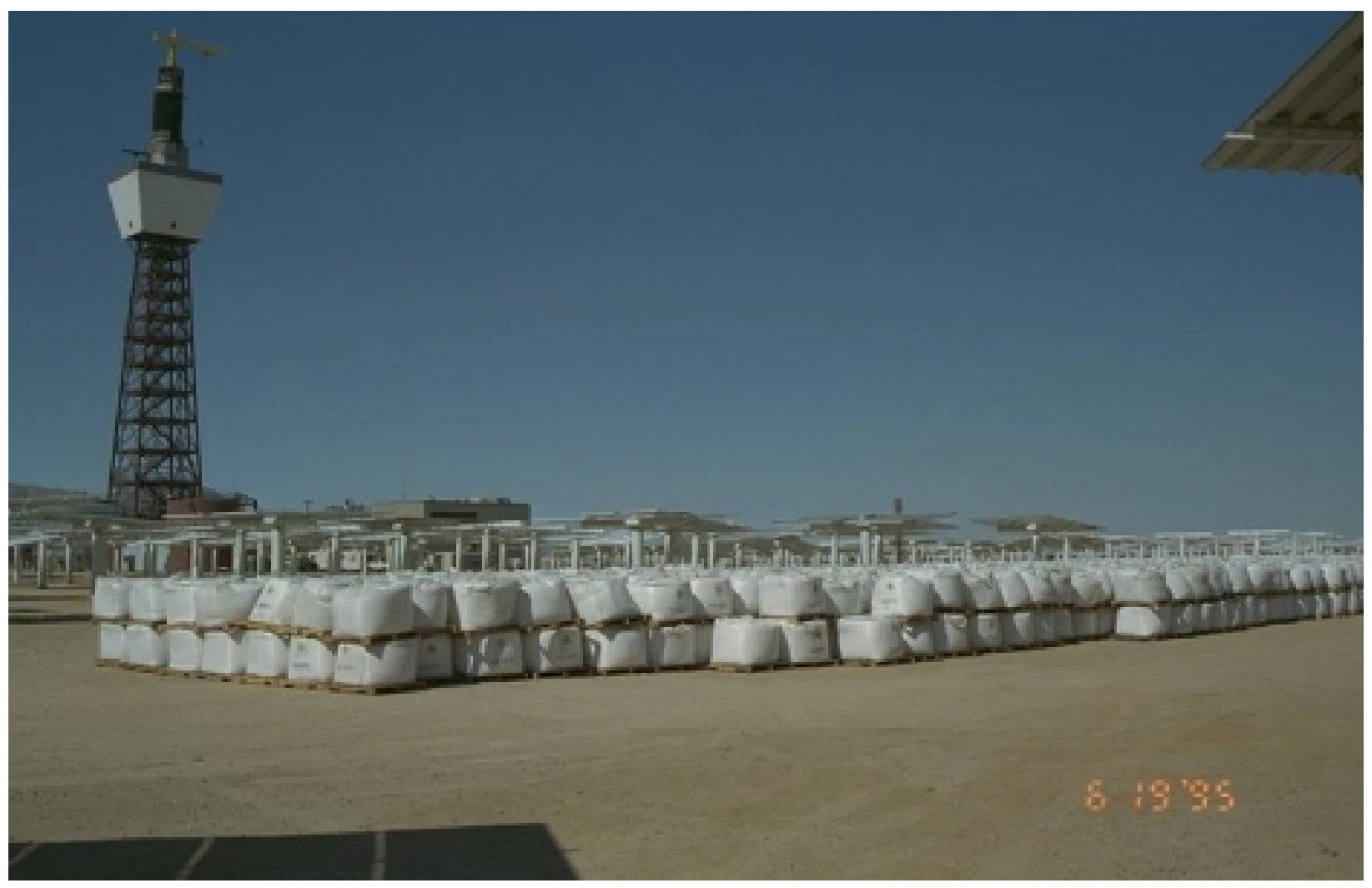

Figure 2-15. 1000-kg Bags of Nitrate Salt After Shipment to the Solar Two Site.

\subsubsection{Unexpected Need to Thermally Treat the Nitrate Salt (August-December 1995)}

A small amount of the Solar Two salt was shipped to SNL's National Solar Thermal Test Facility for analysis. A portion of the salt sample was loaded into salt pots where it was melted and used for corrosion tests on metal samples. As the temperature of the salt rose above $900^{\circ} \mathrm{F}$ $\left(482^{\circ} \mathrm{C}\right)$, a brown cloud appeared. SNL discovered that magnesium impurities in the salt led to chemical reactions when the salt was heated. A detailed analysis revealed the gas production occurred rapidly at temperatures above $900^{\circ} \mathrm{F}\left(482^{\circ} \mathrm{C}\right)$ due to the following decomposition reaction:

$$
\mathrm{Mg}\left(\mathrm{NO}_{3}\right)_{2} \rightarrow \mathrm{MgO}(\mathrm{s})+2 \mathrm{NO}_{2(\mathrm{~g})}+1 / 2 \mathrm{O}_{2(\mathrm{~g})}
$$

Nitrogen dioxide was responsible for the brown gas, and the magnesium oxide precipitated as a white solid. The salt contained approximately $0.05 \mathrm{wt} \%$ magnesium in the form of magnesium nitrate. The salt specification did not limit magnesium content because the decomposition reaction had not been observed in previous tests and experiments.

This reaction meant that gases would rapidly evolve the first time the salt was heated to design hot salt temperatures. Project personnel, concerned about this gas evolving in the receiver, decided to thermally treat the salt in the hot tank prior to its use in the receiver. To drive this reaction towards completion, the salt needed to be thermally treated (heated to $1000^{\circ} \mathrm{F}\left(538^{\circ} \mathrm{C}\right)$ and 
held at that temperature for an extended period of time). A second temporary pump was added to the salt melting equipment train. This pump circulated the salt from the hot tank, through another propane-fired heater, and back to the tank. Figure 2-16 provides an overview photograph of the salt loading, melting, and thermal treatment area in October 1995. Once the entire inventory of salt had been melted, transferred to the hot tank, and heated to $950-1000^{\circ} \mathrm{F}\left(510-538^{\circ} \mathrm{C}\right)$, it was held at that temperature for several weeks. This procedure allowed the magnesium nitrate to be converted to magnesium oxide, which then settled on the tank bottom. A salt sample taken after approximately three weeks indicated that the salt now contained only about $1 \mathrm{ppm}$ of soluble magnesium. These results indicated that the salt was ready for use in the receiver. It was recognized that small amounts of $\mathrm{NO}_{\mathrm{x}}$ would continue to evolve due to the residual magnesium and due to reaction between the salt and virgin stainless steel until a passive oxide layer could form on the steel.

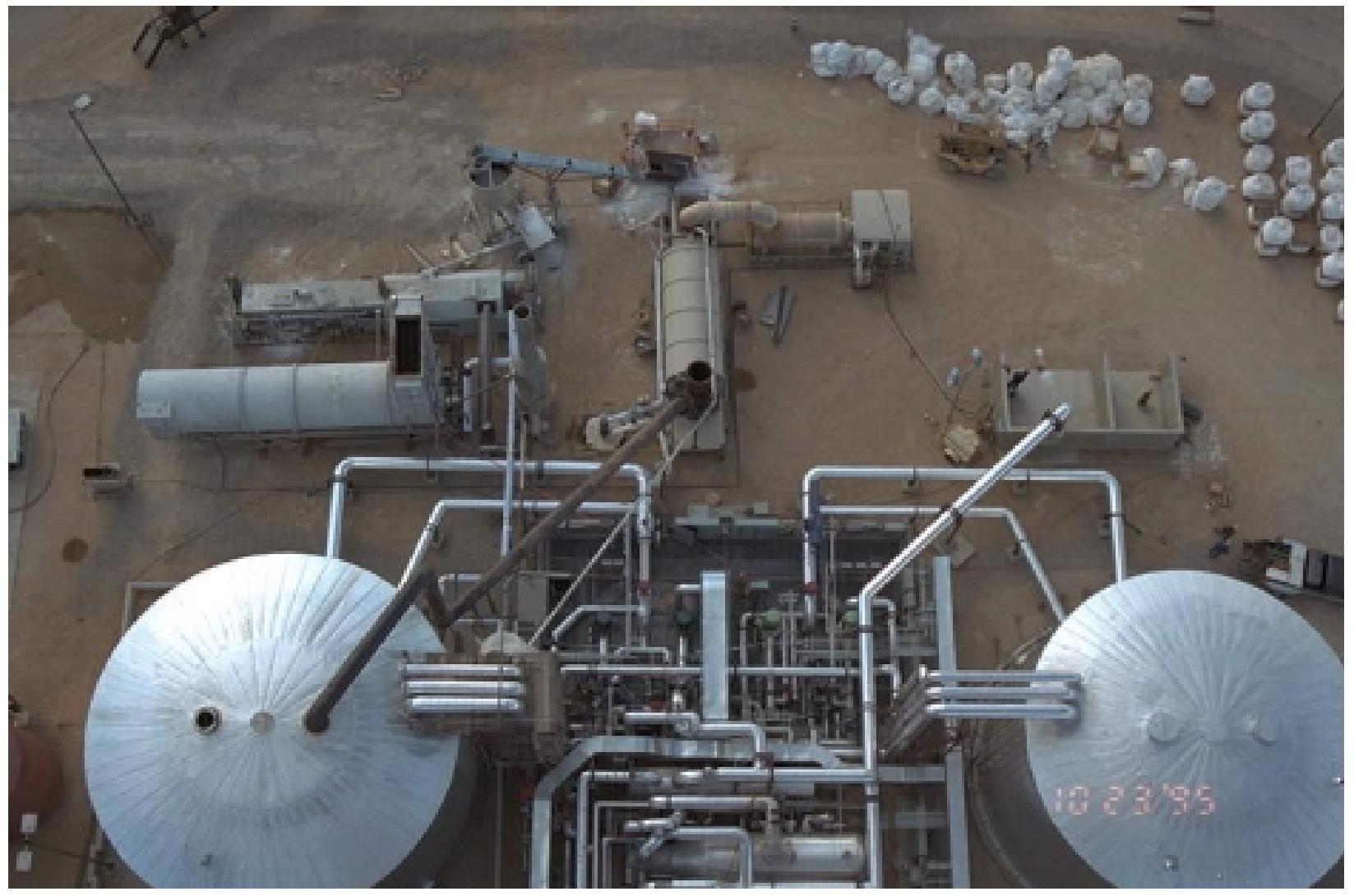

Figure 2-16. Equipment Required to Load, Melt, and Thermally Treat the Nitrate Salt.

\subsubsection{Improper Installation of Heat Trace on Salt Piping (June-October 1996)}

The Solar Two design utilized electric heat trace cables to maintain piping above salt freezing temperatures. The heat trace also served to reduce pipe stresses by preheating piping systems prior to flowing hot salt. The heat trace cables were controlled in zones, with the temperature in a zone being controlled by turning the cables on or off, depending on a temperature control sig- 
nal from two resistance temperature devices (RTDs). (In the receiver system, heat trace operation was controlled by thermocouples, rather than RTDs.)

The heat trace cables were inadvertently not installed uniformly along the length of much of the salt piping. (This problem was not found in the receiver system. A different contractor had been selected by Boeing to install the heat trace in the receiver system.) This nonuniformity caused the portions of the piping with the most heat trace to be heated excessively while regions with less heat trace were relatively cool. If the RTDs were located in a region with less heat trace, regions within the zone with more heat trace were heated excessively. The elevated temperatures lead to rapid corrosion of some of the carbon steel piping used for the cold salt systems. Corrosion products spalled off inside ground-level piping and became entrained in the salt. Salt flow transported some of these corrosion products to the receiver, where they caused pluggage in the receiver. A single receiver tube failed in June 1996 during receiver operation. Later inspection found corrosion products in the lower header of the affected receiver panel. Evidently, the tube was plugged with corrosion products and consequently starved of adequate salt flow. The tube ruptured from excessive temperatures due to the high solar flux, low-flow condition.

Recovery from the consequences of improper installation of heat trace caused a five-month delay and required replacement and reinstallation of much of the heat trace cable; replacement of the ruptured receiver tube; and flushing the piping systems with an aqueous chemical solution to remove the corrosion products.

Heat trace control problems occurred throughout the startup phase. Bechtel chose unique hardware and software to control the heat trace. The heat trace controllers tended to lock up, leaving a heat trace circuit in the "on" or "off" position indefinitely, without warning. This problem was never resolved. New e-PROMs were "burned" to replace the faulty ones. However, the new chips did not solve the lockup problem, but merely reset the controller periodically. In the steam generator area, the heat trace controllers were installed in large, black enclosures. Ambient temperatures in Barstow can exceed $120^{\circ} \mathrm{F}\left(50^{\circ} \mathrm{C}\right)$, causing the controllers in these cabinets to overheat and malfunction. An active chilled-water system was therefore installed to cool the cabinets. In addition, mechanical contactors were initially used, which quickly exceeded their design cycle life. And finally, Chromalox, the heat trace provider, utilized unique, PC-based software to control the heat trace circuits. Despite a number of upgrades, this software tended to lock up and would stop updating heat trace status on the computer monitor, thereby providing misleading information on the temperature and status of heat trace circuits.

\subsubsection{Evaporator Tube Failure and Evaporator Modification (November 1996 - October 1997)}

Solar Two employed a kettle-boiler evaporator with salt on the tube side and water/steam on the shell side. During plant operation on November 7, 1996, an evaporator tube failed, allowing water/steam to enter the failed tube and travel to the salt storage tanks. The water flashed to steam and the steam then exited the tanks through the atmospheric vents on each tank (most of the water/steam preferentially traveled to and out of the cold salt tank, with little of the water/steam reaching the hot salt storage tank.) A subsequent inspection of the evaporator revealed that the ruptured tube was in the lower portion of the tube bundle. In addition, a number of lower tubes had undergone plastic strain, as evidenced by increased tube circumference. 
After the tube ruptured, a detailed review of the SGS revealed a number of contributory problems. These included the following:

- Poor water mixing occurred in the evaporator shell. The SGS design included a recirculation system that drew feedwater from near the bottom of the evaporator shell and fed this flow into the feedwater supply to the preheater. In addition, feedwater was supplied to the evaporator through a sparger at the bottom of the evaporator shell. A combination of low velocity in this sparger, and the location of the recirculation supply nozzle, led to poor mixing in the evaporator. Cold feedwater supplied to the evaporator flowed near the bottom of the evaporator shell and became the feed to the recirculation system, essentially bypassing the bulk of the water inventory in the evaporator. Water temperatures became stratified, with temperatures in the lower portions of the shell well below the indicated evaporator saturation temperature. This arrangement lowered temperatures surrounding the lower tubes and led to salt freeze-thaw cycles on these tubes (such as the one that ruptured and those that were strained.)

- The recirculation pumps' seals added a considerable amount of cold water to the recirculation line. The recirculation pumps required mechanical seals that used a flow of cold water to keep the seals cool. This cold water flowed through the seals and into the recirculating water, further decreasing the temperature of the recirculating flow.

- The preheater was bypassed during SGS startup. As the SGS was heated up after a shutdown, feedwater flow was typically routed around the preheater and sent directly to the evaporator. This action was taken to prevent salt from freezing in the preheater, but it also resulted in feedwater entering the evaporator below design minimum temperatures.

Prior to returning the SGS to service, Bechtel made a number of changes to correct the SGS deficiencies. These changes included the following:

- Bechtel removed the evaporator and shipped it to the manufacturer for repair and modification. Modifications included the following:

1. The addition of two feedwater spargers to the evaporator shell near the top of the tube bundle.

2. The modification of the lower feedwater sparger design to increase the velocity of the feedwater as it exited the sparger.

3. The addition of 12 thermocouples to the evaporator shell to better monitor water temperatures throughout the water inventory.

- Bechtel eliminated the preheater bypass line, forcing all feedwater flow to the evaporator to first flow through the preheater.

- Bechtel added a feedwater valve to the evaporator inlet piping. This valve provided the option to route all feedwater flow through the upper spargers. 
- SNL supplied a larger-capacity recirculation pump as an option to the two recirculation pumps. This pump was of a canned-rotor design, which, when used, eliminated the need for sealing water flow.

- Bechtel added a startup feedwater heater between the preheater and the EPGS first point feedwater heater. This startup heater was supplied with steam from the auxiliary steam header.

- Bechtel and plant personnel modified the SGS startup procedures to reflect the new configuration and to incorporate the lessons learned from the tube rupture.

- The outage revealed that inadequate attention had been given to SGS startup issues, requirements, and procedures during the design phase. To aid in the system redesign, SNL worked with Bechtel to develop a computer code to model the SGS performance at a variety of conditions, including startup.

Although modifications to the SGS required nearly a year to accomplish, they did prove effective in solving the SGS problems. No further tube ruptures occurred; temperature stratification in the evaporator was essentially eliminated; and the system performed more reliably for the remainder of the project. Operating experience also revealed that varying pump speed could reliably control salt flow to the SGS. This experience eliminated the need for flow control valves on the SGS salt supply piping.

During the SGS outage, SNL provided the project with a $3 \mathrm{MW}_{\mathrm{t}}$ salt cooler. This cooler used fans to convectively cool the salt. Installation of this cooler allowed the project to run the receiver system while the SGS was being repaired. Although the SGS was unavailable, the cooler allowed most of the receiver startup and checkout procedures to be completed during the SGS outage.

\subsubsection{Intergranular Corrosion (August 1997)}

A number of receiver tubes developed slow leaks due to intergranular corrosion (IGC) that initiated on inside tube surfaces. This was unexpected, since extensive laboratory experiments and experience in other solar-thermal molten salt projects have demonstrated that exposure to molten salt does not cause intergranular corrosion or stress corrosion cracking in types 304 and 316 stainless steel, even after long exposure at solar operating temperature. Intergranular corrosion in high-carbon $304 \mathrm{H}$ and $316 \mathrm{H}$ is known to occur, however, under other conditions, i.e. when the alloy has a "sensitized" microstructure due to thermal exposures that cause depletion of chromium in the material's grain boundaries, and it is subsequently exposed to a chloride-containing aqueous environment.

In designing solar thermal systems using 300-series stainless steels for containment of molten nitrate salt, it has always been accepted that service times at elevated temperature would eventually be sufficient to sensitize high-carbon alloys such as $304 \mathrm{H}$ (used in hot-salt piping) and $316 \mathrm{H}$ (used for receiver tubes). This was not thought to be a problem since a sensitized microstructure has no apparent adverse effect on corrosion behavior in molten salt, and exposure of sensitized material to a damaging aqueous environment had not been considered likely. Prior to the Solar 
Two project, there was a low-level concern that IGC might occur on the exterior of $316 \mathrm{H}$ receiver tubes due to their exposure to ambient atmospheric moisture and dust-borne chlorides. That has not, in fact, been found to occur.

However, Solar Two experience has shown that, for certain typical plant operating conditions, the necessary conditions for aqueous environment IGC can occur on interior surfaces of receiver tubes and interconnecting hot-salt piping. Elevated temperature service times for Solar Two $316 \mathrm{H}$ receiver tubes were sufficient to sensitize the material, the greatest sensitization occurring for those tubes having the highest metal operating temperatures. Some sensitization of $304 \mathrm{H}$ hotsalt piping also occurred, although of lesser extent due to the lower operating temperatures compared to receiver tubes. In piping, sensitization was greater near welds, where the effects of weld thermal cycles are superimposed on service thermal exposure. For the receiver, the environment necessary for IGC to occur in sensitized material was provided routinely by: (a) residual, chloride-containing salt films that remain on inside surfaces when tubes were drained, and (b) contact of the hydroscopic salt films with atmospheric moisture drawn into the receiver tubes as they cooled at the conclusion of daily operation. On occasion, similar conditions occurred elsewhere when hot-salt piping was drained, cooled, and exposed to the atmosphere for maintenance activities. In both cases, IGC may have been accelerated by contact with water as a result of flushing the piping system with an aqueous chemical solution (described above).

Leaks in receiver tubes occurred first in tubes with the highest metal operating temperatures, where sensitization would be the most advanced and residual tensile stresses on the front surfaces of tubes would be greatest. For a given tube showing IGC, depth of attack was typically greatest on the front side, where tensile residual stresses at ambient temperature are highest. The attack can be considered to be "stress-assisted intergranular corrosion," but it is probably not true "stress corrosion cracking" since intergranular attack was also seen (to a lesser extent) where tensile stress was minimal or absent.

Once the probable cause for the IGC was determined, the leaking tubes were replaced, a dry-air purge system was installed for nightly post-operation receiver draining, and the plant returned to operation. The plant continued successful operation in this state, despite the likelihood that some original receiver tubes may have contained part-through intergranular cracks that had initiated prior to installation of the air purge system (Dawson 2001).

\subsubsection{Impact of Startup Delays on the Remainder of the Project}

Table 2-3 indicates that the original Solar Two plan provided a six-month period for Phase 5, plant startup, checkout, and acceptance testing starting in July 1995 . In reality, Phase 4, the construction phase, allowed Phase 5 to start in August 1995-essentially on time. However, the startup phase uncovered numerous design, construction, and installation problems, as discussed above. Startup took nearly 31 months to complete, delaying the start of operation (Phase 6). The plant was not turned over for operation by ESI, the O\&M contractor, until February 1998-more than two years later than planned.

By the end of the startup phase, the project was far behind schedule and rapidly exhausting the available funding. The Solar Two Steering Committee met in the fall of 1997 and adopted a modified approach for conducting the remainder of the project. Under the new approach, a sepa- 
rate test and evaluation phase was sacrificed in order to preserve some period of operation during which emphasis would be placed on power production.

The new approach called for the project to meet both test and evaluation goals and power production goals through daily operation of the plant. The startup phase was completed with the turnover of the plant from Bechtel to ESI on February 18, 1998. The operational phase began with a period of plant operation designed to collect test and evaluation data that required the plant to operate in an off-design configuration. After this period (scheduled for one month in the new plan, but actually extending for several months), the new plan called for the plant to operate in a power production mode, generating as much power as possible, as often as possible.

Plant operation under this modified approach did allow many test objectives to be met. In fact, whereas the original test and evaluation plan called for specific plant operating periods to meet specific test objectives, the modified approach meant that data was being collected for most tests whenever the plant was operational. However, the operational phase, shortened by the prolonged startup phase, meant that Solar Two never achieved a true power production phase; it was still in a test and evaluation phase when it was shut down.

The startup phase of Solar Two was costly in terms of schedule, budget, test data, and operation of the plant in a power production mode. The original plan for Solar Two called for a two-year power production phase. The power production phase would have started with an optimization period during which test and evaluation results and lessons learned up to that point would be incorporated into plant operations. In reality, when Solar Two was shut down, test engineers had only begun to address lessons from the testing phase, and plant personnel were still learning new techniques to improve performance. Only limited attempts had been made to optimize performance. Since the emphasis was on operating the plant, very conservative approaches were taken to avoid plant outages. For example, heat trace circuits, which might otherwise be turned off, were left on to increase the likelihood that the plant would be available. The emphasis on plant operation left little time (or incentive) to experiment or test new approaches-approaches that might initially cause or require an outage, but would pay off in the long run through improved performance. Finally, the lack of a sustained power production phase meant that little meaningful data were available for evaluations of equipment operability, maintainability, or lifetime predictions. (The data available to evaluate plant performance are discussed in Section 4.)

\subsection{Operational Phase of Solar Two}

ESI assumed operation and maintenance responsibility for Solar Two on February 18, 1998. As of this date, Bechtel officially turned the plant over to ESI, marking the end of the startup phase and the beginning of the operational phase. As discussed above, the protracted startup phase meant that a single operational phase would have to meet as many of the original test and evaluation, optimization, and power production goals as possible. The following sections describe some of the major test periods, events, outages, and successes of Solar Two during the operational phase from February 1998 until plant shutdown in April 1999. Results of tests and evaluations can be found in Pacheco et al. (2001). 


\subsubsection{Plant Operation to Meet Test Goals (March-June 1998)}

Data for most of the originally planned tests could be collected any time the plant operated. Plant dispatchability and receiver efficiency testing were notable exceptions to this approach, since these tests required the plant to be operated in a number of specified modes. After the plant turnover to ESI in February 1998, initial plant operation was to be devoted to gathering this type of off-design test data. However, repeated experiences with tube freezing during previous receiver fill procedures caused receiver issues to take precedence. Tests were therefore run in March 1998 to evaluate the benefits of filling the receiver in a serpentine pattern, rather than using a flood-fill technique. Receiver efficiency data were actually collected in September and October of 1997 and in March 1999. Dispatch scenarios were run in June 1998 to demonstrate the ability to generate electricity for extended periods from stored energy. By operating the steam generator and turbine at reduced loads, Solar Two's three-hour thermal storage system was used to demonstrate electricity production for up to 12 hours per day.

\subsubsection{Continuous Production of Electricity (June-July 1998)}

To further demonstrate the dispatchability of electricity generated by a molten-salt power tower, project personnel set an objective of demonstrating around-the-clock production of electricity. This objective was met in June and July 1998. Solar Two continuously delivered power to the electric grid for 69 hours and 45 minutes between June 13 and 16, 1998. Winds in excess of 40 $\mathrm{mph}(18 \mathrm{~m} / \mathrm{sec})$ on the morning of June 16 prevented startup of the receiver, causing the streak to end later that morning when the supply of hot salt was exhausted. Solar Two surpassed June's on-line record by continuously delivering power to the electric grid for 153 hours between July 1 and 7, 1998. As with the June record, weather again ended the streak as persistent afternoon clouds on July 7 prevented production of sufficient hot salt to allow the steam generator to run through the night. The nearly weeklong run therefore ended that evening when the supply of hot salt was exhausted.

\subsubsection{Power Production Under Semi-Optimized Conditions (September-November 1998)}

Starting in September 1998, the daily operations of Solar Two shifted to a power production mode. This period started with a concerted campaign to reduce electric power parasitics caused by excessive operation of heat trace and other unnecessary power consumption. Prior to this campaign, concerns about parasitic power consumption were secondary to ensuring high system availability. As a result, most heat trace circuits were active (i.e., cycling on and off to achieve the setpoint temperature) at all times. The parasitic reduction campaign identified more realistic heat trace setpoint temperatures and periods of operation, resulting in a dramatic first step towards reducing and optimizing heat trace power consumption. Along with these changes in heat trace operating strategy, the overall plant operating approach was focused on producing as much electricity as possible, as often as possible. 


\subsubsection{Receiver Downcomer Piping Failure, Subsequent Repairs, and Plant Operation (November 98-April 1999)}

The period of emphasized power production ended on November 18, 1998, when the downcomer piping failed near a horizontal pipe section below the receiver. Both the receiver and the downcomer piping grow considerably as they heat up to the $1050^{\circ} \mathrm{F}\left(565^{\circ} \mathrm{C}\right)$ operating temperature. The downcomer piping included a large expansion loop near its lower end; it also had a jog or short horizontal section about $50 \mathrm{ft}(15 \mathrm{~m})$ below the receiver. A combination of design inadequacies meant the downcomer's thermal growth was not properly accommodated during heatup/cooldown cycles. The downcomer piping failed at an elbow adjacent to the short horizontal section.

Identifying the extent, causes, and solutions for the piping failure caused considerable delay in repairing and returning the downcomer to service. In parallel with the piping failure, concerns surfaced regarding the financial status of the overall project. As evaluation of the failed piping dragged on, restarting the plant seemed less and less likely. In late January 1999, SNL proposed and DOE accepted a plan to hire Bechtel to repair the downcomer and return the piping system to an operational condition. Furthermore, under the plan, the plant would be operated to collect data to address a few specific receiver startup issues, then shut down in early April. The aggressive plan resulted in the plant returning to operation in late February 1999 and concluding operations on April 8, 1999.

Upon return to operation in February 1999, a major technical objective of plant operation was to address problems with receiver startup. In an earlier effort to improve receiver fill operations, the receiver fill procedure had been changed from a flood fill to a more rapid serpentine fill technique. However, this change did not solve all receiver startup problems. An inability to heat receiver header ovens to $450^{\circ} \mathrm{F}\left(232^{\circ} \mathrm{C}\right)$ often delayed introduction of salt into the receiver. In addition, frozen tubes (as revealed by the infrared camera) often delayed the transition from receiver fill to normal operation. During the downcomer outage, project personnel implemented a number of modifications, including changing the oven-to-tube seal, adding heat trace behind the tubes at the oven-to-tube interface, and adding baffles between oven covers. Since these modifications were only implemented on several of the west (windward) lower oven covers, they did not eliminate all receiver startup delays. The modifications did, however, indicate that receiver startup delays could be minimized or eliminated with some simple design changes. One simple change would be to locate the tube clips away from the oven-to-tube interface area, since the tube clips represent a heat sink, which is hard to heat when located at this interface. Another modification would be to change the oven-to-tube sealing technique.

\subsubsection{Additional Operating Results}

The lengthy startup phase and problems during the operational phase exhausted much of the project funding that was intended for an extended operational period. Therefore, inadequate funds were available to prove long-term availability and lifetime of the plant. Recognizing these limitations, a number of important results were achieved during the operational phase of the project. In addition to the operational results discussed above and in the Test and Evaluation Report (Pacheco et al., 2001), other results include the following: 
- Demonstrated daily operation of all systems. This was particularly evident during the continuous operation periods in June and July 1998, as well as during the September-toNovember 1998 semi-optimized period.

- Demonstrated continuous operation of the SGS. Continuous operation helped demonstrate the improvements in system availability and reliability. Continuous operation also helped improve water chemistry control in the SGS.

- Reduced the daily energy required to start the SGS. The goal in the SOLERGY simulation code was to limit SGS startup energy requirements to $10 \mathrm{MWh}_{\mathrm{t}}$. Early in the project, more than $20 \mathrm{MWh}_{\mathrm{t}}$ were consumed in starting the SGS. On October 8, 1998, SGS startup required only 8.7 $\mathrm{MWh}_{\mathrm{t}}$.

- During the continuous runs, the O\&M contractor accomplished critical maintenance activities overnight, avoiding delays in starting the plant the next morning.

- Solar Two demonstrated that a nuclear level sensor can provide reliable indication and control of level in the pressurized receiver inlet vessel. A nuclear level sensor was installed on the inlet vessel in December 1997. Initially, a number of problems hampered the performance of the sensor, including inadequate nuclear source strength, faulty electronics, and inadequate setup of the sensor electronics. These problems were all resolved. By March 1999, the sensor was routinely used to monitor and control level in the inlet vessel.

\subsection{Overview of Collector System Problems}

Problems with the Solar Two collector system occurred throughout the project. These problems reduced energy collection but seldom caused a plant outage. The Solar Two collector system included the 1818 original Solar One heliostats, the 108 added Lugo heliostats, the heliostat controllers (contained in each heliostat pedestal), the heliostat field controllers (additional circuits contained in 64 of the Solar One heliostat controllers), two Lugo heliostat control computers located in the control room, the beam characterization system (BCS), and the heliostat array controller. The last item was part of the master control system provided by Queue Systems, Inc. Queue Systems also provided software for BCS data entry and coordinate conversion.

Many of the problems that occurred in the collector system, and many of the fixes or workarounds applied to the system, were a result of either the age of the system components or represented unique problems, requiring equipment-specific solutions or accommodations. Much of the experience with the collector system was therefore not particularly relevant to future plants. The following subsections briefly describe some of the more significant collector system problems; further details are available in Pacheco, et al., (2001). Table 2-4 presents a brief timeline of collector system issues. 
Table 2-4. A Brief History of the Solar Two Collector System

\begin{tabular}{|c|c|}
\hline Date & Event \\
\hline Aug 87 & Solar One plant shut down. Heliostat field stowed. \\
\hline Jun 28, 1992 & $\begin{array}{l}\text { Nearby Landers earthquake causes hundreds of mirror modules to fall off } \\
\text { heliostats (which were in face-down stow position). }\end{array}$ \\
\hline 1992 & $\begin{array}{l}\text { Sandia surveys heliostat field corrosion, missing facets, etc. Contractor rivets all } \\
\text { facets to heliostat structure. }\end{array}$ \\
\hline Aug 93 & Sandia and Bechtel evaluate field operation and control \\
\hline Dec 94 & First Lugo heliostat installed at Solar Two \\
\hline Jan 95 & $\begin{array}{l}\text { Heliostat field recognized as requiring a major repair effort. Bechtel establishes } \\
\text { Work Order system to track heliostat repairs }\end{array}$ \\
\hline Mar 95 & Bechtel adds engineer to oversee troubleshooting of heliostat field \\
\hline Dec 95 & $\begin{array}{l}\text { Total of } 508 \text { heliostats communicating in east field. All } 508 \text { commanded to } \\
\text { Standby position; } 484 \text { respond. }\end{array}$ \\
\hline Jan - May 96 & $\begin{array}{l}\text { Major effort to ready heliostat field for receiver operation, dedication, etc. } \\
\text { Number of available heliostats climbs from } 1200 \text { to } 1750 \text {, but reliability an issue }\end{array}$ \\
\hline Feb 26 & 1253 heliostats available. 780 sent to Track, heat salt to $480^{\circ} \mathrm{C}$ in receiver. \\
\hline March & Numerous communication issues isolated and fixed. \\
\hline Mar 19 & Number of available heliostats first breaks 1500 (no Lugos). \\
\hline Apr 4 & 98 Lugos at Standby. \\
\hline Feb 97 & $\begin{array}{l}\text { Number of heliostats at Track peaks at } 1890 \text { ( } 98 \% \text { of field), slowly declines } \\
\text { throughout } 1997 .\end{array}$ \\
\hline Sep 97 & Lugo motors discovered to be backdriving, causing aiming errors. \\
\hline Jan 98 & Maximum number of tracking heliostats climbs back to 1847 . \\
\hline Mar 98 & $\begin{array}{l}\text { Installation of quadrature circuits completed on all Lugo heliostats to correct aim- } \\
\text { ing errors caused by motors backdriving. }\end{array}$ \\
\hline Apr 98 & Improper aiming causes heliostats to burn several header oven covers. \\
\hline May 98 & $\begin{array}{l}\text { Heliostat aiming, surveyed locations of receiver tower and heliostat field, and } \\
\text { aiming software (SAPS) all corrected/improved. }\end{array}$ \\
\hline Aug-Nov 98 & $\begin{array}{l}1690 \text { heliostats available in early August, field still recovering from a lightning } \\
\text { strike on } 7 / 22 / 98 \text {. } \\
\text { Concentrated effort initiated to regain } 98 \% \text { field availability (meets with limited } \\
\text { success). }\end{array}$ \\
\hline Apr 99 & $\begin{array}{l}\text { Solar Two plant shut down. Heliostat field stowed. A limited number of heliostats } \\
\text { kept operational for Univ. Calif./Riverside astrophysics experiments. }\end{array}$ \\
\hline Oct 99 & $\begin{array}{l}\text { Two Lugo, one Solar One heliostats removed (and a portion of a second Solar } \\
\text { One heliostat dismantled) to determine effort required to dismantle heliostat field. }\end{array}$ \\
\hline
\end{tabular}




\subsubsection{Problems with Aging and Outdated Equipment}

During the construction and startup of Solar Two, it became readily apparent that the collector system was not as functional as previously anticipated. Many heliostat components (wiring harnesses, controllers, motors, and encoders) were inoperable, causing delays in "waking up" the 15-year-old heliostat field that had been dormant for seven years prior to the Solar Two startup phase. Some components were obsolete and hard to find. In addition, Queue Systems, Inc. had difficulty in establishing communications with the heliostats. Considerable effort was required to get this first-of-a-kind master control system to communicate with the heliostats. Queue Systems, Inc., SNL, SCE, ESI, and others spent a great deal of time troubleshooting and revising communication hardware and software (including communication protocols).

\subsubsection{Mirror Condition}

Many of the Solar One heliostat mirror facets were broken, corroded, or no longer able to maintain their concave shape. During construction, Modern Alloys, Inc. replaced approximately 1400 facets on 577 Solar One heliostats. The replacement facets were flat "Lugo" facets, not the optically preferred curved Solar One facets they replaced. Throughout the project, high winds continued to cause facets to break or fall.

Not surprisingly, the mirror modules were heavily soiled at the start of the project, requiring an initial scrubbing of the mirror surfaces. A window-cleaning contractor (whose expertise was in cleaning the massive amounts of window glass in Las Vegas casinos) provided an initial contact cleaning of all the installed Solar One and Lugo heliostat facets.

Periodic spray cleaning was required and planned throughout the project. ESI purchased a wash truck to allow plant operators to clean the field. Washing the field was a cumbersome and inefficient task. The truck was large, making it difficult to maneuver in the heliostat field and requiring that the facets be positioned in a less-than-optimal, horizontal, face-down orientation for washing. The truck also included numerous mechanical and hydraulic systems, rendering it prone to breakdowns.

\subsubsection{Heliostat Aiming}

An attempt was made to realign (cant) many of the heliostat facets. Since the Solar Two receiver was smaller than the Solar One receiver, analysis indicated that it would be beneficial to recant the inner 17 rows of the original field. All of the facets on the 108 Lugo heliostats required canting after installation. In addition, canting was required for the facets that were installed on Solar One heliostats to replace broken or missing facets.

SNL provided the project with a "lookback" camera system, which allowed heliostats to be correctly aligned. The process was time-consuming and the system was not particularly rugged or robust. The field crews quickly abandoned the lookback system in favor of an easier "on-sun" cant. SNL then provided the project with guidelines for on-sun canting. An on-sun technique attempts to cant a heliostat based on the image it projects on the beam characterization system target on the receiver tower. Though simpler to implement, the technique can lead to poor mirror 
alignment if procedures are not carefully followed. It is believed that much of the canting performed during the project was actually not beneficial. Improper canting can introduce heliostat tracking errors (Stone and Jones, 1999).

During the startup phase of Solar Two, field personnel observed poor aiming of the Lugo heliostats. In September 1997, SNL discovered that the 108 Lugo heliostats were prone to loss of aimpoint due to the inability of the heliostat controller to detect backdriving of the elevation motors. After the heliostat achieved its proper position, the beam would drift as the weight of the heliostat caused the elevation motor to spin. Advanced Thermal Systems designed and installed a quadrature circuit to compensate for this problem.

A number of other aiming problems initially plagued the Solar Two heliostat field. These included difficulties with the Static Aimpoint Processing System (SAPS) implemented on the master control system; inaccuracies in the sun position algorithm; incorrect information about the location of the 32 relocated heliostats; conversion of the field coordinate system to the Lambert coordinate system used in California; problems with the BCS coordinate conversion system; and the aiming errors due to improper canting, mentioned above.

\subsubsection{Beam Characterization System}

The beam characterization system was a cumbersome, manual process; it used the same limited methodology employed during Solar One (Stone and Jones, 1999; and Jones and Stone, 1999). As a consequence, more heliostats spent more time with poor aiming parameters than had been anticipated in the plant performance modeling. This poor heliostat alignment caused greater beam spillage than predicted.

\subsection{Final Briefings to Industry and Shutdown of Solar Two}

The January 1999 agreement among the Department of Energy, the project (represented by Southern California Edison), and SNL paved the way for repair of the downcomer and operation of the plant through early April 1999. The plant was shut down on April 8, 1999.

One of the major shutdown tasks was the removal of the nitrate salt inventory. Chilean Nitrate Corporation had loaned the salt to the project and agreements with them specified that the salt would be returned to their control at the conclusion of the project. The salt was removed by prilling it, loading it into sacks, and loading the sacks onto trucks for transport offsite. A prilling tower was constructed on the south side of the receiver tower. The salt was cooled to approximately $518^{\circ} \mathrm{F}\left(270^{\circ} \mathrm{C}\right)$, then pumped up the tower, through a specially fabricated set of spray nozzles, and then fell through the prilling tower. Figure 2-17 shows the tower and vertical chute constructed for the prilling operation.

Prior to the final shutdown of Solar Two, the plant was showcased one last time. On April 8, 1999, SNL hosted a meeting at the Solar Two site to brief interested parties on the history, status, and successes of the Solar Two project. Industry, utilities, and other parties interested in power tower technology witnessed the last day of full operation of Solar Two. SNL presented the 


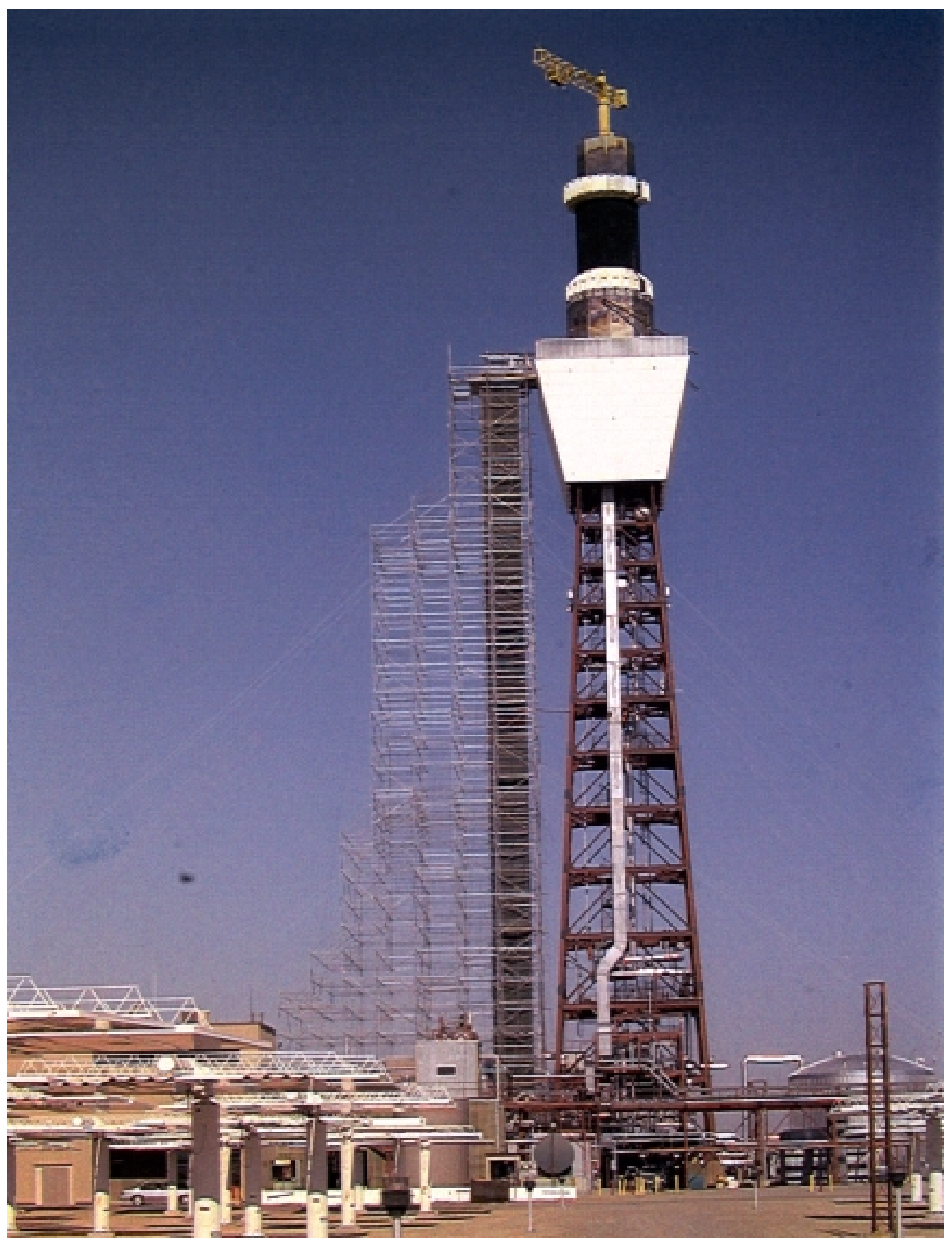

Figure 2-17. Structure Assembled for Prilling Tower. Salt is sprayed into top of rectangular canvas chute adjacent to receiver tower. 
project history and top-level results of the test program. In addition, Spanish participants presented details of the premium payments Spain intended to offer for electricity generated from solar energy. The successful conclusion of Solar Two, and the encouraging conditions in Spain, opened the door to meeting Solar Two's objective of stimulating commercial development of molten-salt power towers. 


\section{Design of the Next Molten-Salt Power Tower Plant}

\subsection{Introduction}

The Solar Two project validated molten-salt technology, including the design, operation, and performance of a molten-salt receiver. Solar Two also provided important lessons that can help guide the design of the first commercial molten-salt power tower plants. This section lists the important technology validations resulting from Solar Two; discusses some design considerations and enhancements resulting from Solar Two and concurrent molten-salt technology development; and introduces the preliminary design of the next molten-salt power tower plant.

\subsection{Technology Validation at Solar Two}

\subsubsection{Receiver System}

Solar Two validated the design, performance, and operation of a large-scale molten-salt receiver system. Based on experiences with the Solar One receiver, many of the uncertainties regarding power towers centered on concerns about the receiver system. For example, there were concerns about panel warpage. The single-phase molten-salt poses less of a problem in this regard than the two-phase water/steam receiver at Solar One. For the Solar Two receiver, Boeing also addressed and eliminated warpage by utilizing an effective tube clip design to provide independent thermal growth of each receiver tube.

Solar Two also validated a new receiver panel design based on a new alloy. After successful testing of a few-tube panel at Sandia National Laboratories, Boeing fabricated a full Solar Two replacement panel. This panel was installed at Solar Two in December 1997 and performed without problems through the remainder of the project. This new panel design promises improved receiver performance, reliability, and cost.

\subsubsection{Thermal Storage System}

Molten salt was validated as a viable, large-scale thermal energy storage medium. Solar Two achieved round-trip energy storage efficiencies of 97\%. Solar Two also demonstrated the design, construction, and performance of large, field-erected, externally insulated tanks for storing molten salt.

\subsubsection{Electricity Dispatch}

Solar Two demonstrated the electricity dispatch capability of a molten-salt power tower by routinely producing electricity when the sun wasn't shining. Although Solar Two's thermal storage system was only sized for three hours of full-power operation, in a continuous-operation demonstration test the plant achieved 153 consecutive hours of electricity production before cloudy weather ended the test. 


\subsubsection{Steam Generation System}

Once the initial design flaws and operating procedures were resolved, the SGS performed well, delivering design steam flows to the turbine-generator.

\subsubsection{Salt Pumps}

All salt pumps at Solar Two performed well and were operated intermittently and at variable speeds without problems. Both multistage turbine (cold salt and mixer pumps) and cantilevered centrifugal (hot pumps) designs were demonstrated.

\subsubsection{Instrumentation}

Solar Two demonstrated the use of a new level sensor for use in pressurized salt vessels. The sensor is based on attenuation of radiation emitted from a nuclear source. The sensor utilized two 100-microcurie Cesium sources (contained in shuttered enclosures) and two detectors to monitor level in the receiver inlet vessel. The sensor was effective over the full range of vessel pressure (atmospheric to $320 \mathrm{psig}[2.2 \mathrm{MPa}]$ ) and levels (0-120 in. [0-3.05 m]).

A vortex-shedding flowmeter was used to measure cold salt flow rates. The flowmeter effectively measured salt flow rates through the SGS from approximately 40 to $193 \mathrm{lbs} / \mathrm{sec}$ (18 to 88 $\mathrm{kg} / \mathrm{sec}$ ), or 20 to $100 \%$ of design flow rates.

\subsection{Design Considerations and Enhancements for the Next Molten-Salt Power Tower Plant}

In addition to the technology validations accomplished through the Solar Two project, a number of Solar Two experiences will be useful in the design of the next molten salt power tower. In parallel with the Solar Two project, industry and SNL continue to analyze molten-salt systems and develop and test molten-salt components. The following subsections draw on Solar Two lessons learned, and continuing development activities, to suggest design considerations and enhancements for incorporation into the first commercial plant design.

\subsubsection{Long-Shafted Pumps for Salt Service}

SNL recently demonstrated the performance of a long-shafted, centrifugal, hot salt pump with salt-cooled bearings. Testing identified a number of bearing sleeve-housing material combinations that work well in hot molten salt (Barth et al., 2001). These pumps appear ready for commercial application to pump hot and cold salt.

This development has a significant impact on plant design. A long-shafted salt pump can be mounted directly above the salt storage tank, extending into the tank and drawing salt from near the tank bottom. Use of long-shafted hot and cold salt pumps eliminates the two pump sump vessels, along with the associated large-diameter isolation and flow control valves, piping, and 
heat trace. In addition, a number of failure modes are eliminated, including sump overflow caused by failure of the sump isolation or control valves.

\subsubsection{Salt Valves}

Solar Two utilized a variety of valve designs in the hot and cold salt piping. Gate and cagedplug valves worked reasonably well. Ball valves did not perform successfully in salt service at Solar Two. Prior to Solar Two, project participants, including SNL, had limited experience or operating history with ball valves in salt service. Solar Two utilized a variety of ball valve designs, both large- and small-diameter, in both hot and cold salt service. By the end of the project, most of the ball valves had been replaced with gate valves; seal-welded to prevent leakage (also eliminating valve operation); or eliminated by system redesign. Solar Two experience indicates that ball valves should not be used in salt service.

\subsubsection{Heat Trace}

The Solar Two experience once again demonstrated the importance of proper installation of heat trace. As described earlier, much of the heat trace at Solar Two was initially not applied uniformly and was removed and replaced. However, once properly installed and maintained, electric heat trace proved effective and reliable.

\subsubsection{Piping Materials}

Intergranular corrosion (IGC) was a problem in some areas at Solar Two where high-carbon stainless steel piping and fittings were used for containment of molten salt. Prior to the Solar Two project, external IGC was a potential concern for the receiver tubes due to their exposure to ambient atmospheric moisture and dust-borne chlorides. While no instance of external IGC was found, some IGC occurred at Solar Two that was initiated on the inside surface of receiver tubes and pipes that experienced an aqueous chemical flush and were vented to the atmosphere during shutdowns. Future molten-salt power tower designs will use piping materials that are not susceptible to IGC.

\subsection{Preliminary Design of the Next Molten-Salt Power Tower Plant}

One objective of Solar Two was to stimulate the commercialization of molten-salt power tower technology. Shortly after the conclusion of the Solar Two project, industry began forming international consortia to pursue opportunities to build power tower plants. One such consortium is Solar Tres, S.L., a group formed to build a molten-salt power tower plant in Spain. In addition to the consortia being formed, and in support of the overall power tower commercialization effort, Nexant, a new subsidiary of Bechtel (the Engineering and Construction Management contractor for Solar Two) and SNL initiated a preliminary design effort for a next-generation, molten-salt power tower plant. This section describes plant features that are under consideration or have been incorporated into the plant design. 


\subsubsection{Commercialization Approach and Plant Size}

Electricity produced from pre-commercial solar power plants is still an expensive alternative; power towers are not exceptions (see Figure 1-5). Subsidies are currently available to promote the development of renewable energy plants. Sponsoring organizations include the World Bank, through the Global Environment Facility, and some European countries that are interested in renewable energy as a means to meet their Kyoto Protocol commitments to reduce greenhouse gas emissions. The current power tower commercialization strategy seeks to utilize these subsidies to help finance the next plant. Under this strategy, the next plant would be a three-fold scale-up of Solar Two. This plant would provide a reasonable scale-up from Solar Two, with manageable technological and financial risks, while providing a significant step towards a fully commercial design.

\subsubsection{Expected New Design Features}

The next molten-salt power tower plant is expected to be rated at $15 \mathrm{MWe}$, with 12 to 16 hours of storage. The solar systems for this plant will therefore be about three times the size of Solar Two. The design approach includes features incorporated to improve component reliability and plant availability. These expected design features include the following:

- $\quad$ SGS: Use of four tube-in-shell vessels (preheater, evaporator, superheater, reheater) with salt on the shell side. The evaporator will be of a forced circulation design with separate steam drum. The vessels will be stacked to provide simplified drain and maintenance procedures.

- Salt Pumps: Use of long-shafted, multi-stage, turbine pumps as hot, cold, and salt mixer pumps mounted on a structure immediately above the hot and cold salt storage tanks.

- Receiver System: Utilize the proven advanced alloy for receiver tubes.

- Collector System: Utilize a proven glass mirror module design, innovative azimuth and elevation drives, state-of-the-art controllers with non-volatile memory, and possibly corrective aiming strategies. Incorporate lightning protection and an automated Beam Characterization System.

- Plant-wide: Incorporate rigorous efforts to minimize the number of valves in salt service. For salt systems, use 347 or 321 stainless steels to avoid IGC.

\subsubsection{Current Development Efforts}

Industry and SNL are collaborating on the development, test, and implementation of a number of additional design improvements, including the following:

- $\quad$ Alternative valve designs for hot salt service. To date, the best valve packing system developed for use in nitrate salt utilizes alternating layers of Teflon ${ }^{\circledR}$ and wire-reinforced graphite braid packing material. This packing system has an upper temperature limit well below the $1050^{\circ} \mathrm{F}\left(565^{\circ} \mathrm{C}\right)$ temperature of hot salt. Current hot salt valve designs therefore utilize an 
extended bonnet to reduce the temperature experienced by the packing. However, both the packing system and the extended bonnet are specialty items and require maintenance. In an attempt to minimize or eliminate these problems, alternative valve designs are being developed and tested in hot salt.

- Alternative salt downcomer designs. After being heated in the receiver, the hot salt must descend through a downcomer pipe from the receiver to the hot salt storage tank. Current designs use a receiver outlet vessel, to keep the downcomer full of salt, and energy-dissipating drag valves, to reduce the salt dynamic head (velocity) at the bottom of the downcomer. Testing is underway for a head-reducing downcomer design, which could eliminate the need for the hot salt drag valves and the receiver outlet vessel.

- Materials testing. Tests on stainless steels 347 and 321 are planned to demonstrate their resistance to IGC in salt service. 
Evaluation of Molten Salt Power Tower Technology 


\section{Power Tower Commercial Technology Goals versus Actual Experience}

The commercial technology forecasts for solar power towers and other renewable-electric power plants are published in a report by DOE and the Electric Power Research Institute (EPRI) (DOE and EPRI, 1997). This Technology Characterization (TC) Report indicates that the LEC for solar power towers should be $\sim 14$ cents/kWh for the first commercial project, ${ }^{2}$ which is about three times larger than Solar Two. Subsequent commercial plants having heliostat field sizes that are ten or more times larger than Solar Two are forecast to achieve solar-only LECs of 4 to 8 cents/kWh.

To achieve these LECs, power tower technology must meet goals established for: 1) power and energy performance, 2) capital cost, and 3) O\&M cost. The TC Report also indicates that power towers deliver dispatchable, rather than intermittent, electricity to the utility grid, thus significantly increasing the electricity value. This claim forms the basis for the final goal, 4) dispatchability. In this chapter, we will compare the four commercial goals with the experience at the pre-commercial Solar One and Solar Two demonstration projects.

A comparison of the key design features of the Solar One and Solar Two demonstration projects and the assumed commercial plant are presented in Table 4-1.

Table 4-1. Power Tower Key Design Features

\begin{tabular}{|l|l|l|l|}
\hline \multicolumn{1}{|c|}{ Design Features } & \multicolumn{1}{c|}{ Solar One } & \multicolumn{1}{c|}{ Solar Two } & \multicolumn{1}{c|}{ Commercial } \\
\hline Plant location & Daggett, California & Daggett, California & Southern Spain \\
\hline Annual insolation & $2.7 \mathrm{MWh} / \mathrm{m}^{2}$ & $2.7 \mathrm{MWh} / \mathrm{m}^{2}$ & $2.1 \mathrm{MWh} / \mathrm{m}^{2}$ \\
\hline Annual capacity factor & $16 \%$ & $19 \%$ & $60 \%$ \\
\hline Steam turbine/generator size & $10 \mathrm{MW}_{\mathrm{e}}$ & $10 \mathrm{MW}$ & $50 \mathrm{MW}$ \\
\hline Heliostat mirror area & $71130 \mathrm{~m}^{2}$ & $81400^{2}$ & $845000 \mathrm{~m}^{2}$ \\
\hline Tower height $($ optical) & $73 \mathrm{~m}$ & $73 \mathrm{~m}$ & $155 \mathrm{~m}$ \\
\hline Receiver fluid & water/steam & $\mathrm{molten} \mathrm{salt}$ & $\mathrm{molten} \mathrm{salt}$ \\
\hline Receiver dimensions $(\mathrm{D} \times \mathrm{H})$ & $7 \mathrm{~m} \times 13.7 \mathrm{~m}$ & $5.1 \mathrm{~m} \times 6.2 \mathrm{~m}$ & $15 \mathrm{~m} \times 16.5 \mathrm{~m}$ \\
\hline Receiver peak flux & $300 \mathrm{~kW} / \mathrm{m}^{2}$ & $850 \mathrm{~kW} / \mathrm{m}^{2}$ & $1000 \mathrm{~kW} / \mathrm{m}^{2}$ \\
\hline Receiver size & $42 \mathrm{MW}$ & $42 \mathrm{MW}$ & $400 \mathrm{MW}$ \\
\hline Steam generator size & $\mathrm{N} / \mathrm{A}$ & $35 \mathrm{MW}$ & $135 \mathrm{MW}$ \\
\hline Solar multiple & 1.0 & 1.1 & 3.0 \\
\hline Thermal storage size & $\mathrm{N} / \mathrm{A}$ & $114 \mathrm{MWh}(3 \mathrm{hrs})$ & $2200 \mathrm{MWh}(16 \mathrm{hrs})$ \\
\hline
\end{tabular}

2 This cost applies to the solar portion of a fossil hybrid configuration in which the power tower supplies energy to the steam cycle within a natural-gas combined cycle plant. If the initial commercial project is solar only, energy costs will be somewhat higher. 
The Solar One/Two data are actuals. The commercial plant design was estimated via simulations with the DELSOL and SOLERGY computer codes (Kistler, 1986; Stoddard et al., 1987); it is a plausible design for the second commercial project to be deployed in Spain. ${ }^{3}$

\subsection{Actual Plant Performance versus Commercial Goals}

\subsubsection{Peak Performance}

Attainment of plant performance goals can be gauged by comparing the efficiency of converting direct-normal insolation falling on the heliostat mirrors to electricity. A comparison of the peak efficiencies is presented in Table 4-2. As noted, two columns are actuals and two columns are goals. There are several reasons why the efficiencies differ, as described below.

- Unlike the commercial plant, Solar One/Two did not use a reheat turbine cycle. Consequently, gross Rankine-cycle efficiency was lower at Solar One/Two (34\% versus 42\%). In addition, Solar One was slightly lower than Solar Two because the design steam temperature was $\sim 150^{\circ} \mathrm{F}\left(\sim 66^{\circ} \mathrm{C}\right)$ lower at Solar One.

Table 4-2. Comparison of Peak Efficiencies

\begin{tabular}{|l|c|c|c|c|}
\hline \multicolumn{1}{|c|}{ Category } & $\begin{array}{c}\text { Solar One Mature } \\
\text { Operation } \\
\text { (Typical Actual) }\end{array}$ & $\begin{array}{c}\text { Solar Two } \\
\text { Goal }\end{array}$ & $\begin{array}{c}\text { Solar Two Test } \\
\text { and Evaluation } \\
\text { Phase (Actual) }\end{array}$ & $\begin{array}{c}\text { Commercial } \\
\text { Plant Goal }\end{array}$ \\
\hline A. Mirror Reflectivity & $90.3 \%$ & $90.7 \%$ & $90.7 \%{ }^{4}$ & $94 \%$ \\
\hline B. Field efficiency & $76 \%$ & $72 \%$ & $66 \%$ & $71 \%$ \\
\hline C. Field availability & $99 \%$ & $98 \%$ & $94 \%$ & $99 \%$ \\
\hline $\begin{array}{l}\text { D. Mirror corrosion } \\
\text { avoidance }\end{array}$ & $\sim 100 \%$ & $97 \%$ & $97 \%$ & $100 \%$ \\
\hline E. Mirror cleanliness & $95 \%$ & $95 \%$ & $90 \%$ & $95 \%$ \\
\hline F. Receiver & $78 \%$ & $87 \%$ & $88 \%$ & $88 \%$ \\
\hline G. Storage & $\mathrm{N} / \mathrm{A}$ & $99 \%$ & $>99 \%$ & $>99 \%$ \\
\hline H. EPGS & $33 \%$ & $34 \%$ & $34 \%$ & $42 \%$ \\
\hline $\begin{array}{l}\text { Overall Peak Efficiency } \\
\text { (Gross) }\end{array}$ & $16.6 \%$ & $17.2 \%$ & $14.7 \%$ & $23.2 \%$ \\
\hline I. Parasitics & $90 \%$ & $88 \%$ & $87 \%$ & $93 \%$ \\
\hline $\begin{array}{l}\text { Overall Peak Efficiency } \\
\text { (Net) }\end{array}$ & $15 \%$ & $15 \%$ & $13 \%$ & $22 \%$ \\
\hline
\end{tabular}

3 The solar design of the $50 \mathrm{MW}$ commercial plant for Spain is similar to the $100 \mathrm{MW}$ commercial plant described in the TC Report. The size of the heliostat field, receiver, and storage tanks are similar. The Spanish plant has a smaller steam generator to work with the smaller steam turbine.

4 This is an area-weighted reflectance. Reflectance of Solar One heliostats $\left(71130 \mathrm{~m}^{2}\right)$ was $90.3 \%$ (Radosevich, 1988 ) and large-area heliostats $\left(10270 \mathrm{~m}^{2}\right)$ were measured to be $93.9 \%$, for a total of $90.7 \%$. 
- The Solar Two heliostat field was not state-of-the-art. The reflectance of these older mirrors was below today's commercial-plant standard (90.3\% for Solar One type versus 94\%). Corrosion caused many of the original Solar One mirrors to lose reflective area and to lose their focus, causing a degradation in the field efficiency at Solar Two relative to Solar One. In addition, 108 large-area heliostats were added to the south field during the Solar Two project to increase the total field area from $71130 \mathrm{~m}^{2}$ to $81400 \mathrm{~m}^{2}$. These new heliostats, though inexpensive, did not have focussed facets and were too large for the Solar Two receiver. Consequently, the reflected beams from these heliostats were too large and 20 to $30 \%$ of the beams did not intercept the receiver target, causing further reductions in field efficiency relative to Solar One and the commercial plants. Most of these heliostat optics problems were known before Solar Two was built but were accepted by the project team because the purpose of Solar Two was to prove molten-salt technology, not heliostat technology. This is why the field efficiency goal for Solar Two (72\%) was significantly lower than Solar One. The field efficiency ${ }^{5}$ in the commercial plant will be significantly better than Solar Two because new, focused, and properly-sized heliostats will be used. However, the commercial field efficiency should be lower than Solar One's; like the commercial plant, Solar One also used a new heliostat field, but since the field is much smaller, it should have lower losses associated with atmospheric attenuation.

- The Solar One heliostat field was very reliable and achieved nearly $99 \%$ availability over a several year period (Radosevich, 1988). This field was to be reused during Solar Two and the project team hoped to achieve 98\% availability during Solar Two. However, after restart of the field for Solar Two, it became apparent that abandonment of the field for seven years had taken a severe toll on the heliostat control system electronics. The $94 \%$ availability value listed in Table 4-2 for Solar Two was a rare occurrence; a more typical value was $90 \%$. Figures 4-1 and 4-2 indicate the degradation of the heliostat field since Solar One. Figure 4-1 presents the peak (maximum) daily heliostat availability during the Solar Two project. (The very low values on the lower portion of the figure were recorded on days when the full field was not commanded to standby status and therefore do not accurately reflect true field availability.) Even these peak daily values are below Solar One's routine field availability. Figure 4-2 shows how heliostat availability tended to decline during the course of a day.

- The $99 \%$ availability goal set for the commercial plant can be achieved since it will employ a new heliostat field. If properly maintained, this new field should be reliable for many years. For example, after more than 10 years of operation, SEGS troughs routinely achieve $99 \%$ collector field availability.

- Since Solar One/Two were only $10 \mathrm{MW}_{\mathrm{e}}$ plants, economies of scale dictate that parasitic electricity use will be a greater fraction of the total gross generation than for a $50 \mathrm{MW}_{\mathrm{e}}$ commercial plant (88\% versus 93\%). Solar One's parasitics were slightly lower than Solar Two's, as more optimization was done at Solar One because the plant operated much longer (10,000 hours versus 2000 hours).

5 Field efficiency includes the following losses: a) heliostat cosine, b) heliostat shading and blocking, c) receiver intercept, and d) atmospheric attenuation between heliostat and receiver. 


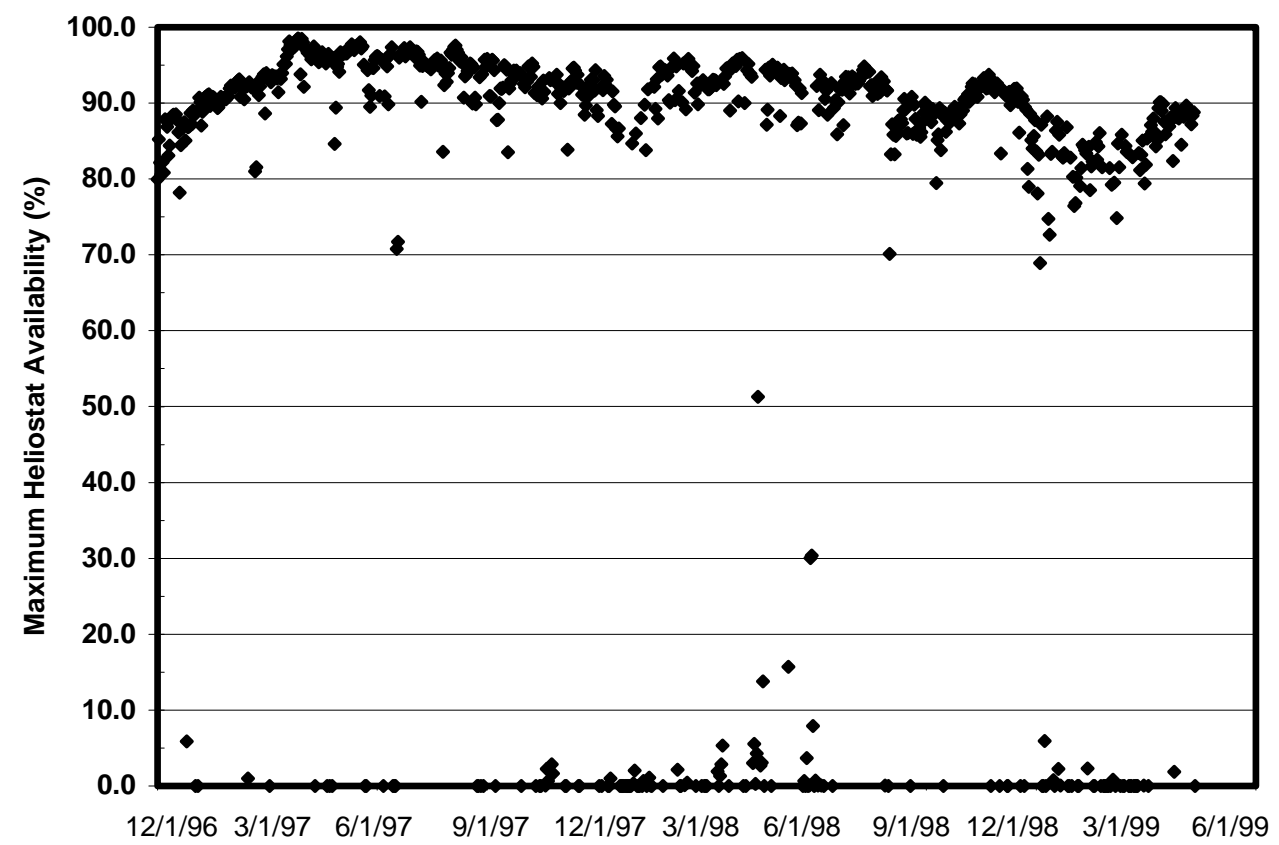

Figure 4-1. Solar Two Maximum Daily Heliostat Availability, December 1996 to April 1999.

- A thermal storage system was installed at Solar One. However, operation from storage was inefficient (net electric charge/discharge efficiency of $\sim 75 \%$ ). Consequently, the storage was usually bypassed and steam produced in the receiver was sent directly to the turbine. A fire destroyed the system after four years of operation (Radosevich, 1988). On the other hand, the molten salt storage system at Solar Two routinely demonstrated very high charge/discharge efficiencies $(97 \%)$ and the molten salt is not flammable.

- Table 4-1 indicates the allowable peak flux in the Solar Two receiver was much higher than in the Solar One receiver. This is due to the improved heat transfer characteristics associated with the use of molten salt at Solar Two. Consequently, the receiver at Solar Two was smaller (1/3 the surface area) and more efficient (measured to be $88 \%$ (Pacheco et al., 2001) versus 78\% (Radosevich, 1988)) because thermal losses were reduced. The efficiency of the commercial receiver will be higher than Solar Two because a more resilient receiver tube material will be used that will allow a higher peak flux (1000 versus 850 suns).

It can be seen that Solar Two fell short of its peak net-efficiency goal of $15 \%$. The discussion above and the efficiencies recorded as items B through E in Table 4-2 indicate the cause was due to the poor condition of the heliostat field during the Solar Two project. Mirror cleanliness was often better than the $90 \%$ value listed in Table 4-2, but on those days, field availability was less than $94 \%$. The overall peak efficiency of $13 \%$ was the best coincidence of all subsystem factors. 


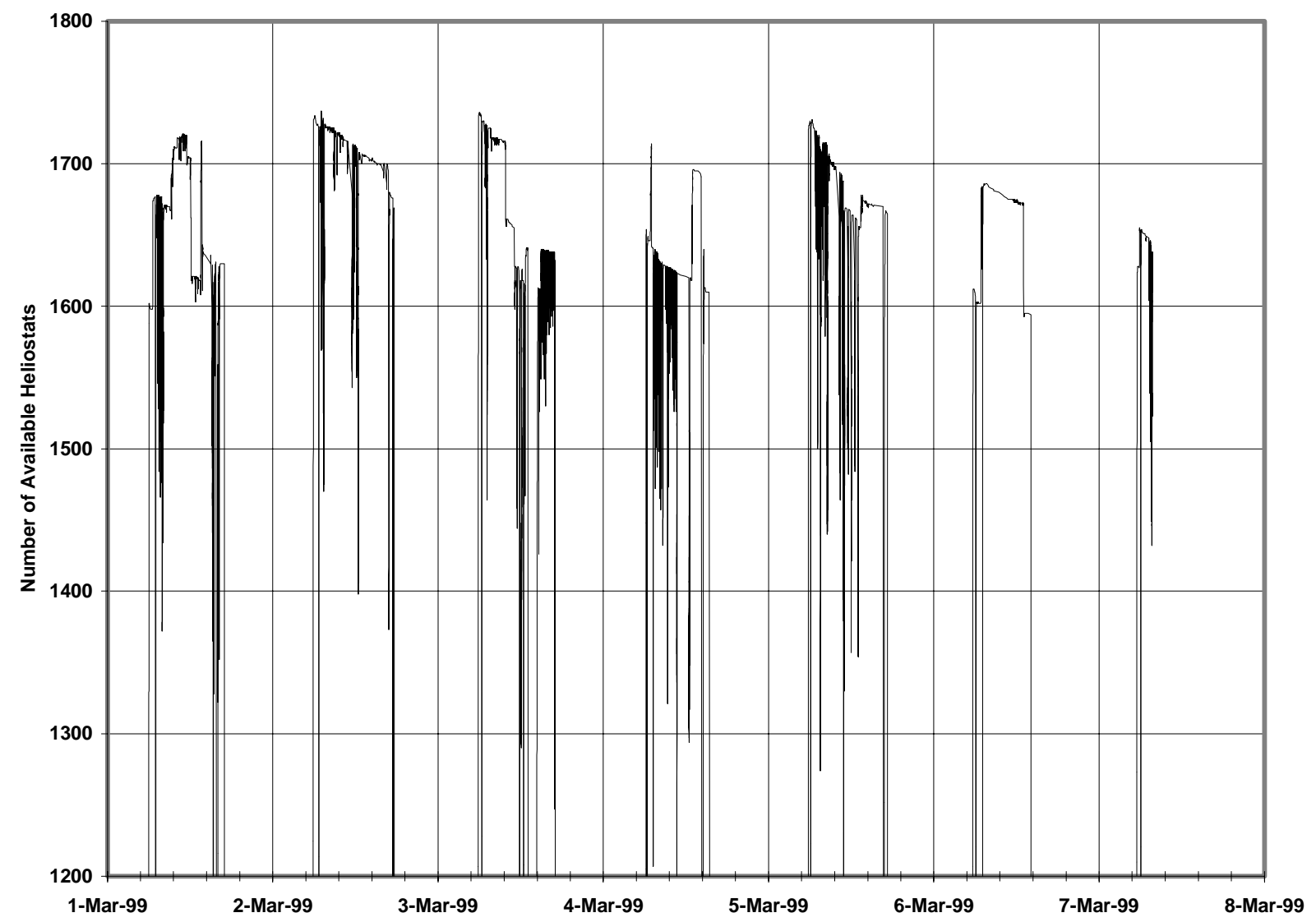

Figure 4-2 Solar Two Heliostat Availability in Early March 1999. For Solar Two, there were a total of 1926 heliostats in the field.

The peak efficiency recorded at Solar One was higher than Solar Two because of the better performance of the heliostat field during the Solar One project and has nothing to do with the use of molten salt at Solar Two versus water/steam at Solar One. Given optimized heliostat fields of equal area for both plants, the peak efficiency of a molten salt plant is expected to be $\sim 12 \%$ higher due to its higher receiver efficiency.

\subsubsection{Annual Performance}

Peak efficiency is a snapshot that indicates plant performance at a moment in time. It gives useful insights into the plant power output, but says little about the ability of the solar plant to deliver electric energy to the grid on a daily, monthly, and annual basis. To gauge the plant energy performance, annual efficiency is used as the figure of merit. It includes all the factors that influence energy production in a solar power tower. These factors are listed in column 1 of Table 4-3.

With the annual efficiency, annual insolation, and field area, one can calculate the annual electricity produced and the corresponding capacity factor. For example, the annual performance of a $50 \mathrm{MW}$ commercial plant in Spain is projected to be 
Net Annual Electricity $=($ Net Annual Efficiency $) *($ Annual DNI $) *($ Heliostat Area $)$

$$
=0.146 * 2.1 * 845000
$$$$
=260 \mathrm{GWhrs}
$$

Capacity Factor $=($ Net Annual Electricity $) /($ Plant Power Rating $* 8760$ hrs $)$

$$
\begin{aligned}
& =260000 /(50 * 8760) \\
& =59 \%
\end{aligned}
$$

Such a high capacity factor is possible for the commercial plant because the peak thermal output of the solar field/receiver is greater than the thermal rating of the steam generator by a factor of 3 (i.e., solar multiple of 3 in Table 4-1) and the excess solar energy is put in the thermal storage system for later use.

Table 4-3. Comparison of Annual Efficiencies

\begin{tabular}{|l|c|c|c|}
\hline $\begin{array}{c}\text { Factors that Influence Energy } \\
\text { Production in a Solar Power Tower }\end{array}$ & $\begin{array}{c}\text { Solar One } \\
\text { SOLERGY } \\
\text { (Mature Plant) }\end{array}$ & $\begin{array}{c}\text { Solar Two } \\
\text { SOLERGY } \\
\text { (Goal) }\end{array}$ & $\begin{array}{c}\text { Commercial } \\
\text { SOLERGY } \\
\text { (Goal) }\end{array}$ \\
\hline Plant-wide availability & $\mathbf{0 . 9 0}$ & $\mathbf{0 . 9 0}$ & $\mathbf{0 . 9 1}$ \\
\hline Field & $\mathbf{0 . 5 8}$ & $\mathbf{0 . 5 0}$ & $\mathbf{0 . 5 6}$ \\
availability & 0.99 & 0.98 & 0.99 \\
reflectance & 0.905 & 0.907 & 0.94 \\
mirror corrosion & $\sim 1.0$ & 0.97 & 1.0 \\
cleanliness & 0.95 & 0.95 & 0.95 \\
high wind outage & 0.99 & 0.99 & 0.99 \\
cos/S\&B/intercept/attenuation & 0.69 & 0.62 & 0.64 \\
\hline Receiver & $\mathbf{0 . 6 5}$ & $\mathbf{0 . 7 6}$ & $\mathbf{0 . 7 9}$ \\
low insolation/startup/clouds & 0.85 & 0.90 & 0.92 \\
absorptance & 0.93 & 0.93 & 0.93 \\
thermal losses & 0.82 & 0.91 & 0.92 \\
\hline Piping & $\mathbf{0 . 9 9}$ & $\mathbf{0 . 9 9}$ & $\mathbf{0 . 9 9 5}$ \\
\hline Storage & $\mathrm{N} / \mathrm{A}$ & $\mathbf{0 . 9 7}$ & $\mathbf{0 . 9 9}$ \\
\hline EPGS & $\mathbf{0 . 3 0}$ & $\mathbf{0 . 3 2}$ & $\mathbf{0 . 4 1}$ \\
startup efficiency & 0.93 & 0.96 & 0.985 \\
Rankine cycle efficiency & 0.32 & 0.33 & 0.42 \\
\hline Gross Annual Efficiency & $\mathbf{0 . 1 0 1}$ & $\mathbf{0 . 1 0 5}$ & $\mathbf{0 . 1 6 3}$ \\
(multiplication of bolded entries) & & & \\
\hline Parasitics & $\mathbf{0 . 7 2}$ & $\mathbf{0 . 7 3}$ & $\mathbf{0 . 9 0}$ \\
\hline Net Annual efficiency & $\mathbf{0 . 0 7 3}$ & $\mathbf{0 . 0 7 7}$ & $\mathbf{0 . 1 4 6}$ \\
(gross ${ }^{*}$ parasitics) & & & \\
\hline
\end{tabular}

By comparing Table 4-2 and 4-3, it can be seen that subsystem annual efficiencies are lower than peak efficiencies. This is expected because annual efficiencies include additional losses incurred during startup, part-load, and offline periods. The values presented in Table 4-3 were developed with SOLERGY simulations, which model the energy flows throughout the plant using 15- 
minute timesteps for the full 8760 hours in a year. This code was validated with actual performance at Solar One (Alpert and Kolb, 1988) and Solar Two (Hale, 1999).

The only annual efficiency in Table 4-3 that has been "demonstrated" was the value for Solar One. The expected mature annual efficiency predicted by SOLERGY for Solar One was achieved during the fourth year of its power production phase (October 1987 to September 1988) which followed a two-year test and evaluation phase. (Solar Two remained in test and evaluation phase throughout its relatively short life, as discussed earlier). Operating on a Monday through Friday schedule, Solar One produced 9245 MWh (net) during the 247 days the plant was open. Extrapolating this to 365 days, the projected net annual output from the plant was $13660 \mathrm{MWhrs}$. Annual insolation during this period was measured to be $2.5 \mathrm{MWh} / \mathrm{m}^{2} / \mathrm{yr}$. Annual efficiency based on this insolation is 7.6\%. However, insolation measurements are believed to be biased low during this period. A typical value for Barstow is $2.7 \mathrm{MWh} / \mathrm{m}^{2} / \mathrm{yr}$. Based on the typical insolation, annual efficiency would be $7.1 \%$. Plant-wide availability during the 247 days was an impressive $96 \%$.

Many of the reasons why the subsystem annual efficiencies in Table 4-3 differ for the three plants are the same reasons why they differ in Table 4-2. A few additional insights are listed below:

- Because of molten salt storage, the Solar Two power plant remained connected to the utility grid through partly cloudy weather. Solar One, operating without storage, usually tripped offline when clouds became significant. ${ }^{6}$ At Solar One, when clouds cleared, the receiver/turbine had to be restarted, which caused the additional startup losses indicated for the receiver and the EPGS.

- At Solar Two, the minimum allowable salt flow to the receiver was 15 to $20 \%$ of the maximum flowrate. This was a conservative value adopted during test and evaluation. For a smaller salt receiver tested at SNL, it was demonstrated that $13 \%$ could be safely implemented. In addition, for the case of the commercial plant, presumably a more aggressive receiver startup flowrate will be implemented. This is why the receiver startup efficiency is improved for the commercial plant.

- The receiver absorptance values listed in Table 4-3 (0.93) are determined by the quality of the black Pyromark paint that covers the tubes. The values listed are below the value that was measured at Solar Two at the end of the project (0.95) and at Solar One shortly after its receiver was repainted (0.96). However, the Pyromark is expected to degrade over several years of operation, and this was seen at Solar One (Radosevich, 1988). Thus, the value selected for Table 4-3 is meant to be an average between new and repaint.

- Annual storage efficiency is higher in a commercial plant because the storage tanks are much larger and thermal losses are a smaller fraction of the total thermal energy stored.

6 The validation of SOLERGY with Solar One data (Alpert and Kolb, 1988) indicated that tripping during clouds led to a $12 \%$ loss in annual energy production at Solar One relative to SOLERGY predictions. This $12 \%$ loss is included with the 0.85 receiver efficiency category entitled "low insolation/startup/clouds" in Table 4-3. 
- Plant wide availability should exceed $90 \%$ for the commercial design based on a reliabilityblock-diagram analysis of a proposed commercial design (Becker et al., 1993).

- In the later, more mature years of operation at Solar One, high winds rarely prevented operation of the plant when the skies were sunny (Alpert and Kolb, 1988). This happened more frequently during the test and evaluation phase of Solar Two because procedures for operating in high winds (and receiver modifications to eliminate tube freezing) had not yet been developed. Improved receiver and heliostat operating procedures should be implemented in the commercial plant.

- The primary reason why the annual parasitic efficiency is significantly improved in the commercial plant is because it will have a much higher annual capacity factor $(60 \%$ versus 19\%). Since the design of Solar One/Two called for a low annual capacity factor, the plants spent most of the time in a shutdown state and parasitics during the offline period contributed $\sim 50 \%$ of the total. In the commercial plant, the offline period is significantly reduced and offline parasitics are only about $15 \%$ of the total.

The Solar Two annual efficiency goal presented in Table 4-3 implies the following annual energy production was ultimately expected from the plant in a mature operating year:

Gross Annual Electricity $=\left(2.7 \mathrm{MWh} / \mathrm{m}^{2} \mathrm{yr}\right) * 81400 \mathrm{~m}^{2} * 0.105=23100 \mathrm{MWh}_{\mathrm{e}}$

Net Annual Electricity $=23100 * 0.73=16900 \mathrm{MWh}_{\mathrm{e}}$

Because of several construction-related problems that plagued the project, there was only one extended time period in which all power plant systems were generally available. ${ }^{7}$ This 13 -month period was mid-October 1997 to November 13th, 1998. During that time, final acceptance tests were performed to allow the construction crew (Bechtel) to turn over the plant to the O\&M crew (ESI). The turnover occurred in mid February and operator training began in earnest. Concurrently with all this activity, project engineers were directing many tests dictated by the test and evaluation plan. Needless to say, the plant was not optimized during this period while the O\&M crew and the test engineers were getting comfortable with the overall system. However, a significant amount of gross electricity was produced at Solar Two during this period and net electricity also began to improve in the latter half of the 13-month period. To gauge the annual performance of Solar Two relative to Solar One, it is necessary to compare the plants at similar points in their lives, during the first December-to-November run during the respective plant's test and evaluation phase.

Annual energy performance of Solar One and Two were similar during their test and evaluation periods, as shown in Table 4-4. During this period, Solar Two produced 1/3 of the gross energy that was expected to be produced in a mature power production year. Net energy performance was poor at both plants during test and evaluation. However, as stated previously, Solar One eventually succeeded in achieving the net annual performance predicted by SOLERGY after test and evaluation and plant optimization were completed. Could Solar Two have achieved its

7 Plant outages occurred during this period to debug the plant design, but they typically lasted from a few days to a few weeks. 
Table 4-4 Annual Energy Performance of Solar One and Solar Two During T\&E

\begin{tabular}{|l|r|r|r|r|}
\hline Month & $\begin{array}{c}\text { Solar Two } \\
\text { Gross } \\
\text { (MWh) }\end{array}$ & $\begin{array}{c}\text { Solar One } \\
\text { Gross } \\
\text { (MWh) }\end{array}$ & $\begin{array}{c}\text { Solar Two } \\
\text { Net (MWh) }\end{array}$ & $\begin{array}{c}\text { Solar One } \\
\text { Net (MWh) }\end{array}$ \\
\hline Dec & 293 & 200 & -256 & -500 \\
\hline Jan & 353 & 300 & -363 & -375 \\
\hline Feb & 503 & 250 & -64 & -350 \\
\hline Mar & 478 & 450 & -141 & -125 \\
\hline Apr & 188 & 610 & -378 & 125 \\
\hline May & 74 & 1300 & -513 & 700 \\
\hline Jun & 1193 & 1100 & 532 & 560 \\
\hline Jul & 903 & 750 & 284 & 260 \\
\hline Aug & 678 & 250 & 94 & -200 \\
\hline Sep & 954 & 550 & 367 & 90 \\
\hline Oct & 1015 & 540 & 532 & 90 \\
\hline Nov & 422 & 200 & 17 & -310 \\
\hline Total & 7053 & 6500 & 110 & -35 \\
\hline
\end{tabular}

SOLERGY goal if it had operated the same length of time as Solar One (2000 total hrs at Solar Two versus 10,000 hours at Solar One)? It is difficult to say because the degradation of the heliostat field at Solar Two turned out to be worse than originally anticipated. The effects of these heliostat field problems are addressed in the analysis conducted in the next section.

\subsubsection{Daily Performance}

Though there is no meaningful annual efficiency data for Solar Two, there is daily energy performance and efficiency data. Comparing this Solar Two data to SOLERGY goals on a daily basis indicates the likelihood of whether Solar Two could have eventually met its annual performance goal and provides insights into how the Solar Two goals compare to the commercial goals.

To judge daily performance at Solar Two, the test and evaluation team used the three "inputoutput" metric plots depicted in Figures 4-3 through 4-5. Each point on the plots represents the daily performance of the plant subsystems on a particular day in the period July to midNovember 1998, and the line is the SOLERGY goal. If the daily subsystem goals can be routinely accomplished, combined with an annual plant availability of $90 \%$, the net annual electricity goal for Solar Two would be achieved.

Examination of the three figures indicates the goals for energy conversion and parasitic energy consumption were routinely met during the late September through mid-November period. 
However, the plant fell short of the original energy collection goal. The reasons behind the behavior exhibited in the three figures, and how they relate to commercial plant goals, are discussed in the sections that follow.

\subsubsection{Daily Energy Collection Goals versus Actual Experience}

Figure 4-3 indicates that Solar Two did not meet the original daily energy collection goal over the full range of daily solar conditions. There are three primary reasons why the points are below the line.

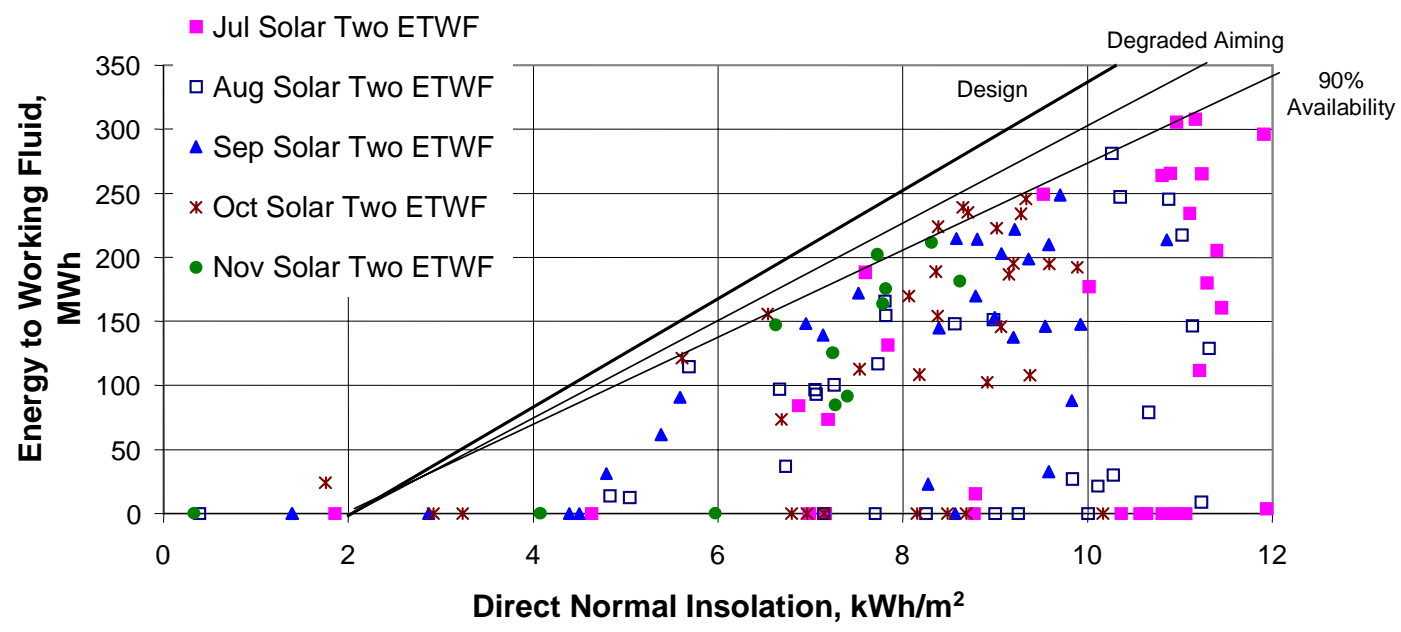

Figure 4-3. Daily Solar Energy Collected by the Heliostat/Receiver Systems at Solar Two versus SOLERGY Goal. Since heliostat aiming and availability were below the goals for these parameters, the original SOLERGY goal could not be met.

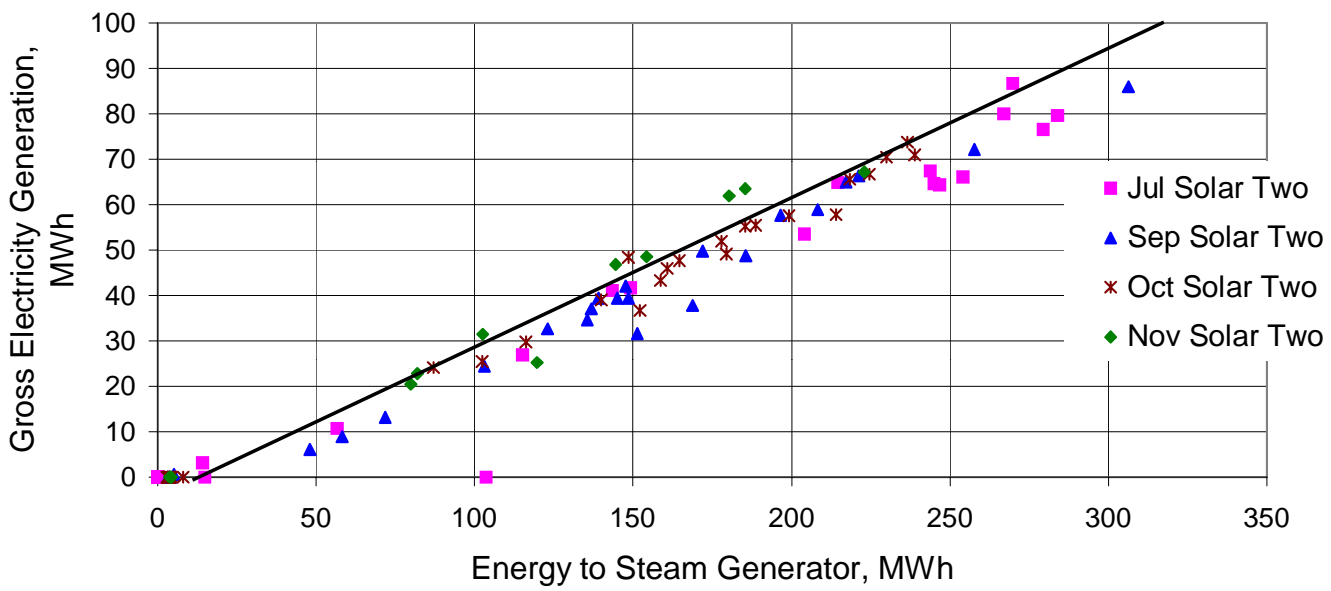

Figure 4-4. Conversion of Thermal Energy to Electric Energy at Solar Two versus SOLERGY Goal. 
1. The percentage of heliostats tracking the receiver was significantly below the $98 \%$ goal each month. For example, maximum percentages of heliostats tracking the receiver on operating days were $91.9 \%$ in July, $87 \%$ in August, $88.8 \%$ in September, $91.4 \%$ in October, and 90.5\% in November.

2. There was a heliostat aiming problem that caused $\sim 10 \%$ of the design-level power from the heliostat field to miss the receiver. During 1998, a survey of 119 heliostats with the beam characterization system (BCS) indicated that $16.8 \%$ of them had significant receiver-spillage problems, i.e. greater than $50 \%$ of their image was not intercepting the receiver. In addition, a study of the historical BCS records for the entire field indicates the RMS beam aiming error for the field was $7 \mathrm{mrad}$, whereas the design value demonstrated at Solar One was $2.1 \mathrm{mrad}$. The DELSOL optical performance code predicts this increased aiming error leads to a

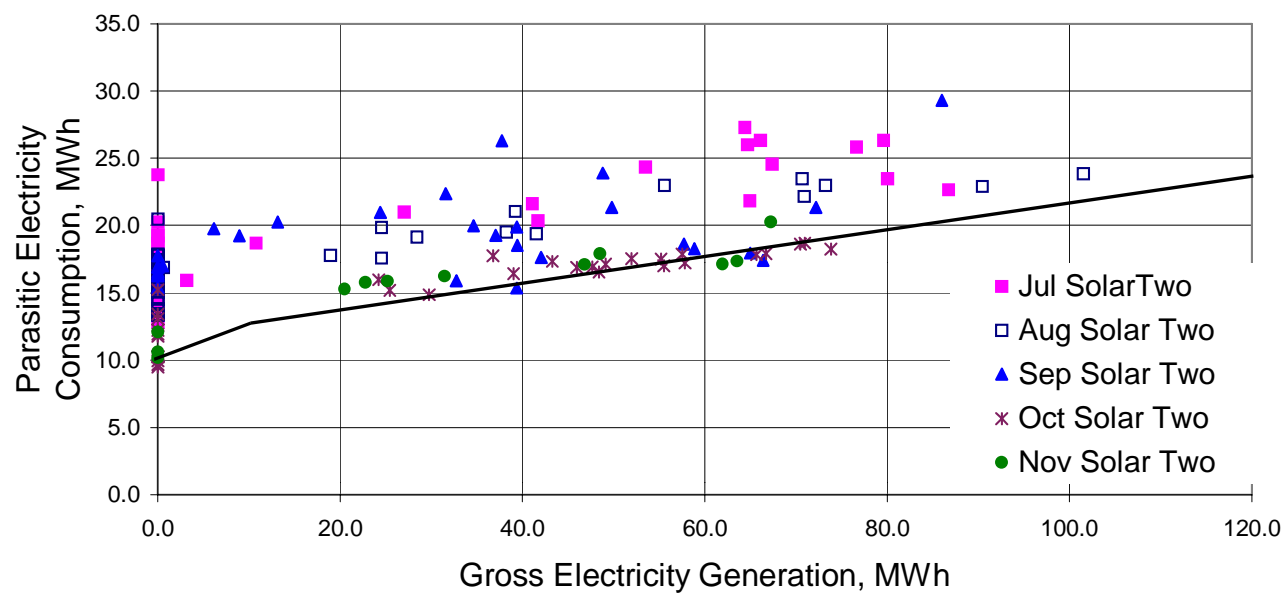

Figure 4-5. Parasitic Consumption at Solar Two versus SOLERGY Goal.

decrease in field performance of $14 \%$ from the design value and measurements of the efficiency of the entire field in March 1999 indicated $~ 10 \%$ decrease. The Solar Two aiming error was postulated to be much worse than Solar One because a) degradation of heliostat encoders and control electronics often caused heliostats to mistrack, and b) the canting of the heliostats had worsened relative to Solar One. The reason for the former was discussed previously, but what was the reason for the latter? The inner 17 rows of the field $(\sim 1000$ heliostats) were recanted to the slant range for each individual heliostat during 1996 in an attempt to create a tighter focus for the much smaller Solar Two receiver. Poor implementation of the recanting procedure appeared to make canting worse, not better. As discussed in Section 2.6.3, the geometric misalignment caused by poor canting can cause tracking errors. In a commercial plant, a single "quality-controlled" cant for the entire field would likely be implemented, as was successfully done at Solar One. Other heliostat aiming errors would be solved by software corrections that have been demonstrated at SNL (Jones and Stone, 1999), and were not possible to implement at Solar One/Two because old control technology was employed. 
Correcting for the actual heliostat aiming, availability, and cleanliness on a given day, a revised daily energy collection goal can be calculated. The results of this analysis are plotted in Figure 4-6. It shows improvement in approaching and sometimes surpassing the revised daily collection goal. For example, the number of days exceeding $80 \%$ of the revised daily goal in the May/June, July/August, and September/October were 9, 15, and 23 days, respectively.

3. Outages occurred that prevented the plant from operating on a given day (points on abscissa), or allowed operation for only a portion of the day (these points are the ones significantly below the goal lines in Figures 4-3 and 4-6). Here, an outage is defined as anytime energy production was below the SOLERGY goal (as corrected for actual daily condition of the heliostat field). The outage events for September and October (71\% plant availability during these months) are depicted in Figure 4-7.

The pie charts indicate that most of the plant outages were related to the receiver. Elimination of some of the outages would have occurred naturally given additional operating time.

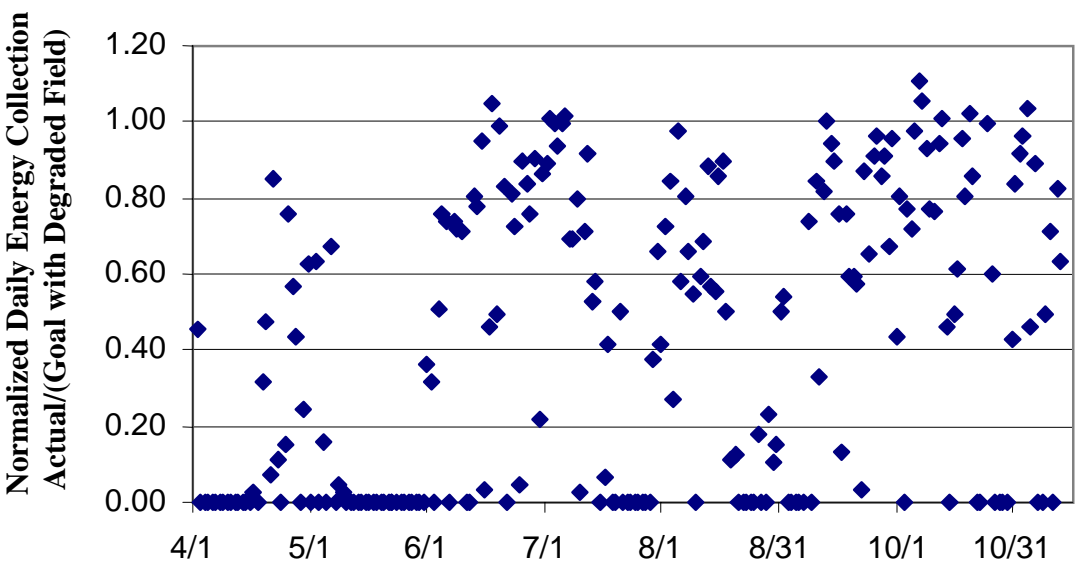

Figure 4-6. The Daily Energy Collected versus a Corrected SOLERGY Goal That was Corrected for Aiming Problems, Actual Daily Field Availability, and Actual Daily Cleanliness. Data are for seven months in 1998.

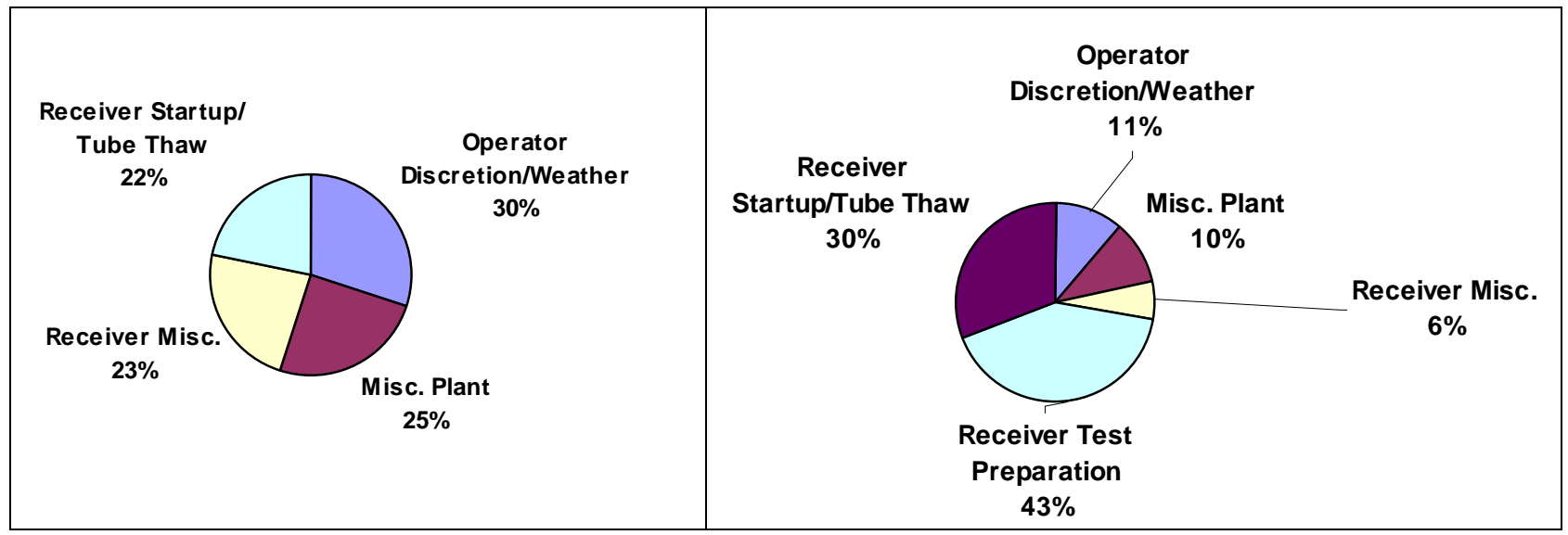

Figure 4-7. Causes for Outages at Solar Two During September (left) and October (right) 1998. 
For example, outages caused by test preparation would have been eliminated after the test and evaluation program was completed and outages caused by operator decisions/weather would have been reduced as the operators became more comfortable operating the plant, especially during partly cloudy and windy weather. However, other outages will require corrective action to fix the root cause of the problem. For example, outages caused by tube freeze-up during startup of the receiver will require a design modification, as described below.

During fill of the receiver in the morning, the salt within one or more tubes on the windward side of the receiver sometimes froze, thereby delaying startup (sometimes for several hours) until the salt thawed. The problem was especially tenacious when ground wind speeds approached $20 \mathrm{mph}(9 \mathrm{~m} / \mathrm{sec})$, which meant considerably higher winds on top of the tower. Tube freezing appears to be due to the inability of the receiver header ovens to exceed the salt freezing point during windy conditions. Winds caused air leakage into the oven space to suppress oven temperatures. In particular, there was an 8 -inch $(20-\mathrm{cm})$ tube section at the interface between the receiver surface and the oven that was difficult to heat with either solar heat or oven heat. It appears that salt in one or more tubes tended to freeze in this region. The salt that froze at the interface may have come from the initial flow to the receiver panels during each receiver startup, or it may have come from the residual salt film, attached to the inside tube wall from the previous day's run, which was melted by the preheat heliostat beams and flowed downward towards the lower oven interface. If the interface or the tubes within the oven were too cold, the salt froze and formed a plug. Boeing is currently rethinking the oven and oven interface designs for the commercial plant. They expect to solve the problem, which appears plausible since the salt receivers tested at Sandia prior to Solar Two did not have this problem.

In Figure 4-8, the Solar Two and commercial goals for daily energy collection efficiency are compared. The Solar Two goals were developed directly from the goal lines in Figure 4-3 by transforming the y-axis via

Daily Collection Efficiency $=\frac{\text { Daily Energy Collected }}{(\text { Daily DNI }) \times(\text { Heliostat Area })}$.

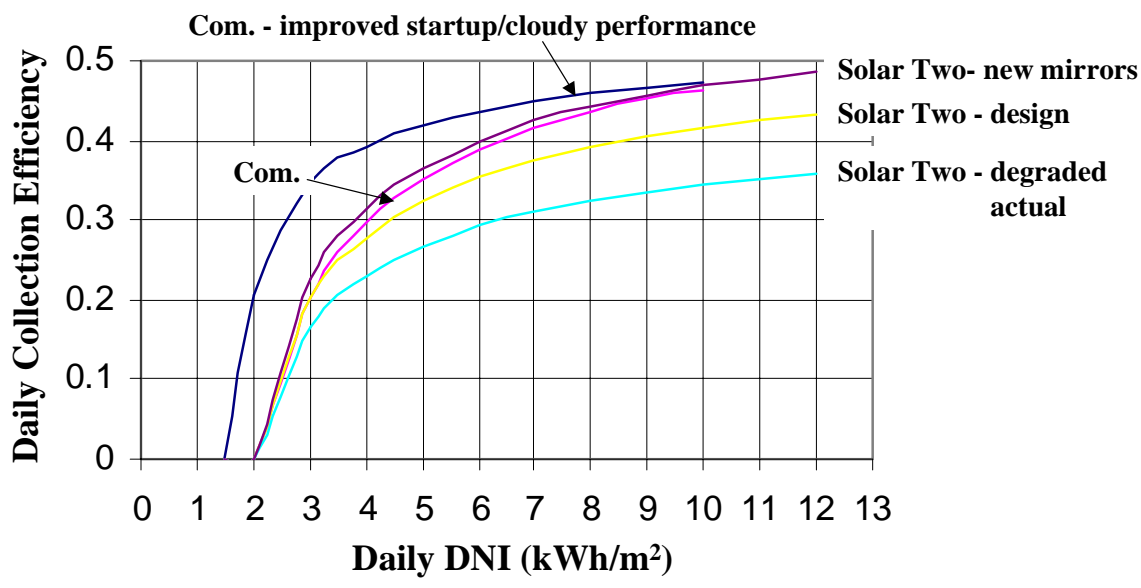

Figure 4-8. Comparison of Daily Collection Efficiency Goals. 
The comments below interpret the results displayed in Figure 4-8.

The daily insolation does not exceed $10 \mathrm{kWh} / \mathrm{m}^{2}$ for the commercial plant because the plant is assumed to be located in Spain; insolation in Spain (Osuna et al., 2000) is less than at Solar Two.

In order for Solar Two to have matched the collection efficiency predicted for the commercial plant, three significant changes to the Solar Two field would have been necessary that were beyond the scope and budget of the Solar Two project. The first change would be to replace the old 90\%-reflectance mirrors on the reused Solar One heliostats with state-of-the-art, 94\% mirrors. The second change would be to reduce heliostat-tracking errors to the values measured during Solar One. The final change would be to eliminate all 108 large-area heliostats that were added to the south field. (Eliminating the Lugo heliostats would require a rearrangement of the rest of the field to meet receiver power and flux distribution requirements.) As discussed previously, the optical performance of the large-area heliostats was poor. Placing them in the southern portion of the field reduces field efficiency further because cosine efficiency is low. Simulations with DELSOL have indicated that if these three changes were made, total power absorbed by the receiver would have been virtually the same as the design value for Solar Two, without significantly exceeding the receiver flux limit. Furthermore, the total reflective area would be the same as the original Solar One field; $71130 \mathrm{~m}^{2}$ rather than $81400 \mathrm{~m}^{2}$. This reduction in field area, for the same receiver power, causes the improvement in collection efficiency shown in Figure 4-8.

The commercial curve entitled "improved startup/cloudy performance" can be achieved by lowering the minimum salt flow at which the receiver can operate from $20 \%$ to $13 \%$ (see Section 4.1.2). This allows the plant to start up and collect useful daily energy at a daily DNI value of 1.5 rather than $2 \mathrm{kWh} / \mathrm{m}^{2}$.

Based on the results presented in Figure 4-8, it can be concluded that because of a degraded heliostat field, the daily energy collection efficiency recorded at Solar Two was significantly below the commercial goal. However, the disparity is fully understood and it appears the commercial goal can be achieved. Solar Two demonstrated the capability of approaching/surpassing a revised "degraded field" goal (Figure 4-6), over the full range of daily insolation conditions, on "several" days towards the end of the project. Resolution of the receiver outage causes displayed in Figure 4-7 would have been required to allow routine achievement of the goal.

\subsubsection{Daily Energy Thermal-to-Electric Conversion Goals versus Actual Experience}

Figure 4-4 indicates that Solar Two routinely met the daily energy conversion goal in the latter months of plant operation. There were two major reasons for this. First, the plant operators began to run the turbine at full output power much more frequently, due to improved plant operations, as well as completion of the dispatchability and SGS characterization tests. Operating the turbine in this way is more thermodynamically efficient than running it at part load. This change in the mode of operation is depicted in Figure 4-9. Second, the energy required to start up the molten-salt steam generator and turbine was significantly reduced. The new startup procedure was developed by ESI in October and implemented in November. The new procedure allowed some of the ESI operating crews to surpass the SOLERGY startup-energy goal of $10 \mathrm{MWh}$. It is believed that, with additional training and run time, all crews would have routinely achieved the 
startup energy goal. This improvement is depicted in Figure 4-10. Combining these two improvements led to an improved daily efficiency of converting thermal energy to electric energy, as shown in Figure 4-11.

In Figure 4-12, the Solar Two and commercial goals for daily thermal-to-electric conversion efficiency are compared. This figure was constructed by converting the Solar Two goal in Figure 4-4 via:

$($ Daily T-to-E Efficiency $)=($ Gross Electricity Generation $) /($ Thermal Energy Sent to Steam Generator).

To allow comparison to the commercial plant, the daily efficiency is plotted as a function of fullload steam generator hours (e.g., the Solar Two x-axis values in Figure 4-12 were constructed by dividing the $\mathrm{x}$-axis values in Figure $4-4$ by the $35 \mathrm{MWt}$ steam generator rating listed in Table 4-1.) The comments below interpret the results presented in Figure 4-12.

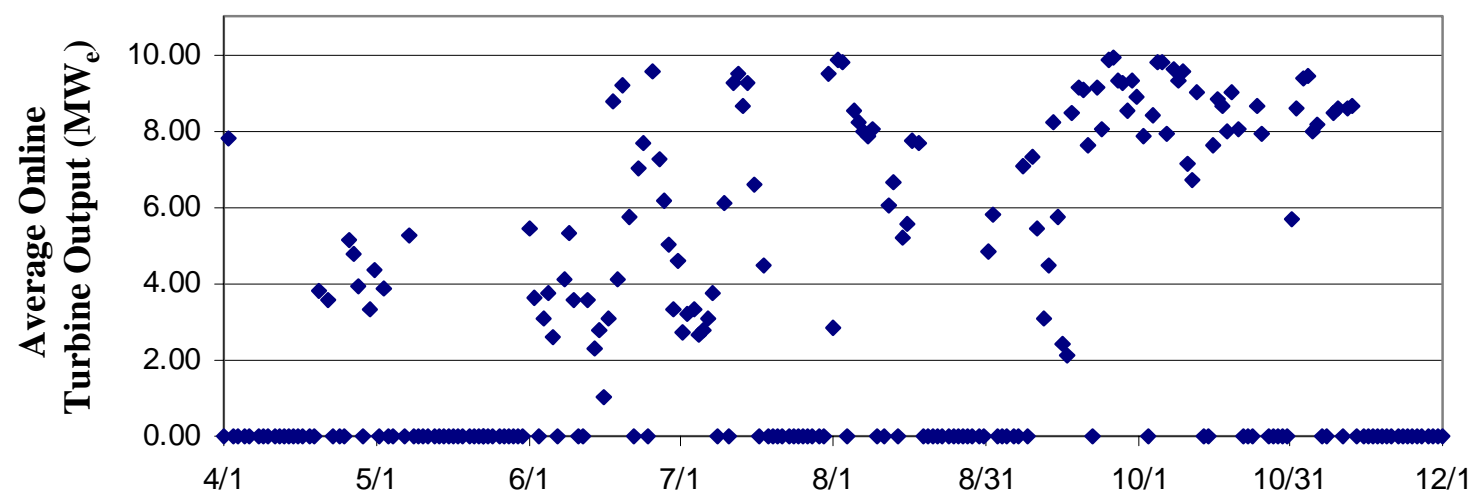

Figure 4-9. Average Turbine Output was Maintained Closer to the $10 \mathrm{MW}$ Rating from Late September to Mid-November.

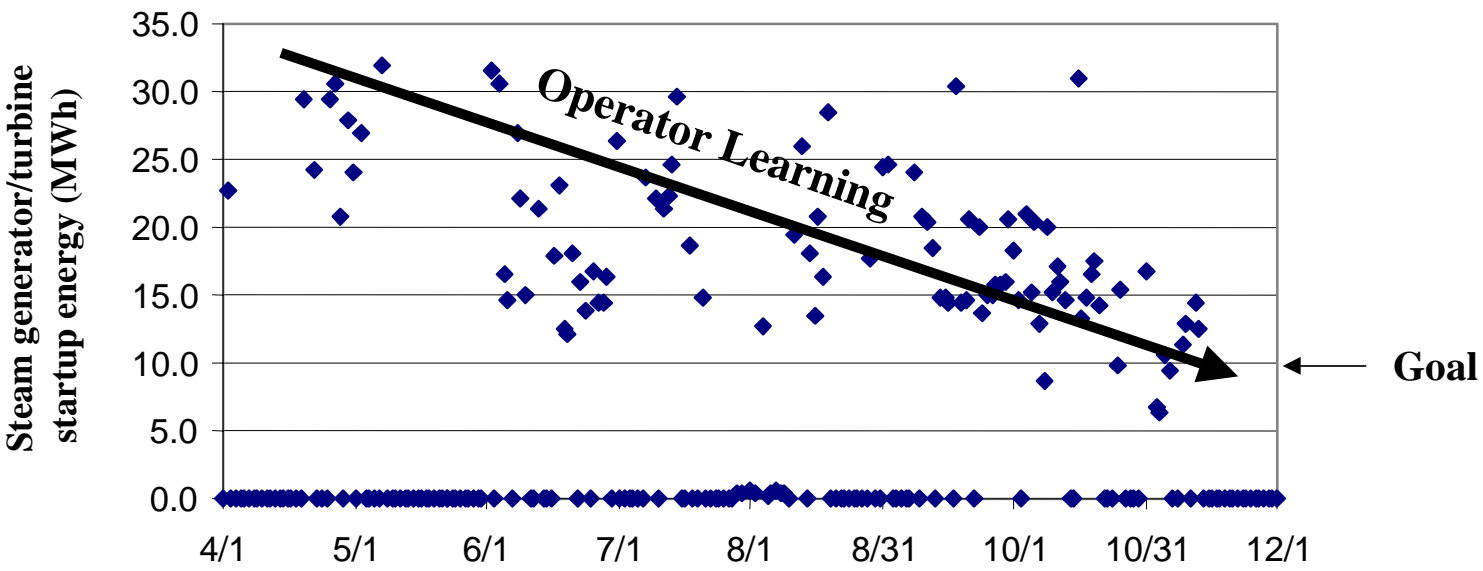

Figure 4-10. It Took Time to Achieve the Startup Energy Goal for the Molten-Salt Steam Generator. 


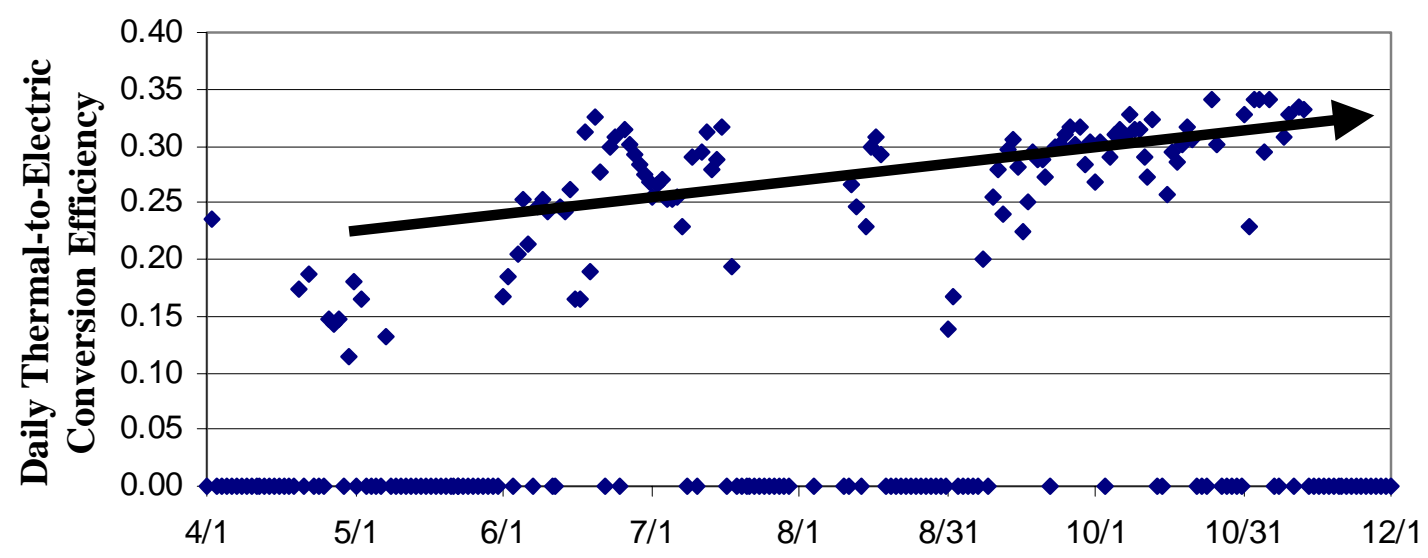

Figure 4-11. Daily Thermal-To-Electric Conversion Efficiency Improved Over Time.

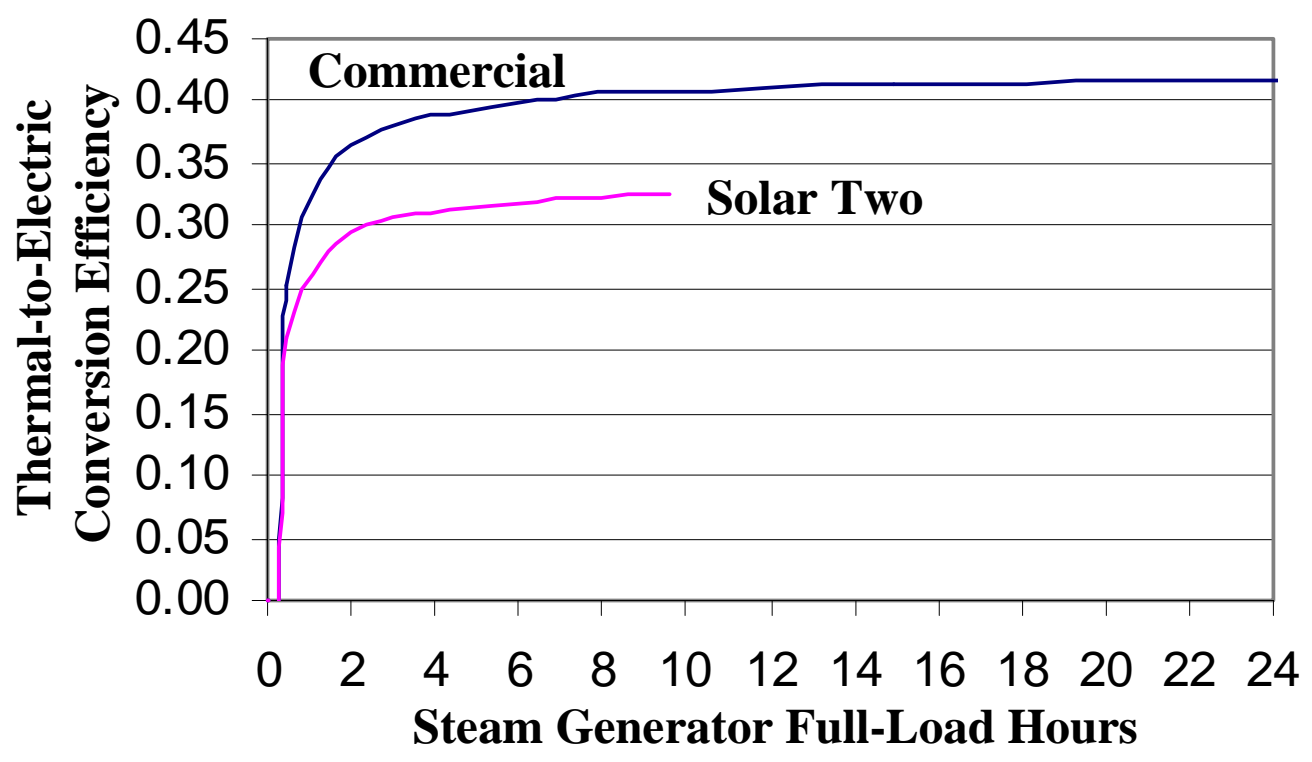

Figure 4-12. Comparison of Daily Thermal-to-Electric Conversion Efficiency Goals.

The commercial goal is significantly higher than Solar Two's because a larger, more efficient steam turbine is used in the commercial plant that also employs steam reheat within the Rankine cycle.

As demonstrated at Solar Two, the energy equivalent of $1 / 3$ of a full-load hour was also assumed to be required to start up the commercial steam generator/turbine.

Because the solar multiple is relatively low at Solar Two, the maximum full-load hours the steam generator could operate during the summer was less than 10 hours/day. In the commercial plant, the solar multiple is significantly increased to allow 24-hours/day operation on summer days. 
Since Solar Two achieved the daily thermal-to-electric conversion goal, there is high confidence the commercial goal can also be reached.

\subsubsection{Daily Parasitic Energy Consumption Goals versus Actual Experience}

Figures 4-5 and 4-13 indicate that plant parasitics dropped significantly in the latter months of the project. This was due to the initiation of parasitic reduction tests on September 25, 1998. Prior to these tests, no significant effort was made at Solar Two to reduce heat-trace parasitics. Heater setpoints were set conservatively high in all circuits (often equal to or above the normal operating temperature of the salt within a pipe), and the heater circuits in the receiver system were not turned off overnight. Consequently, the plant was not being operated in the optimized mode intended by the plant designers, and parasitic usage was very high. The parasitic reduction tests frequently allowed the achievement of the SOLERGY goals for offline and online parasitic energy consumption.

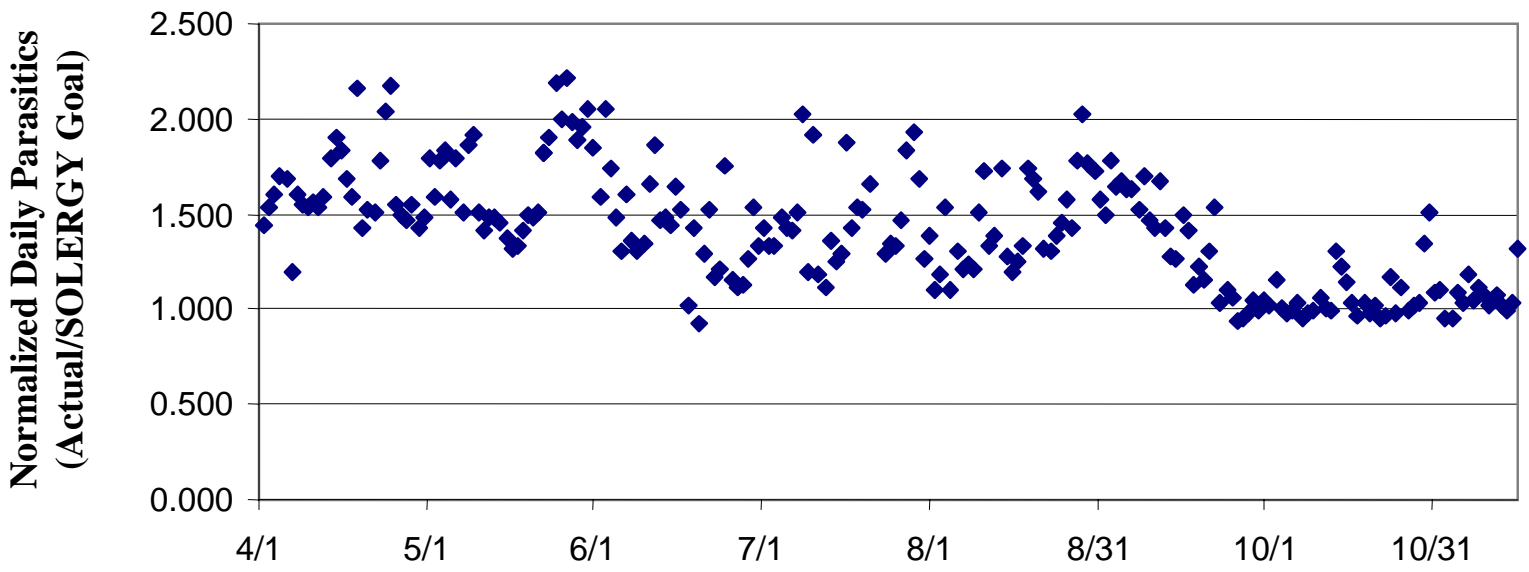

Figure 4-13. The Daily Parasitic Energy Consumption Goal was Routinely Met After Initiating Parasitic Reduction Tests on September 25, 1998.

Parasitics were reduced by turning off unnecessary cooling water pumps, plant lights, and reducing the setpoints of more than 100 heat trace circuits. The tests implemented were relatively benign and considered to be "Phase 1" in nature. Results from Phase 1 suggested that more aggressive Phase 2 tests should be able to improve daily parasitic consumption beyond the results presented here (Pacheco et al., 2001). This would allow the SOLERGY goal to be surpassed and allow parasitic consumption to be similar to that recorded at Solar One. ${ }^{8}$

In Figure 4-14, the Solar Two and commercial goals for daily parasitic consumption efficiency for online days are compared. It was constructed by converting the Solar Two goal in Figure 4-5 via:

8 In late 1987 (towards the end of the power production phase), Solar One typically consumed $\sim 9 \mathrm{MWh}$ on offline days and 17MWh on online days in which $\sim 70 \mathrm{MWh}$ gross was produced. These are about 1 to $2 \mathrm{MWh} / \mathrm{day}$ lower than recorded at Solar Two after the Phase 1 tests for the same type of days (see Figure 4-5). 
$($ Daily Parasitic Efficiency $)=($ Gross - Parasitic Electricity $) /($ Gross Electricity $)=$ Net $/$ Gross .

To allow comparison to the commercial plant, the daily efficiency is plotted as a function of fullload turbine generator hours (e.g., the Solar Two x-axis values in Figure 4-14 were constructed by dividing the $\mathrm{x}$-axis values in Figure $4-5$ by the 10 MWe turbine generator rating listed in Table 4-1.) The comments below interpret the results presented in Figure 4-14.

The commercial parasitic goal is significantly improved relative to Solar Two's because a larger, more efficient steam turbine is used in the commercial plant. Thus, online parasitics in the commercial plant for similar categories of auxiliary equipment within the Rankine cycle are a smaller relative fraction of the gross turbine output (Becker et al., 1993). The commercial turbine also operates for a much longer period every day because of the much higher solar multiple. Thus, offline parasitics will be a much lower fraction of the total gross generation within the commercial plant. Other improvements are also assumed in the commercial plant relative to

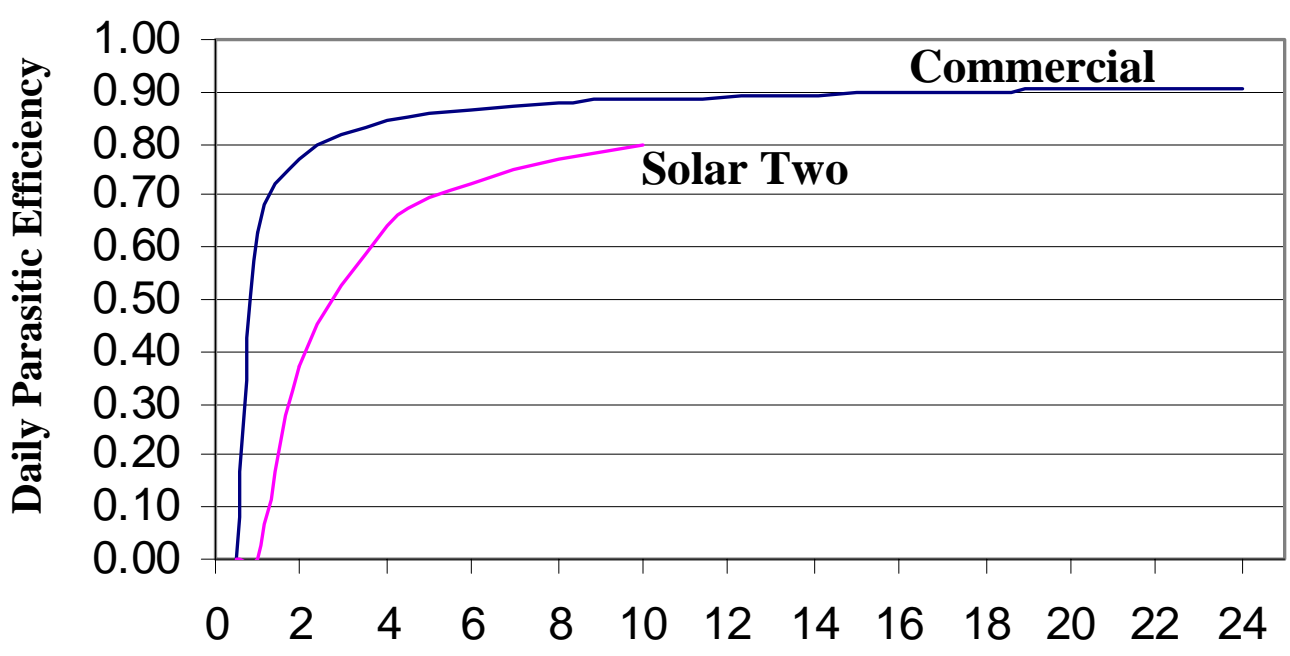

Turbine Generator Full-Load Hours

Figure 4-14. Comparison of Daily Parasitic Efficiency Goals.

Solar Two. For example, the Solar Two (and Solar One) parasitics for the heliostat field were the same during the online and offline period. Current technology will allow the electricity to the field to be turned off during the offline period.

Offline day parasitics at Solar Two were $10 \mathrm{MWh} /$ day during the parasitic reduction tests. Thus, the turbine had to run for one hour to "pay the daily parasitic toll." In the 50 MW commercial plant, offline day parasitics are estimated to be $\sim 16 \mathrm{MWh}$, or about $1 / 3$ of a full-load hour.

Because the solar multiple is relatively low at Solar Two, the maximum full-load hours the turbine generator could operate during the summer was less than 10 hours/day. In the commercial plant, solar multiple is significantly increased to allow 24-hours/day operation on summer days. 
Since Solar Two achieved the daily parasitic efficiency goal, there is high confidence the commercial goal can also be reached.

\subsubsection{Overall Daily Efficiency Goals versus Actual Experience}

In this section, the energy collection, energy conversion, and parasitic energy consumption goals are combined into overall daily goals for converting direct normal insolation into electricity. These goals are plotted in Figures 4-15 and 4-16 on a gross and net basis, respectively. Also plotted is the Solar Two experience recorded in the period from September 25 to November 13, 1998. These days are plotted because during this period the plant was being operated in a semioptimized manner, meaning the steam turbine was run in a more efficient mode (see Figure 4-9 and 4-11) and the initial parasitic reduction test was underway (see Figure 4-13), but the field was degraded and outage problems still persisted.

To put the Solar Two experience in perspective, daily efficiency data recorded at Solar One are also plotted on the same calendar days, but in the year $1985 .{ }^{9}$ It can be seen that the highest achieved daily efficiencies recorded at Solar Two were lower than Solar One. They are lower at Solar Two because of the degraded heliostat field, which has nothing to do with the use of molten salt at Solar Two versus water steam at Solar One.

Because of energy storage, it is possible that not all energy collected on a particular day will be sent to the steam generator and converted to electricity on the same day. At Solar Two, this could happen on days with daily insolation less than $\sim 4 \mathrm{kWh} / \mathrm{m}^{2}$; if there was not enough energy collected to fill the hot salt tank, the operators would not start up the steam generator for a very short operation of the turbine generator, since this would waste startup energy. Nevertheless, the efficiency goal plots assume that all energy collected on a particular day will be sent to the steam generator on the same day. The actual daily efficiency data points from Solar Two were developed by multiplying the individual energy collection, energy conversion, and parasitic efficiencies achieved on a particular day.

The comments below interpret the results presented in Figures 4-15 and 4-16.

- There were three reasons why Solar Two occasionally exceeded the degraded daily goal line: 1) the plant operated for the full day without any of the outage causes listed in Figure 4-7, 2) the heliostat availability (day-long average) slightly exceeded the $90 \%$ degraded daily average goal value by 1 or 2 points, and 3) Solar Two collected more energy on partly cloudy days (i.e., for points between 6 and $7 \mathrm{kWh} / \mathrm{m}^{2}$ ) than the SOLERGY model predicted. The reason for the latter is the demonstrated ability of the receiver flow control system to maintain energy collection in partly cloudy weather (Pacheco et al., 2001). This insight relaxed a conservative "cloudy-weather" assumption in SOLERGY for the calculation of the "improved" commercial goals depicted in the figure.

9 The Solar One efficiencies may be biased high by $2 \%$, e.g., a $13 \%$ gross efficiency may really be $11.7 \%$. During Solar One, the direct normal insolation data was not quality controlled like it was during Solar Two, and evidence suggests the insolation had a low bias (Alpert and Kolb, 1988); this error would result in a higher than actual efficiency estimate at Solar One. 


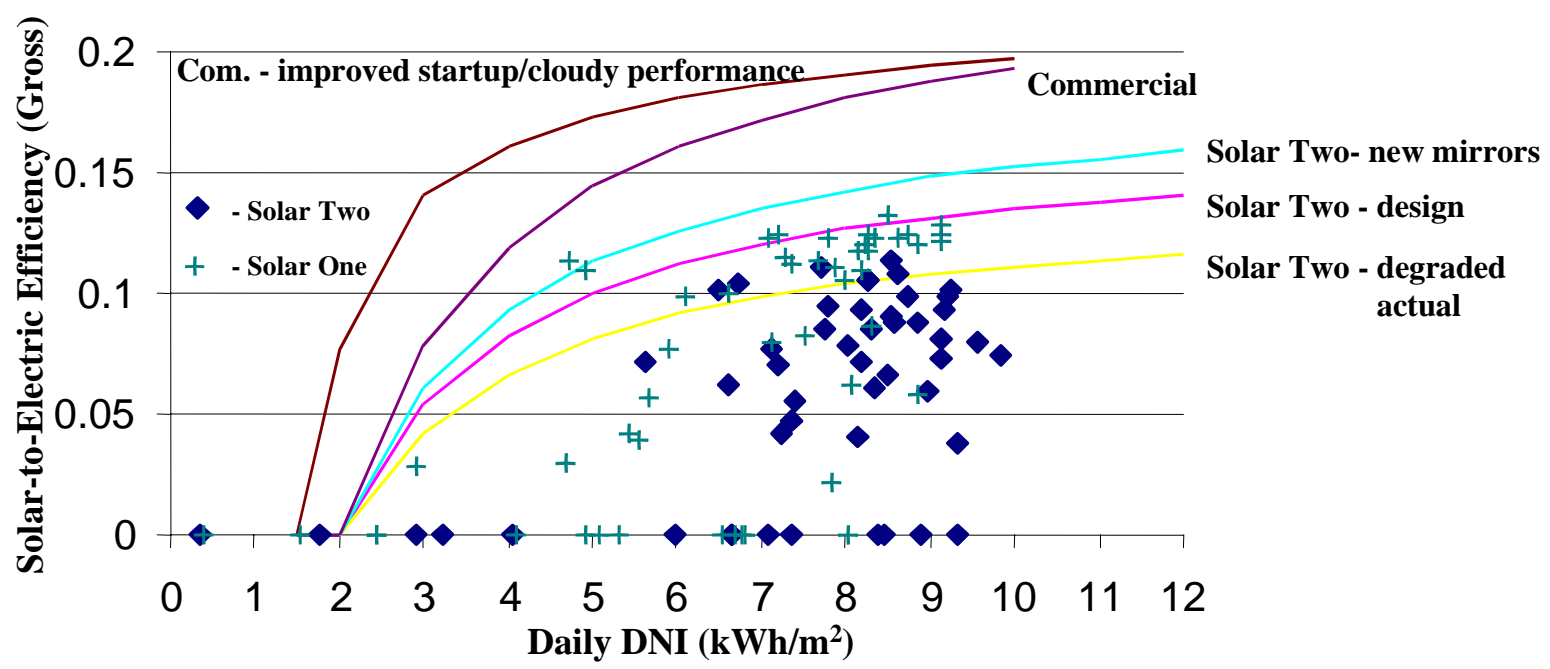

Figure 4-15. Comparison of Daily Solar-to-Electric Conversion Efficiency Goals, on a GROSS Basis, with Actual Experience at Solar One and Solar Two from September 25 to November 13, (1985 at Solar One, 1998 at Solar Two). A degraded heliostat field caused the Solar Two efficiencies to be lower than Solar One's.

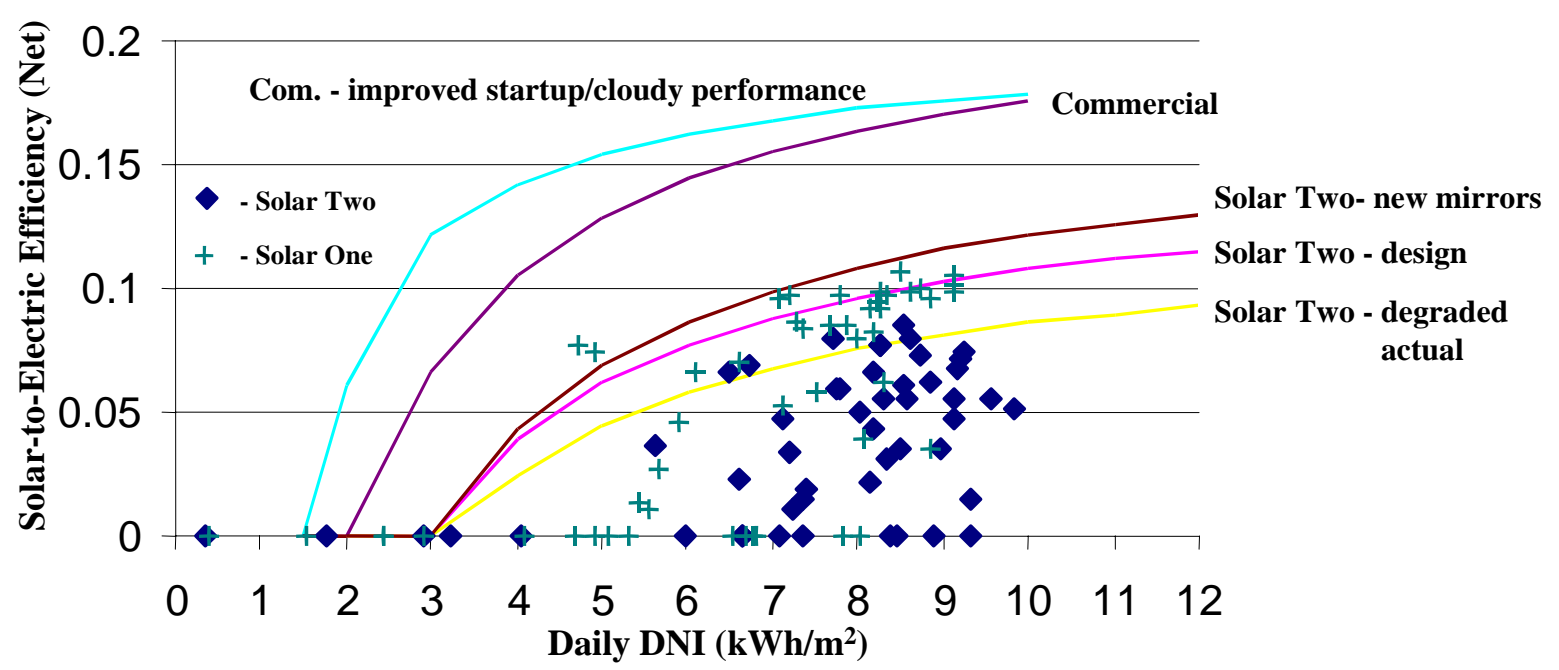

Figure 4-16. Comparison of Daily Solar-to-Electric Conversion Efficiency Goals, on a NET Basis, with Actual Experience at Solar One and Solar Two from September 25 to November 13, (1985 at Solar One, 1998 at Solar Two). A degraded heliostat field and less parasitic optimization at Solar Two caused the Solar Two efficiencies to be lower than Solar One's.

- Because the parasitic and energy conversion efficiencies at Solar Two are significantly worse than the commercial plant, it takes more daily DNI (3 versus $2 \mathrm{~kW} / \mathrm{m}^{2}$ ) for the plant to produce net daily electricity (see $\mathrm{x}$-axis on Figure 4-16).

- As described before, Solar Two data points fall below the degraded goal line because of the outages depicted in Figure 4-7. 
This analysis indicates the daily solar-to-electric conversion efficiency should be significantly higher in the commercial plant than was demonstrated at Solar Two. This would have been true even if the degraded heliostat field were replaced with a state-of-the-art field. To obtain the commercial efficiency, a more efficient Rankine cycle must be installed and electrical parasitics reduced. The latter will be accomplished by increasing solar multiple (i.e., operating at a higher annual capacity factor) and using state-of-the-art equipment that consumes less electricity.

\subsection{Actual Capital Costs versus Commercial Goals}

The TC Report (DOE and EPRI, 1997) provides capital cost estimates for several solar power tower plants with power ratings from 10 to $200 \mathrm{MW}$. The $10 \mathrm{MW}$ case is based on actual experience at Solar Two, but the larger plants are all hypothetical and were based on detailed studies performed by United States utilities and national laboratories (Pacific Gas \& Electric Company, 1988; Becker et al., 1993). The capital costs listed for the hypothetical plants are considered to be goals; once fully achieved, power tower electricity costs will start to become competitive with fossil-based technology (see Figure 1-5).

To facilitate understanding of the Solar Two experience versus the capital cost goals, information from the TC Report has been reformatted and plotted in Figures 4-17 through 4-20. These four curves represent the costs of the four major solar-specific subsystems. Costs for the conventional part of the plant (e.g. steam turbine, master control system, etc.) are not presented because this is mature technology with known costs. The actual Solar Two costs ${ }^{10}$ are plotted, except for the heliostat system. Solar Two heliostat costs are not relevant because most of the heliostats are vintage 1979 technology and new and improved models are available today. To gauge whether we are progressing along the subsystem cost reduction paths, recent cost estimates from the 15MW Solar Tres project are also plotted. The Solar Tres estimates were provided by the same experienced team that built Solar Two. The comments below interpret the results presented in the four figures.

- In Figure 4-17, the cost of the Solar Tres heliostats $\left(\$ 120 / \mathrm{m}^{2}\right)$ is significantly below the heliostat costs assumed for the first post-Solar-Two plant in the TC Report $\left(\$ 180 / \mathrm{m}^{2}\right)$. The field of Solar Tres heliostats $\left(270,000 \mathrm{~m}^{2}\right)$ will be manufactured in Spain, whereas the TC Report assumed manufacture in the United States. The main reasons that Spain's cost is lower is due to the use of relatively inexpensive locally produced mirrors, as well as lower construction-labor costs. Heliostat cost for plants following Solar Tres are expected to drop according to "experience curve theory" (Neij, 1997). Assuming a progress ratio of $0.9,{ }^{11}$ a conservative value for a modular technology like heliostats, the cost of the heliostat field $\left(845,000 \mathrm{~m}^{2}\right)$ for the $50 \mathrm{MW}$ Spanish commercial plant is predicted to be $\$ 100 / \mathrm{m}^{2}$. To achieve the ultimate TC Report goal of $\$ 70 / \mathrm{m}^{2}$ will require a cumulative heliostat build of $\sim 8 \mathrm{E} 6 \mathrm{~m}^{2}$, or approximately nine $50 \mathrm{MW}$ commercial plants, in the Spanish deployment scenario.

$10 \$ 1.5 \mathrm{M}$ was added to the actual Solar Two receiver cost to account for the tower inherited from Solar One.

11 A progress ratio of 0.9 means that for every doubling of cumulative heliostat production, capital costs will be $90 \%$ of the previous capital cost. Progress ratios reported in the literature (Neij, 1997) typically range from 0.7 to 0.95 . 


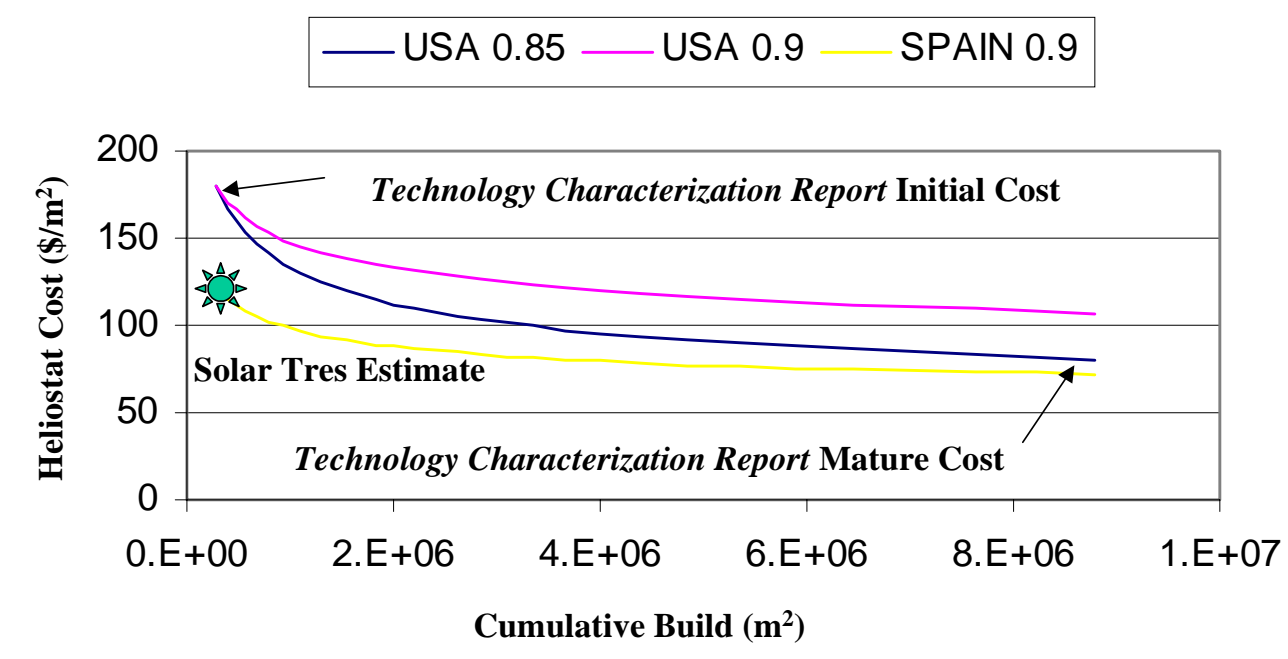

Figure 4-17. Heliostat Costs versus Cumulative Heliostats Built.

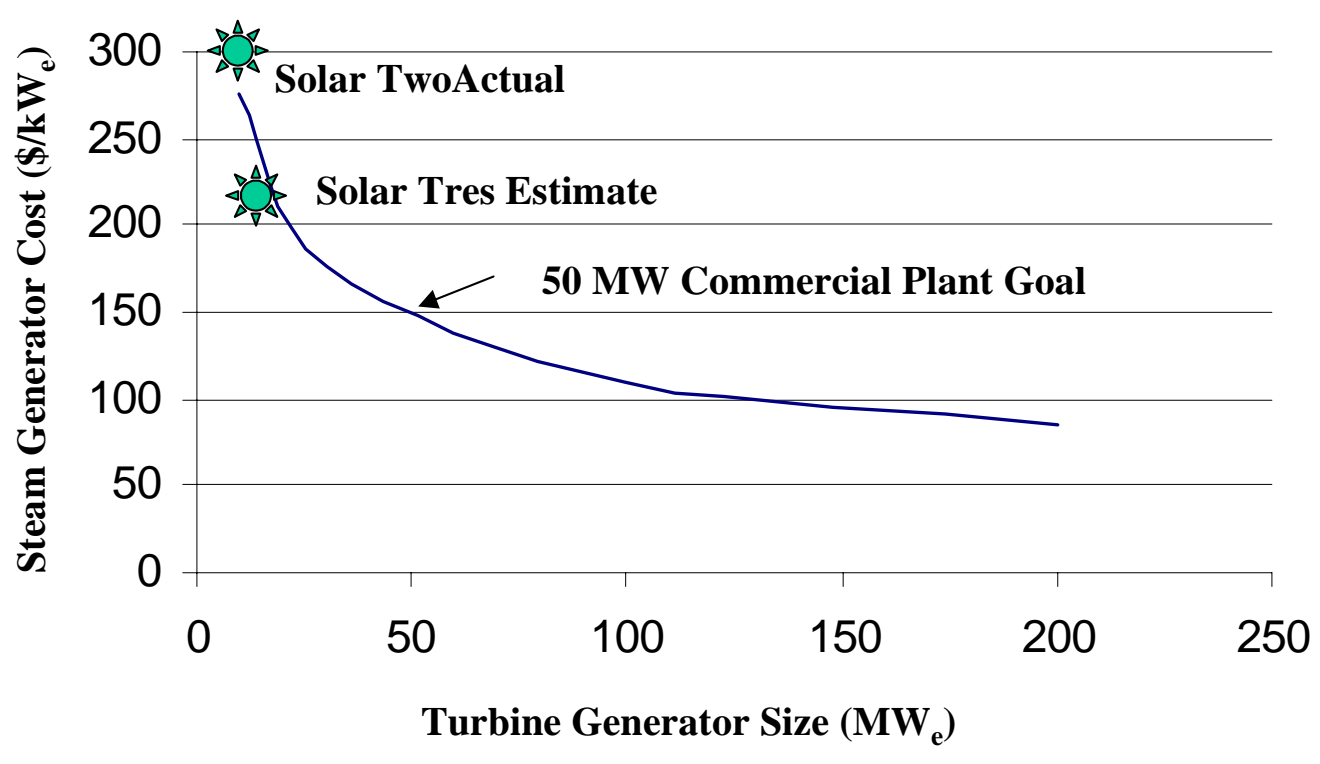

Figure 4-18. Molten-Salt Steam Generator Cost versus Turbine Generator Size. 


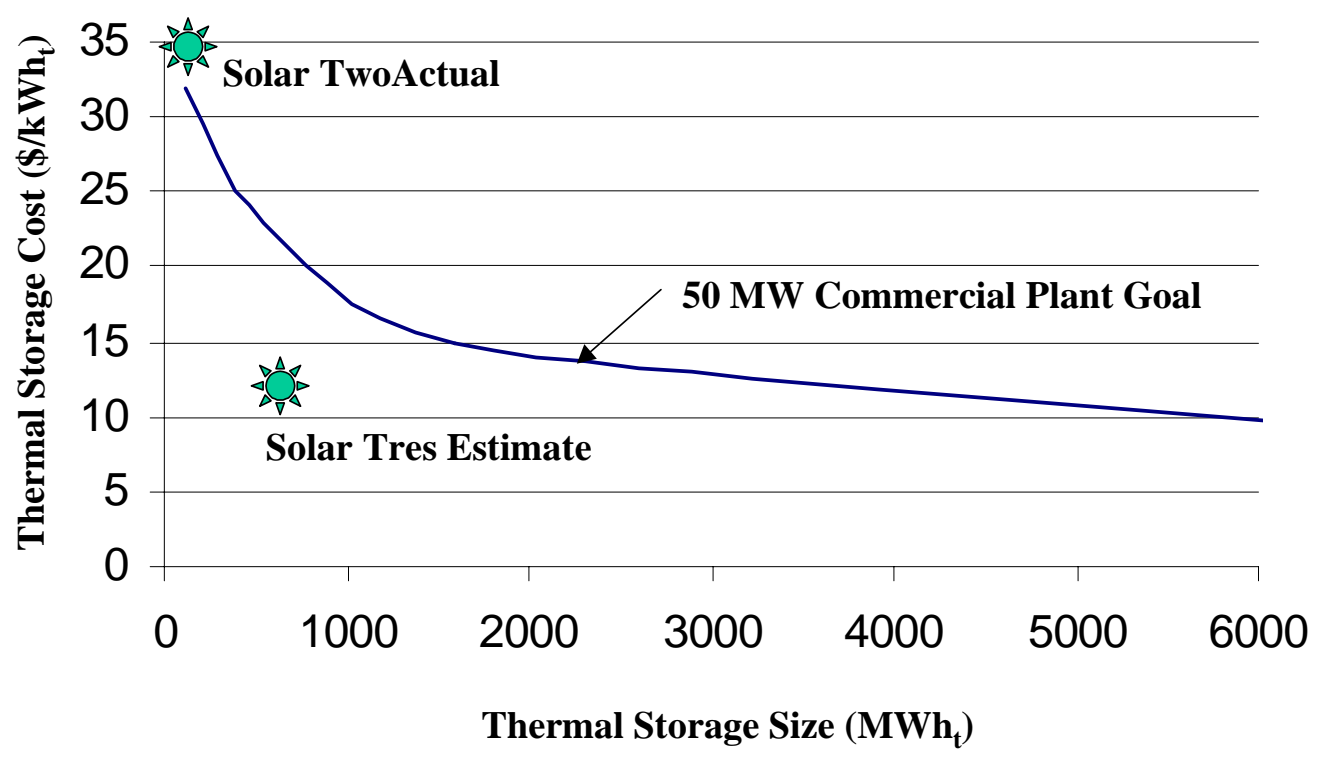

Figure 4-19. Molten-Salt Storage Cost versus Storage Size.

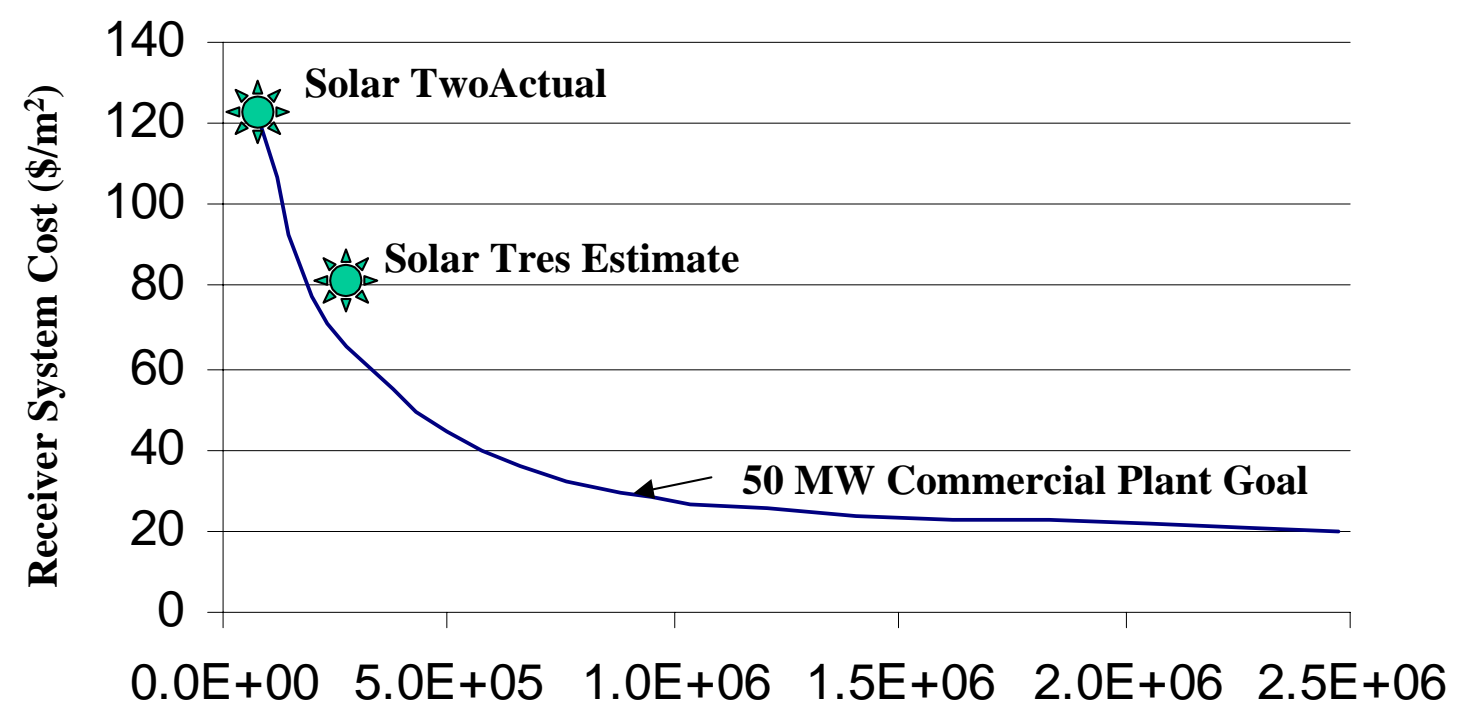

\section{Heliostat Field Area $\left(\mathbf{m}^{2}\right)$}

Figure 4-20. Receiver System Cost Versus Heliostat Field Size.

- In Figure 4-18, the cost of the Solar Tres steam generator is slightly below the TC Report goal. The improvement in cost at Solar Tres relative to Solar Two is primarily due to an improved turbine-generator efficiency at Solar Tres; the gross efficiency of the Solar Tres turbine is $41 \%$ versus $33 \%$ at Solar Two. Because of the improved turbine efficiency, the thermal rating of the Solar Tres steam generator is maintained at approximately the same size 
and cost as Solar Two's (35 to $37 \mathrm{MW}_{\mathrm{t}}$ and $\sim \$ 3 \mathrm{M}$ ). However, steam from the Solar Tres steam generator produces $15 \mathrm{MW}_{\mathrm{g}}$, whereas Solar Two's only produces $11.5 \mathrm{MW}_{\mathrm{g}}$.

- In Figure 4-19, the cost of the Solar Tres thermal storage system is significantly below the TC Report goal. On a $\$ / \mathrm{kWh}_{\mathrm{t}}$ basis, the cost of thermal storage at Solar Tres is significantly below Solar Two's because of economies of scale associated with the cost of the tanks. Although the cost of the salt scales linearly with the amount used, the cost of the tanks is significantly less, on a per volume basis, for the much larger tanks proposed for Solar Tres.

- The Solar Tres receiver cost depicted in Figure 4-20 is about 20\% above the TC Report cost goal, suggesting that additional design simplification will be necessary to meet the cost goal established for the commercial plant.

The total solar-specific costs of Solar Tres and the TC Report goal for a plant of this size are compared in Table 4-5. It can be seen that Solar Tres is significantly below the total cost goal, a good omen for the future of power tower technology.

Table 4-5. Solar-Specific Subsystem Costs of Solar Tres versus TC Report Goals

\begin{tabular}{|l|c|c|}
\hline \multicolumn{1}{|c|}{ Subsystem } & 15 MW Solar Tres & TC Report Goal \\
\hline Heliostats & $33 \mathrm{M}$ & $49 \mathrm{M}$ \\
\hline Receiver & $22 \mathrm{M}$ & 18 \\
\hline Thermal Storage & $7 \mathrm{M}$ & 13 \\
\hline Steam Generator & $3.2 \mathrm{M}$ & 3.6 \\
\hline Total Subsystem Cost & $65.2 \mathrm{M}$ & $83.6 \mathrm{M}$ \\
\hline
\end{tabular}

Power towers must be fairly large to be economically preferred over parabolic trough technology. This statement can be supported by comparing the capital cost information presented in Figure 4-17 and 4-20 with similar data for parabolic troughs. For example, the trough field within a next generation plant is expected to cost $\sim 220 / \mathrm{m}^{2}$ (Pilkington Solar International, 1996) for a plant with a total field area about the size of Solar Tres $\left(\sim 270,000 \mathrm{~m}^{2}\right)$. The trough field cost includes the mirror reflectors, as well as the solar receivers. To compare this value with a power tower, one must combine the heliostat and receiver costs in Figures 4-17 and 4-20 for a plant with a similar solar field size. For the Solar Tres plant, this is $\sim \$ 200 / \mathrm{m}^{2}$. This suggests that power towers start to have a small economic advantage over troughs for this size plant (assuming that energy performance is approximately the same, a good first-order assumption for this size plant). However, information in the TC Report suggests that for much larger plants, the economics of power towers are significantly preferred over troughs.

\subsection{Actual O\&M Cost versus Commercial Goals}

Solar Two did not operate long enough to demonstrate the O\&M cost goal of $\$ 3 \mathrm{M} / \mathrm{yr}$ established for the project. The goal was to be achieved during the third year of plant operation by the O\&M company, ESI, after plant testing was completed and after O\&M activities were optimized. If the 
\$3M goal could be demonstrated, the TC Report projects that O\&M cost goals for larger commercial plants could also be achieved. Due to the significant delay caused by design- and construction-related problems, ESI took control of Solar Two from Bechtel in February 1998 and only ran the plant on a 7-day per week basis from then until early November 1998. To extend the calendar time as long as possible, beginning in early November, ESI ran the plant five days per week and employed a skeleton maintenance crew. Thus, the O\&M costs billed by ESI from November forward were not relevant to demonstrating the O\&M cost goals for Solar Two.

ESI's planned budget for the first year of operation, beginning in March 1998, was \$3.8M with expenditures front-loaded during the year. To achieve the $\$ 3.8 \mathrm{M}$ first year target, ESI planned to bill the project at a $\$ 4 \mathrm{M} / \mathrm{yr}$ average rate during the first eight months and a $\$ 3.3 \mathrm{M} / \mathrm{yr}$ average rate during the last four months. Going into year two, the $\$ 3.3 \mathrm{M} / \mathrm{yr}$ rate would be approaching the O\&M cost goal. The actual experience was that ESI billed the project at an average annual rate of $\$ 5 \mathrm{M} / \mathrm{yr}$ during the first eight months, i.e. this rate was $25 \%$ above budget. Possible reasons for going overbudget during this time include two unanticipated major outages in May and August, to replace a receiver panel and to inspect the hot tank, respectively (Pacheco et al., 2001).

O\&M cost at Solar Two was similar to that incurred at Solar One during a similar phase of the project. During the eight-month period, Solar Two was in its test and evaluation phase. Table 4-6 shows that the number of people employed at Solar Two during test and evaluation was consistent with the Solar One experience during the same period. Solar One ultimately achieved $>40 \%$ reduction in O\&M staff during its mature power production years after testing was completed and O\&M operations were optimized. Another conclusion one can draw from Table 4-6 is that O\&M of Solar One is similar to SEGS I. SEGS I is a solar trough plant that has virtually the same solar field size and turbine size as Solar One/Two. Thus, the O\&M costs for solar tower and solar trough technology are expected to be comparable.

The manpower estimates for the commercial plant (Solar 100) ${ }^{12}$ in Table 4-6 were independently provided by ESI and Bechtel during the summer of 1998 and were based on the limited experience at Solar Two. It can be seen that Bechtel's overall manpower estimate is more aggressive than ESI's and that the job categories of the O\&M crew are somewhat different. Comparing these estimates with the experience at the 80 MW SEGS VIII and IX plants ( 40 to 50 total O\&M crew) again suggests that the O\&M of trough and tower projects of similar size should be about the same.

In Table 4-7, the total O\&M cost for the commercial plant, which includes the Table 4-6 manpower estimates, is presented. It can be seen that personnel cost is the only significant difference between the ESI and Bechtel estimate. ESI's personnel cost is higher because nine more people are employed and the average salary paid is $\$ 22 \mathrm{~K}$ more per person, i.e., $\$ 93 \mathrm{~K}$ versus $\$ 71 \mathrm{~K} / \mathrm{yr}$. Bechtel's cost is lower because they assume a non-union labor force is used, unlike ESI. Assuming the same annual electricity production as in the TC Report, the O\&M costs for ESI and

12 The solar design of the $50 \mathrm{MW}$ commercial plant for Spain is similar to the $100 \mathrm{MW}$ commercial plant described in the TC Report. The size of the heliostat field, receiver, and storage tanks are similar. The Spanish plant has a smaller steam generator to work with the smaller steam turbine. 
Bechtel are 1.7 and 1.2 cents/kWh, respectively. The O\&M cost goal for the Solar 100 plant is 1.3 cents (DOE \& EPRI, 1997).

\subsection{Actual Electricity Dispatch versus Commercial Goals}

Solar Two was designed to have three hours of storage. However, some of the required salt was not shipped to the site. Consequently, storage volume was $\sim 10 \%$ below the design value, which affected the ability to demonstrate that full load generation (10 MW) could be shifted for a full three hours. However, the plant routinely demonstrated that power could be delivered to the utility grid when desired, even at night. Listed in Table 4-8 are several days of actual data from the plant.

During two tests (first two entries in Table 4-8), attempts were made to keep the turbine connected to the grid as long as possible. For example, during the July run, the plant continuously delivered power to the SCE grid for 6.5 days. Operation through the night was accomplished by reducing turbine output power to levels that were well below the $10 \mathrm{MW}$ rating, thus lengthening the storage time. This test demonstrated that it should be possible for a solar-only plant to achieve a high annual capacity factor if the solar field is oversized (up to a solar multiple of 3) and the number of hours of storage is increased (up to 15 hours, as described in Figure 1-2). Unlike Solar Two, the turbine from this plant could be maintained at nearly design rating during the overnight period. The SOLERGY code predicts that $\sim 70 \%$ capacity factor would be possible for such a plant. A high annual capacity factor was not possible at Solar Two because of the low solar multiple (1.1) and because there were only $\sim 3$ hours of storage. Operating Solar Two around the clock was not efficient because the average turbine power was very low; as discussed previously, the most efficient method of operating the plant was to maintain the turbine near its $10 \mathrm{MW}$ design rating (Figures 4-9 and 4-11).

From mid-September to mid-November (remaining entries in Table 4-8), Solar Two began to deliver electricity to the SCE grid in a nearly optimal way. The optimal method is defined as delivering full-turbine-output power (10 MW) to the grid during SCE's peak period, noon to $6 \mathrm{pm}$. To accomplish this method, the hot storage tank was empty (i.e. at the $3 \mathrm{ft}[0.9 \mathrm{~m}]$ "heel level") at the start of the day and was subsequently filled with hot salt during morning operation of the receiver. At $\sim 10: 30$ am, the operators began to start up the steam generator so that the turbine could be brought online shortly before noon and ramped to full at noon. In this operating scenario, the hot tank level peaks at $\sim 75 \%$ shortly after achieving full turbine output, and gradually declines after that until it is emptied at the end of the operating day, which typically occurred near the end of the peak period in the fall months. This type of operating mode is depicted in Figure 4-21.

Examining Table 4-8, it can be seen that the Solar Two operators approached this optimum strategy on most days; the hot tank was nearly empty at the beginning of the day and nearly full turbine output was delivered during the six-hour peak period. However, on several days, the turbine was operated for significantly less than six hours; the reasons for the shortfalls were generally due to problems that caused a plant outage for a portion of a day (see Figure 4-7). 
Table 4-6. Comparison of O\&M Staffing

\begin{tabular}{|c|c|c|c|c|c|c|}
\hline Staff & $\begin{array}{c}10 \mathrm{MW} \\
\text { Solar Two } \\
\text { T\&E }\end{array}$ & $\begin{array}{c}10 \mathrm{MW} \\
\text { Solar One } \\
\text { T\&E }\end{array}$ & $\begin{array}{l}10 \text { MW Solar } \\
\text { One Power } \\
\text { Operation }\end{array}$ & $\begin{array}{c}13 \text { MW SEGS } \\
1 \text { Power } \\
\text { Operation }\end{array}$ & $\begin{array}{c}\text { Solar } 100 \\
\text { (ESI) }\end{array}$ & $\begin{array}{l}\text { Solar } 100 \\
\text { (Bechtel) }\end{array}$ \\
\hline Plant Manager & 1 & 1 & 0 & 1 & 1 & 1 \\
\hline Secretary & 2 & 1 & 0 & 1 & 2 & 1 \\
\hline Operations Manager & 1 & 0 & 1 & 0 & 1 & 1 \\
\hline Senior Operators & 5 & 4 & 0 & 2 & 5 & 4 \\
\hline Control Operators & 4 & 9 & 10 & 5 & 5 & 4 \\
\hline Plant Equipment Operators & 0 & 4 & 2 & 0 & 5 & 4 \\
\hline $\begin{array}{l}\text { Assistant Plant Equipment } \\
\text { Operators }\end{array}$ & 0 & 0 & 0 & 0 & 0 & 4 \\
\hline $\begin{array}{l}\text { Maintenance Supervisor } \\
\text { (or O\&M) }\end{array}$ & 3 & 2 & 1 & 1 & 6 & 1 \\
\hline Electricians & 0 & 1 & 1 & 0 & 0 & 2 \\
\hline $\begin{array}{l}\text { Instrument Technicians (or } \\
\text { I\&E) }\end{array}$ & 7 & 4 & 2 & 2 & 5 & 2 \\
\hline Mechanics & 0 & 2 & 1 & 4 & 5 & 2 \\
\hline Machinest/Welder & 2 & 1 & 0 & 1 & 1 & 1 \\
\hline Warehouse Clerk & 1 & 1 & 0.5 & 1 & 2 & 1 \\
\hline Equipment Mechanic & 0 & 0 & 0 & 0 & 0 & 1 \\
\hline $\begin{array}{l}\text { Heliostat Washers (utility } \\
\text { man) }\end{array}$ & 3 & 0 & 0 & 1 & 0 & 6 \\
\hline Engineering & 3 & 1 & 0.5 & 1 & 5 & 1 \\
\hline Chemical Technician & 1 & 1 & 0.5 & 0 & 1 & 1 \\
\hline Security & 1 & 1 & 0 & 0 & 1 & 0 \\
\hline Clerk Supervisor & 1 & 0 & 0 & 1 & 1 & 0 \\
\hline Test \& Evaluation Manager & 1 & 1 & 0 & 0 & 0 & 0 \\
\hline TOTAL & 36 & 34 & 19.5 & 21 & 46 & 37 \\
\hline
\end{tabular}

Table 4-7. Comparison of Total O\&M Cost for Commercial Plant

\begin{tabular}{|l|c|c|}
\hline \multicolumn{1}{|c|}{ Cost Category } & Solar $100(\mathrm{ESI})$ & Solar $\mathbf{1 0 0}$ (Bechtel) \\
\hline Personnel & $\$ 4300 \mathrm{~K}$ & $\$ 2640 \mathrm{~K}$ \\
\hline Service Contracts & $\$ 715 \mathrm{~K}$ & $\$ 631 \mathrm{~K}$ \\
\hline Spare Parts and Equipment & $\$ 774 \mathrm{~K}$ & $\$ 774 \mathrm{~K}$ \\
\hline Miscellaneous & $\$ 289 \mathrm{~K}$ & $\$ 253 \mathrm{~K}$ \\
\hline TOTAL & $\$ 6091 \mathrm{~K}$ & $\$ 4294 \mathrm{~K}$ \\
\hline
\end{tabular}


Table 4-8. Examples of Electricity Dispatch from Solar Two

\begin{tabular}{|c|c|c|c|c|c|c|}
\hline Date & $\begin{array}{c}\text { On-line } \\
\text { Time (h:m) }\end{array}$ & $\begin{array}{c}\text { Avg } \\
\text { Power } \\
\text { (MW) }\end{array}$ & $\begin{array}{l}\text { Hot Tank } \\
\text { Level Start } \\
\text { (ft) }\end{array}$ & $\begin{array}{l}\text { Hot Tank } \\
\text { Level End } \\
\text { (ft) }\end{array}$ & $\begin{array}{l}\text { Turb Start } \\
\text { (h:m) }\end{array}$ & $\begin{array}{l}\text { Turb End } \\
\text { (h:m) }\end{array}$ \\
\hline $6 / 13-6 / 16 / 98$ & $69: 42$ & 2.51 & 5.0 & 4.0 & $6 / 13 \quad 12: 43$ & $6 / 16 \quad 10: 25$ \\
\hline $7 / 1-7 / 7 / 98$ & $152: 16$ & 3.11 & 13.6 & 4.1 & $7 / 1 \quad 10: 17$ & $7 / 7 \quad 18: 33$ \\
\hline $9 / 18$ & $8: 29$ & 8.49 & 11.0 & 3.6 & $10: 06$ & $18: 35$ \\
\hline $9 / 19$ & $4: 03$ & 9.10 & 3.7 & 3.6 & $15: 48$ & $19: 51$ \\
\hline $9 / 20$ & $4: 20$ & 9.04 & 3.6 & 3.6 & $15: 10$ & $19: 31$ \\
\hline $9 / 21$ & $4: 32$ & 7.60 & 3.4 & 3.6 & $15: 13$ & $19: 46$ \\
\hline $9 / 23$ & $6: 26$ & 9.15 & 3.6 & 3.6 & 13:05 & $19: 32$ \\
\hline $9 / 24$ & $5: 13$ & 8.06 & 3.6 & 3.6 & $15: 00$ & $20: 14$ \\
\hline $9 / 25$ & $5: 50$ & 9.82 & 3.6 & 3.6 & $12: 24$ & $18: 15$ \\
\hline $9 / 26$ & $6: 41$ & 9.94 & 3.6 & 3.6 & $11: 57$ & $18: 38$ \\
\hline $9 / 27$ & $4: 15$ & 9.31 & 3.7 & 3.4 & $12: 09$ & $16: 24$ \\
\hline $9 / 28$ & 7:02 & 9.26 & 3.4 & 3.4 & $12: 07$ & 19:09 \\
\hline $9 / 29$ & $3: 50$ & 8.51 & 3.4 & 6.2 & $12: 23$ & $16: 14$ \\
\hline $9 / 30$ & $6: 43$ & 9.31 & 6.1 & 3.2 & $12: 30$ & $19: 14$ \\
\hline $10 / 1$ & $2: 51$ & 8.89 & 3.2 & 3.6 & $21: 16$ & 0:08 \\
\hline $10 / 2$ & $7: 19$ & 7.85 & 3.5 & 3.3 & $12: 20$ & $19: 40$ \\
\hline $10 / 4$ & $5: 51$ & 8.38 & 3.4 & 3.3 & $13: 49$ & $19: 40$ \\
\hline $10 / 5$ & $5: 41$ & 9.76 & 3.4 & 3.7 & $13: 03$ & $18: 44$ \\
\hline $10 / 6$ & $7: 15$ & 9.78 & 3.7 & 3.5 & $11: 40$ & $18: 55$ \\
\hline $10 / 7$ & $6: 33$ & 7.93 & 3.4 & 3.5 & $11: 35$ & $18: 08$ \\
\hline $10 / 8$ & $7: 41$ & 9.59 & 3.4 & 3.6 & $11: 37$ & $19: 18$ \\
\hline $10 / 9$ & $7: 10$ & 9.29 & 3.5 & 3.6 & $11: 04$ & $18: 38$ \\
\hline $10 / 10$ & $5: 46$ & 9.56 & 3.5 & 3.4 & $11: 36$ & $18: 42$ \\
\hline $10 / 11$ & $6: 04$ & 7.12 & 3.3 & 3.1 & $12: 37$ & $18: 41$ \\
\hline $10 / 12$ & $4: 26$ & 6.71 & 3.2 & 3.6 & $11: 24$ & $15: 51$ \\
\hline $10 / 13$ & $7: 48$ & 9.03 & 3.7 & 3.1 & $11: 42$ & $19: 30$ \\
\hline $10 / 14$ & $0: 00$ & 0.00 & 3.2 & 14 & $\mathrm{~N} / \mathrm{A}$ & $\mathrm{N} / \mathrm{A}$ \\
\hline $10 / 16$ & $4: 50$ & 7.59 & 13.9 & 3.6 & $6: 51 / 21: 53$ & $8: 41 / 24: 53$ \\
\hline $10 / 17$ & $4: 25$ & 8.83 & 3.6 & 3.5 & $14: 36$ & 19:01 \\
\hline $10 / 18$ & $6: 40$ & 8.65 & 3.4 & 3.4 & $12: 24$ & $19: 05$ \\
\hline $10 / 19$ & $5: 46$ & 7.96 & 3.3 & 3.5 & $11: 47$ & $19: 03$ \\
\hline
\end{tabular}


Table 4-8. Examples of Electricity Dispatch from Solar Two (continued)

\begin{tabular}{|c|c|c|c|c|c|c|}
\hline Date & $\begin{array}{c}\text { On-line } \\
\text { Time (h:m) }\end{array}$ & $\begin{array}{c}\text { Avg } \\
\text { Power } \\
\text { (MW) }\end{array}$ & $\begin{array}{c}\text { Hot Tank } \\
\text { Level Start } \\
\text { (ft) }\end{array}$ & $\begin{array}{c}\text { Hot Tank } \\
\text { Level End } \\
\text { (ft) }\end{array}$ & $\begin{array}{c}\text { Turb Start } \\
\text { (h:m) }\end{array}$ & $\begin{array}{c}\text { Turb End } \\
\text { (h:m) }\end{array}$ \\
\hline $10 / 20$ & $7: 17$ & 9.01 & 3.5 & 3.6 & $11: 36$ & $18: 53$ \\
\hline $10 / 21$ & $5: 54$ & 8.07 & 3.5 & 6.1 & $12: 20$ & $18: 14$ \\
\hline $10 / 25$ & $5: 34$ & 8.67 & 8.5 & 5.2 & $10: 12$ & $15: 47$ \\
\hline $10 / 26$ & $3: 02$ & 7.94 & 5.1 & 6.0 & $12: 24$ & $15: 27$ \\
\hline $11 / 1$ & $11: 52$ & 5.67 & 17.4 & 3.9 & $5: 22$ & $17: 14$ \\
\hline $11 / 2$ & $2: 55$ & 8.60 & 3.9 & 5.2 & $14: 52$ & $17: 48$ \\
\hline $11 / 3$ & $6: 47$ & 9.36 & 5.1 & 4.9 & $10: 42$ & $17: 29$ \\
\hline $11 / 4$ & $6: 34$ & 9.43 & 5.0 & 5.0 & $10: 42$ & $17: 26$ \\
\hline $11 / 5$ & $2: 34$ & 7.97 & 5.0 & 3.2 & $15: 17$ & $17: 52$ \\
\hline $11 / 6$ & $5: 43$ & 8.17 & 3.2 & 5.4 & $11: 24$ & $17: 08$ \\
\hline $11 / 9$ & $2: 40$ & 8.49 & 5.5 & 3.1 & $15: 22$ & $18: 02$ \\
\hline $11 / 10$ & $3: 40$ & 8.56 & 3.1 & 3.7 & $14: 18$ & $17: 59$ \\
\hline $11 / 12$ & $5: 39$ & 8.58 & 3.8 & 3.4 & $11: 55$ & $17: 34$ \\
\hline $11 / 13$ & $3: 54$ & 8.62 & 3.5 & 5.0 & $13: 52$ & $17: 46$ \\
\hline
\end{tabular}

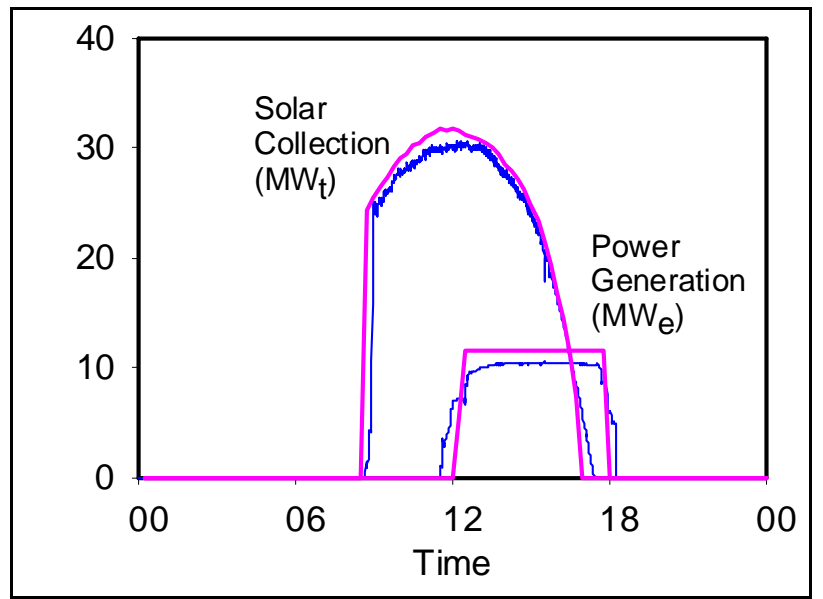

Figure 4-21. Actual Solar Energy Collection and Electricity Delivery at Solar Two (blue) versus SOLERGY Prediction (pink).

Energy storage gave Solar Two significant flexibility in the method of turbine operation. Besides demonstrating $24 \mathrm{hr} /$ day operation, as well as supplying reliable peaking power, the plant was also capable of collecting solar energy on one day, saving that energy and producing electricity from the energy a few days later. Referring again to Table 4-8, it can be seen that on October $14^{\text {th }}$, the receiver operated and filled the hot tank to a level of $14 \mathrm{ft}(4.27 \mathrm{~m})(\sim 60 \%$ full), but the turbine was not placed in operation. The next day (Oct. $15^{\text {th }}$, not shown) the receiver did 
not operate due to inclement weather and the operators again decided to not run the turbine. However, on October $16^{\text {th }}$, the operators finally decided to run the turbine during two different time periods, for $\sim 2$ hours in the early morning and for three hours late at night. 


\section{Summary and Conclusions}

As this report illustrates, the Solar Two project worked through many problems-a reality not unexpected for a large-scale, demonstration project-and demonstrated that no showstoppers exist for the technology. By demonstrating molten-salt power tower technology at a large scale, many lessons were learned, some lessons were relearned from small-scale experiments, and the path was laid for the first commercial implementation of the technology.

It is common for unforeseen problems to occur at large-scale demonstration projects. (It is also common for these problems to be resolved in successive plant builds; the SEGS plants demonstrated this progression in the 1980s for a similar solar thermal technology.) In the case of Solar Two, it is clear that retrofitting 1970s vintage hardware to reduce project costs led to even more problems than a typical first prototype plant would experience. Problems and delays consumed much of the Solar Two budget, preventing Solar Two from reaching the mature, highly reliable operation achieved during the Solar One project.

Section 4 of this report includes a comparison of power tower commercial technology cost goals (as documented in the Technology Characterization report (DOE and EPRI, 1997)) to actual experience at Solar Two. Data collected from the Solar Two project suggest that the electricity cost goals established for power towers are reasonable and can be achieved with some simple design improvements.

Solar Two achieved a number of technology validations. Solar Two:

- Validated the design, performance, and operation of a large-scale molten-salt receiver system;

- Demonstrated the use of bulk quantities of commercial-grade molten salt in a viable, lowcost, highly efficient thermal energy storage system; and

- Demonstrated the electricity dispatch capability of a molten-salt power tower by routinely producing electricity when the sun wasn't shining_after dark, even 24 hours/day.

During and after Solar Two, partnerships have continued within industry and between Sandia National Laboratories and industry. These partnerships have led to a number of advances, including the following:

- Nexant (a new subsidiary of Bechtel) and Ghersa, a Spanish company, formed Solar Tres, S.L., a partnership to develop power towers in Spain. The partnership anticipates the first plant to be a 15 MWe molten-salt power tower in the southern part of Spain.

- The Boeing Company developed a new receiver design based on a new steel material. In partnership, Boeing fabricated and Sandia tested a few-tube panel based on this design. Following successful operation of this panel, a full-scale Solar Two replacement panel was installed and operated at Solar Two without problems. This new panel design promises improved receiver performance and reliability. 
- Sandia is working with Nexant and Nagle Pumps to specify, procure, and test a long-shafted, multistage turbine salt pump with salt-cooled bearings. Nexant expects this pump design to be used in the next plant, and, by eliminating pump sump vessels, salt valves, and associated piping and heat trace, greatly simplify and increase the reliability of the salt circuits.

- Nexant, Boeing, and Sandia are working on the specification and preliminary design of the next molten-salt power tower plant.

One of the goals for Solar Two, established by the Solar Two Steering Committee, was to stimulate the commercialization of molten-salt power tower technology. The successful conclusion of Solar Two; continued development at Sandia and in industry; and international interest, including the Solar Tres consortium, all indicate that Solar Two met this critical objective. The power tower has emerged as a viable source of grid-scale electricity. 


\section{References}

Alpert, D. J., G. J. Kolb, Performance of the Solar One Power Plant as Simulated by the SOLERGY Computer Code, SAND88-0321, Sandia National Laboratories, Albuquerque, NM, 1988.

Barth, D.L., J.E. Pacheco, W.J. Kolb, and E.E. Rush, "Development of a High-Temperature, Long-Shafted Molten-Salt Pump for Power Tower Applications," Proceedings of Solar Forum 2001, Washington, D.C., April 21-25, 2001.

Becker, M. and P. Klimas (eds.), G. Kolb, J. Chavez, W. Meinecke (authors), Second Generation Central Receiver Technologies: A Status Report, Verlag C. F. Muller Karlsruhe, DLR and Sandia National Laboratories, ISBN 3-7880-7482-5, 1993.

Dawson, D.B., Sandia National Laboratories, Correspondence to H.E. Reilly, subject: Intergranular Corrosion at Solar Two, April 30, 2001.

Gould, W., A. Zavoico, W. Collier, and I. Grimaldi, "Solar Tres 10 MWe Central Receiver Project," Energex 2000: Proceedings of the $8^{\text {th }}$ International Energy Forum, Las Vegas, NV, July 23-28, 2000.

Haeger, M., L. Keller, R. Monterreal, A. Valverde, Phoebus Technology Program Solar Air Receiver (TSA), Operational Experiences with the Experimental Set-Up of a $2.5 \mathrm{MWt}$ Volumetric Air Receiver (TSA) at the Plataforma Solar de Almeria, PSA-TR02/94, Almeria, Spain, July 1994.

Hale, M., "Solar Two Performance Evaluation Methodology," Proceedings of the Renewable and Advanced Energy Systems for the $21^{\text {st }}$ Century, April 11-15, 1999, Maui, HI.

Jones, S. A., and K. Stone, "Analysis of Strategies to Improve Heliostat Tracking at Solar Two," Proceedings of the Renewable and Advanced Energy Systems for the 21st Century, a joint ASME/JSME/JSES/KSME International Conference, April 11-15, 1999, Maui, HI.

Kistler, B., A User's Manual for DELSOL3: A Computer Code for Calculating the Optical Performance and Optimal System Design for Solar Thermal Central Receiver Plants, SAND868018, Sandia National Laboratories, Livermore, CA, November 1986.

Meinecke, W., and M. Bohn, Solar Energy Concentrating Systems: Applications and Technologies, M. Becker and B. Gupta (Eds.), Muller Verlag, Heidelberg, Germany, 1995.

Neij, L., "Use of Experience Curves to Analyse the Prospects for Diffusion and Adoption of Renewable Energy Technology," Energy Policy, Vol. 23, No. 13, pp. 1099-1107, 1997.

Osuna, R., V. Fernandez, M. Romero, M. Blanco, "PS-10: A 10 MW Solar Tower Power Plant for Southern Spain," Proceedings of the $10^{\text {th }}$ SolarPACES International Symposium on Solar Thermal Concentrating Technologies, Sydney, Australia, 8-10 March 2000. 
Pacheco, J.E. (ed), G.J. Kolb, H.E. Reilly, S.K. Showalter, S.H. Goods, R.W. Bradshaw, D.B. Dawson, S.A. Jones, M.J. Hale, R.L. Gilbert, M.R. Prairie, P. Jacobs, Final Test \& Evaluation Results from the Solar Two Project, SAND2001-XXXX, Sandia National Laboratories, Albuquerque, NM, 2001.

Pacific Gas \& Electric Company, "Solar Central Receiver Technology Advancement for Electric Utility Application, Phase 1 Topical Report," Report No. 007.2-88.2, San Francisco, CA, September 1988.

Pilkington Solar International, Status Report on Solar Thermal Power Plants, ISBN 3-98049010-6, Cologne, Germany, January 1996.

Radosevich, L., Final Report on the Power Production Phase of the 10 MWe Solar Thermal Central Receiver Power Plant, SAND87-8022, Sandia National Laboratories, Livermore, CA, March 1988.

Stoddard, M.C., S.E. Faas, C.J. Chiang, J.A. Dirks, SOLERGY - A Computer Code for Calculating the Annual Energy from Central Receiver Power Plants, SAND86-8060, Sandia National Laboratories, Livermore, CA, May 1987.

Stone, K., and S.A. Jones, "Analysis of Solar Two Heliostat Tracking Error Sources at Solar Two," Proceedings of the Renewable and Advanced Energy Systems for the 21 st Century, a joint ASME/JSME/JSES/KSME International Conference, April 11-15, 1999, Maui, HI.

U.S. Department of Energy and Electric Power Research Institute, Renewable Energy Technology Characterizations, EPRI TR-109496, December 1997; may be downloaded from www.eren.doe.gov/power/techchar.html. 